\title{
Measurement of growth in the lichen Rhizocarpon geographicum using a new photographic technique
}

\author{
by \\ Nicole M. Henry, B.Sc.

\begin{abstract}
A thesis
submitted in partial fulfillment

of the requirements for the degree of
\end{abstract} \\ Master of Science
}

Faculty of Mathematics and Science, Brock University

St. Catharines, Ontario

April 21, 2011.

(C) Nicole M. Henry, 2011 


\section{Abstract}

Lichenologists and users of lichenometry have long used calipers or photogrammetry to measure the growth of crustose lichens. Now, digital photography and popular computer software provide methodological alternatives. This thesis developed and tested a new methodology for tracking change and growth of the lichen, Rhizocarpon geographicum. Adobe Photoshop CS3 Extended software and a photographic time series $(1996,2003,2006$ and 2007) were used to measure thallus diameter, area, prothallus width and areolae area in 115 small $R$ geographicum thalli $\left(0.53-1049.88 \mathrm{~mm}^{2}\right)$. Measures of 8 diameters per thallus showed that change in diameter was highly variable and is a weak index of growth. Thallus area was a reliable measure of growth (power correlation, $R^{2}=0.89$ ). Rapid, highly irregular growth occurred in small thalli $\left(<30 \mathrm{~mm}^{2}\right)$, and steady, uniform growth occurred in larger thalli $\left(>30 \mathrm{~mm}^{2}\right)$. This new methodology is tedious but can potentially generate accurate and precise measures for even the tiniest of lichens. 


\section{Acknowledgments}

At this time I would like to thank everyone who has helped me in various ways during the course of this study.

I would like to express my gratitude to my supervisor, Dr. Daniel McCarthy, whose expertise, constructive criticism and patience has helped me throughout the course of this thesis. I am also very appreciative to him for lending me his photographic collections for my use. I would also like to thank the other members of my committee, Dr. Gary Pickering and Dr. Miriam Richards for their valuable guidance and insight over the course of this study. Finally, I would like to thank Dr. Irwin Brodo for taking the time to serve as my external examiner providing his expertise and enthusiasm for the subject.

I would also like to thank my family and friends who have provided encouragement and support in all my academic endeavors. Without whom I could not have completed this project. A special thanks to my boyfriend and best friend, Antonio Coia for his unfailing love, help and encouragement.

Thank you to all the individuals, who have assisted and encouraged me in one way or another, I feel very grateful. 


\section{Table of contents}

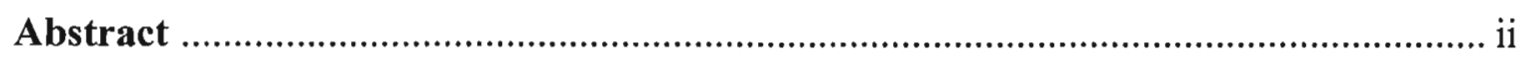

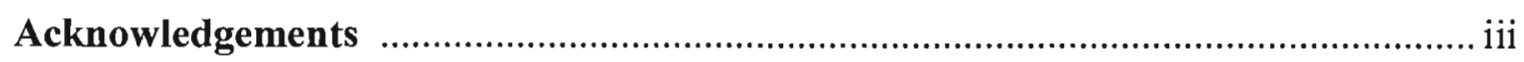

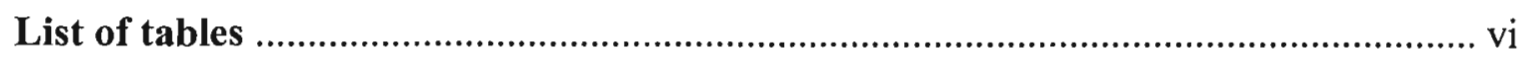

List of illustrations ................................................................................... vii

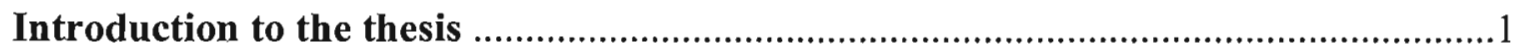

An introduction to the yellow-green Rhizocarpons

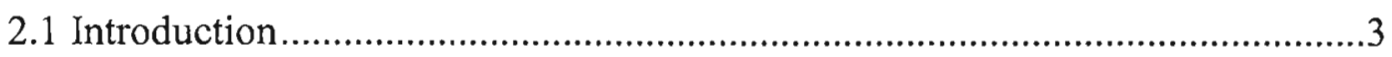

2.2 Taxonomy of the yellow-green Rhizocarpons ........................................... 3

2.3 Ecology of the yellow-green Rhizocarpons ..........................................

2.4 Morphology and early development of yellow-green Rhizocarpon thalli .......10

2.5 Primary growth in Rhizocarpon thalli............................................... 14

2.6 Links between thallus morphology and growth ................................... 16

2.7 Growth of Rhizocarpon thalli over the longer term....................................18

2.7.1 Direct measurement of Rhizocarpon growth .................................22

2.7.2 Growth of Rhizocarpon geographicum ......................................28

2.8 Approach and research objectives .................................................. 34

\section{Methods}

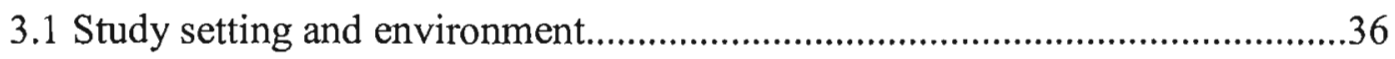

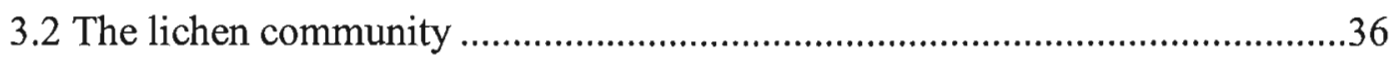

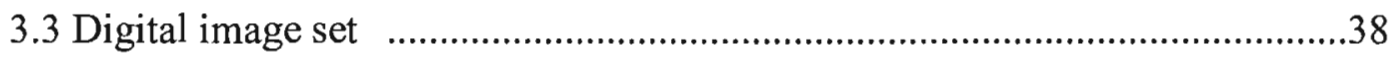

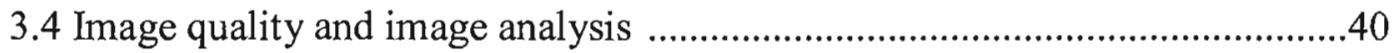


3.4.1 Measurement of areal change

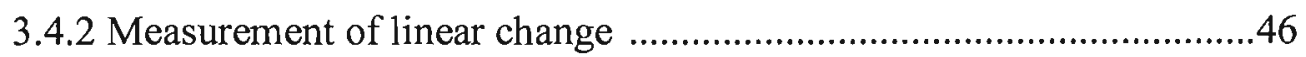

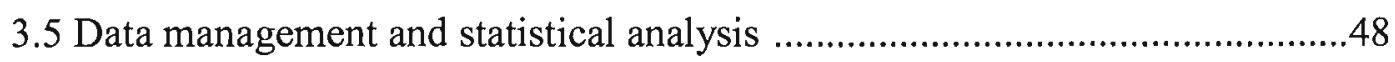

\section{Results}

4.1 Measurement precision: thallus area, thallus perimeter and areola area .........49

4.2 Measurement precision and image quality. ..................................................53

4.3 Quantitative findings on the growth of Rhizocarpon geographicum................53

4.3.1 Thallus growth: area and diameter ....................................................53

4.3.2 Morphological changes …………………….................................63

\section{Discussion}

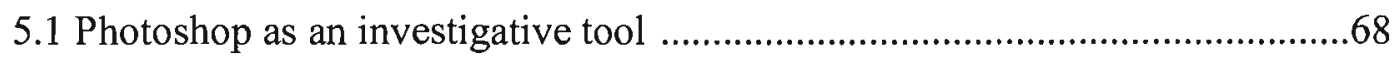

5.2 Quantitative findings on the growth of Rhizocarpon geographicum................73

Conclusions . .79

Literature cited .81

\section{Appendices}

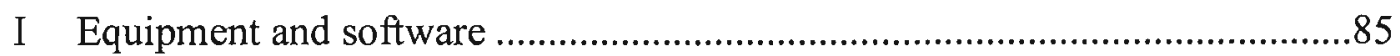

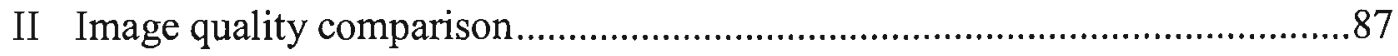

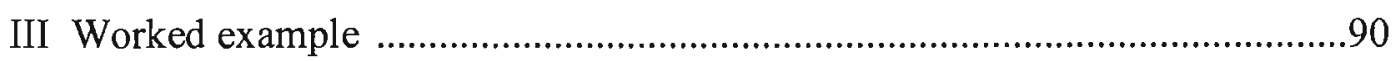

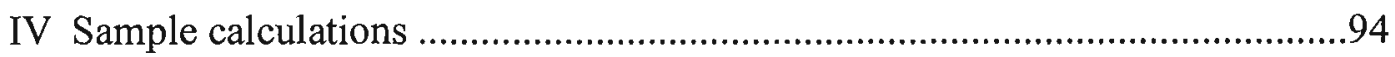

V Measurement reproducibility by different operators ......................................100 


\section{List of tables}

Table 2.1 Classification of the Rhizocarpon sub-genus (Runemark, 1956).

Table 2.2 Summary of major growth studies on Rhizocarpon geographicum thalli .......29

Table 3.1 Number and sizes of lichens measured in the repeated photographs...............39

Table 3.2 Thallus size and image resolution data for test thalli. These thalli were used to assess the precision of areal measurements ......................................................4

Table 4.1 Summary list of the change in thallus area data .58

Table 4.2 Details of percent change in area for Rhizocarpon geographicum thalli (Companion table to Fig. 4.9). Data were standardized by dividing the raw measurements by the number of years in the photographic interval 


\section{List of illustrations}

Figure 2.1 Cross section of the internal characteristics of an apothecium (A) and areola (B), of a $R$. geographicum thallus.

Figure 2.2 Rhizocarpon geographicum thallus showing gross morphological features

Figure 2.3 Comparison of lichenometric dating curves from Alaska and vicinity.......19

Figure 3.1 Illustration of how an image was scaled and superimposed (B), aligned and traced (C) using Adobe Photoshop CS3 Extended..... .42

Figure 3.2 Illustration of how thallus outlines were traced .44

Figure 3.3 Illustration of the grid pattern used to measure the diameter (A) and prothallus width (B) of a lichen.....

Figure 4.1 Plot used to assess the precision of thallus area measurements .50

Figure 4.2 Plot used to assess the precision of thallus perimeter measurements. .51

Figure 4.3 Plot used to assess the precision of areolae area measurement. .52

Figure 4.4 Plot used to assess the precision of thallus area measurements with image quality.....

Figure 4.5 Plot used to assess the precision of thallus perimeter measurements with image quality.

Figure 4.6 Plot used to assess the precision of thallus areolae area measurements with image quality .56

Figure 4.7 Scatterplots showing linear regression of thallus size $(\mathrm{mm})$ against mean change in area $\left(\mathrm{mm}^{2}\right)$ for all three growth intervals

Figure 4.8 Scatterplot showing mean initial area $\left(\mathrm{mm}^{2}\right)$ against mean percent change in area $\left(\mathrm{mm}^{2}\right)$ for all three growth intervals

Figure 4.9 Scatterplots showing the annual change in diameter in relation to mean initial thallus diameter for all three intervals, 1 year, 3 year and 7 year .....61

Figure 4.10 Annual change in thallus diameter. .64

Figure 4.11 Percent change in thallus diameter for all three growth intervals, 1 year, 3 year and 7 year .65 
Figure 4.12 Scatterplot showing the association between mean areola area and prothallus area $\left(\mathrm{mm}^{2}\right)$

Figure 4.13 Change in the proportion prothallus width.............................................67 


\section{Introduction to the thesis}

In the last fifty years, the growth of yellow-green Rhizocarpon lichens has been the focus of numerous of lichenometric dating studies (Innes, 1985). Unfortunately, biologists and users of lichenometric dating techniques have generated very little ecological data with which to calibrate biologically defensible models of lichen growth and have produced few insights into how lichen colonies grow and slowly evolve (McCarthy, 1999). This thesis will attempt to address this knowledge gap by using a unique set of historical photographs to investigate growth and morphological changes that have occurred in yellow-green Rhizocarpon thalli that are growing on quartzite rocks near an alpine glacier in British Columbia. The digital images used in this study were generated by Dr. D. McCarthy of Brock University. The photographs are part of a time series of repeated photography that began in the summer of 1996 and focused on 143 primary lichen thalli. The thalli ranged from $15-600 \mathrm{~mm}^{2}$ in size and had oval thallus outlines. A unique number was assigned to each thallus and reference crosses were painted on the rock near each thallus. The distance between these reference points was then established using digital calipers (McCarthy, 2003).

McCarthy (2003) reported on the growth of these thalli from 1996 to 2000. That work used digital calipers in the field to measure growth from the thallus edge to the reference points. Subsequent work (e.g., McCarthy et al., 2007) explored the use of Adobe Photoshop software to measure thalli in some of the images and generate growth rate data. That work was of a preliminary nature and has not been published. However, it found that there was considerable variation in growth rate both within and between thalli and it established that the Adobe Photoshop software measurement technique has 
considerable potential as a tool that could be used to quantify lichen growth and morphological changes.

The work described in this thesis will show how photogrammetry could be used to generate a wide variety of accurate and reproducible measures that could not readily be obtained using traditional field methods. 


\section{An introduction to the yellow-green Rhizocarpons}

\subsection{Introduction}

Relatively little is known about the ecology, physiology and growth of lichens in the genus Rhizocarpon. This is in part due to the fact that these lichens are very slow growing, cannot be removed from their substrate without being damaged and cannot readily be identified to species level in the field without chemical testing and examination of spores (Innes, 1985; Benedict, 1988). Accordingly, this review will attempt to focus on the morphology, ecology, development and growth of the yellow-green Rhizocarpons. Where specific information is lacking, generalizations will be made based on what is known about other groups of crustose lichens.

\subsection{Taxonomy of the yellow-green Rhizocarpons}

Several taxonomic keys are available for the yellow-green Rhizocarpons (Runemark, 1956; Thomson, 1967, 1997 and Poelt, 1988). Each key is specific to a geographic region and most have been developed for use in Europe and the Arctic. Unfortunately these keys do not adequately describe the phenotypic or ecotypic differences that exist in other localities and cannot be readily applied to identify tiny thalli to species level (Benedict, 1988). This may explain, in part, why non-lichenologists have been reluctant or unable to use the taxonomic keys to identify the specimens that they have used to generate lichenometric ages. In such studies, the yellow-green Rhizocarpons are identified as Rhizocarpon Ram em. Th. Fr. Subgenus Rhizocarpon (Poelt, 1988) as was done by Bradwell and Armstrong (2007), or within that subgenus, down to the level of section (e.g. section Rhizocarpon) as suggested by Innes (1985) or 
Armstrong (2005b).

Use of a sectional grouping recognizes that it is impractical and sometimes difficult to assign species designations based on field observations alone (Benedict 1988). It also recognizes that there is no clear evidence to show that individual species within each section exhibit different growth rates or ecological characteristics (Innes 1983, 1985; Benedict 1988). No worker has identified all of their specimens to species level (pers. comm. Dr. D. McCarthy, October, 2010). Thus apart from anecdotal claims made by a few geomorphologists (e.g., Luckman and Osborn, 1979) we lack data to show whether individual species of the yellow-green and black Rhizocarpons typically grow at different rates (Innes, 1983, 1985; Benedict, 1988).

The genus Rhizocarpon is divided into two large sub-genera Phaeothallus and Rhizocarpon based on the presence or absence of rhizocarpic acid (Thomson, 1967; Innes, 1985; Benedict, 2009), but this classification has recently been questioned based on genetic studies (Ihlen \& Ekman, 2002). This initial subdivision is determined relatively easily although further subdivisions require the use of a microscope and chemical staining techniques (Poelt, 1988). The subgenus Rhizocarpon can then be further subdivided into four sections, Alpicola, Rhizocarpon, Superficiale and Viridiatrum, based on thallus morphology, spore characteristics, and chemistry of the secondary metabolites found in the medulla (Innes, 1985) (see Table 2.1). These sections can be broadly subdivided based on the number of cells in a spore (Benedict, 1988). Superficiale and Alpicola have uniseptate spores (two cells) whereas Rhizocarpon and Viridiatrum contain pluriseptate (usually muriform of submuriform) spores (several cells) (Innes, 1985). Section Alpicola and Section Superficiale can then be further subdivided 
by the size of the spores, the hymenial dimensions and colour of the apihymenium. In the sections with pluriseptate spores, Rhizocarpon and Viridiatrum aphihymenium colour and the reaction of the medulla to iodine (turning blue) are common distinguishing characteristics (Runemark, 1956a; Thomson, 1967; Benedict, 1988). A cross section of a Rhizocarpon thallus and apothecium can be found in Figure 2.1.

Identification to species level is best reserved for the lab where apothecia can be removed and the spores can be measured and examined under a microscope (Innes, 1985). In situations where thalli are numerous or workers do not wish to damage a thallus, one or more apothecia can be excised and brought to the lab while chemical spot tests can be done in the field. In such cases a drop of chemical (e.g., potassium hydroxide) is applied using an eyedropper. The drop of chemical either changes colour or not and the excess chemicals are blotted from the thallus. Some species can be readily identified by the reaction of the apihymenium layer to potassium hydroxide $(\mathrm{KOH})$ (Benedict, 1988). For example, a drop of potassium hydroxide placed on the apihymenium of a Rhizocarpon geographicum thallus will become blue (IKI+ dark blue), while this same chemical does not react or will react very weakly if placed on the medulla of a Rhizocarpon inarense thallus (Benedict, 1988). However, thalli of some species do not produce a colour change, and not all thalli are fertile and mature. Therefore positive identification to species level is impossible in these cases. 
Table 2.1: Classification of the Rhizocarpon subgenus (Runemark, 1956).

\begin{tabular}{|c|c|c|}
\hline Genus & Section & Species \\
\hline \multirow{4}{*}{ Rhizocarpon } & Superficiale & $\begin{array}{l}\text { R. dispersum Runem. } \\
\text { R. effiguratum (Anzi) Th.Fr. } \\
\text { R. norvegicum Ras. } \\
\text { R. parvum Runem. } \\
\text { R. pusillum Runem. } \\
\text { R. superficiale (Schaer.) Vain }\end{array}$ \\
\hline & Alpicola & $\begin{array}{l}R . \text { alpicola (Hepp.) Rahb. } \\
R . \text { eupetraeoides (Nyl.) Blomb. } \\
R . \text { inarense (Vain.) Vain. }\end{array}$ \\
\hline & Viridiatrum & $\begin{array}{l}\text { R. atrovirellum (Nyl.) Zahlbr. } \\
\text { R. kakurgon Poelt } \\
\text { R. lusitanicum (Nyl.) Arnold } \\
\text { R. oportense (Vain.) Ras. } \\
\text { R. subtile Runem. } \\
\text { R. tetrasporum Runem. } \\
\text { R. viridiatrum (Wulf.) Koerb. }\end{array}$ \\
\hline & Rhizocarpon & $\begin{array}{l}\text { R. atroglavescens Lynge } \\
R . \text { carpaticum Runem. } \\
R . \text { ferax H. Magn. } \\
R . \text { furax Poelt et V. } \\
R . \text { geographicum (L.) DC. } \\
R . \text { intermediellum Ras. } \\
R . \text { lecanorinum Anders } \\
R . \text { macrosporum Ras. } \\
R . \text { pulverulentum (Schaer.) Ras. } \\
R . \text { rapax V. Wirth et Poelt } \\
R . \text { riparium Ras. } \\
R . \text { saanense Ras. } \\
R . \text { sphaerosporum Ras. } \\
R . \text { sublucidum }\end{array}$ \\
\hline
\end{tabular}




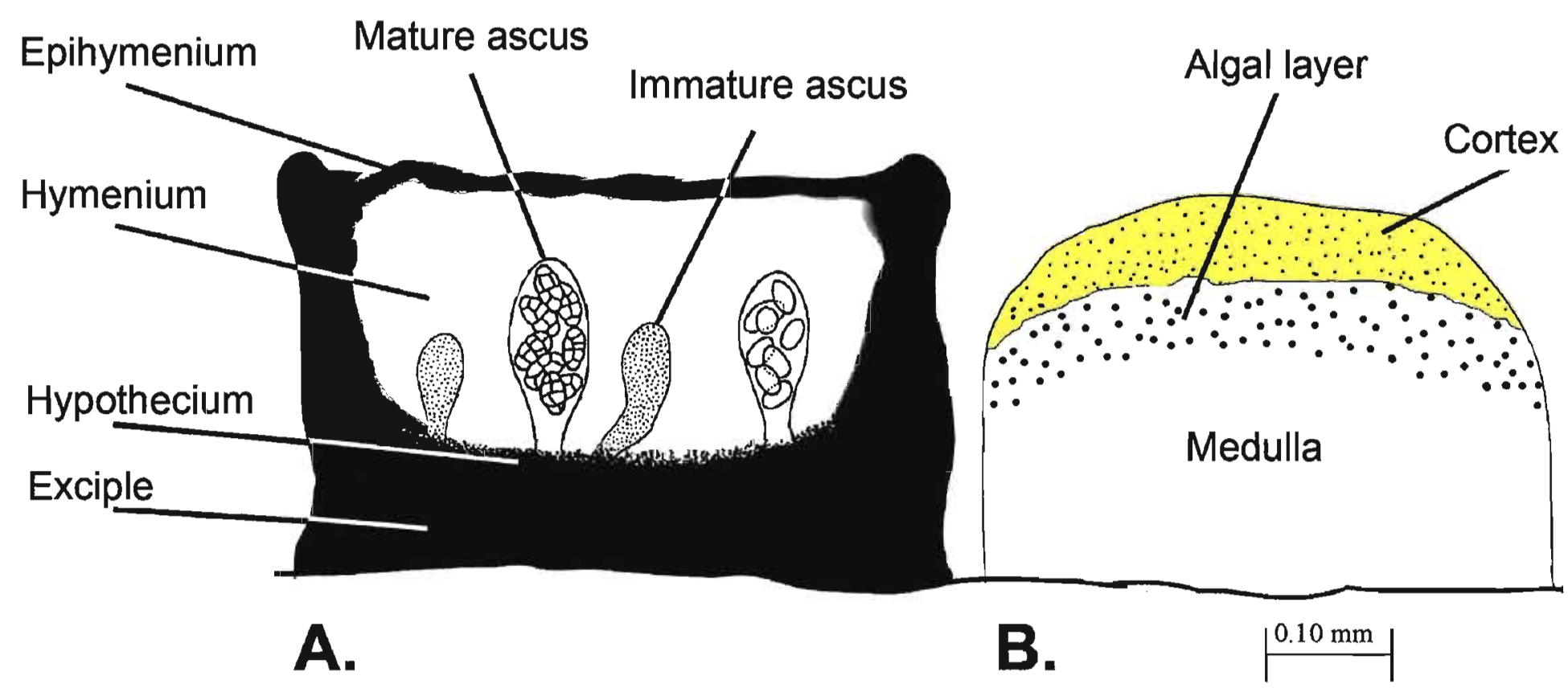

Figure 2.1: Cross section of an apothecium (A) and thallus areola (B) of a $R$. geographicum thallus showing the internal characteristics. Diagram modeled after Benedict (1988). Scale is approximate. 


\subsection{Ecology of the yellow-green Rhizocarpons}

The yellow-green Rhizocarpons have a circumpolar and alpine distribution (Thomson, 1967; Innes, 1985; Brodo, 2001; Asta and Letrouit-Galinou, 1995). They are often found below valley glaciers on granite and quartzite rocks that have been exposed by recent glacial retreat. The Rhizocarpons are some of the first organisms to become established in a successional sequence (Brodo et al., 2001). Rhizocarpon thalli tend to colonize cracks and moist depressions, but they are also found on windswept outcrops where they may form colonies that can persist for centuries (John and Dale, 1989). However, these species are intolerant of burial or prolonged submergence under water, snow or ice and they are generally absent once a canopy of higher plants becomes established (e.g., Benedict, 1990, 1991; Chapin et al., 1994).

Unfortunately, there is a scarcity of data that can be used to characterize the link between micro-environmental conditions and the colonization, growth and ecological interactions of Rhizocarpon thalli. There are several reasons for this lack of data. First it is exceptionally hard to simultaneously monitor micro-environmental differences and ecological interactions between epilithic thalli. Their slow growth rates, close adherence to the underlying substrate and inability to be readily identified to species level in the field are significant obstacles to the study of Rhizocarpon growth and ecology. Secondly, the microenvironment can vary greatly over a substrate depending on numerous factors (e.g., sun exposure, wind, substrate microtopography, etc.). Thus, few workers have quantitatively explored the relationship between microenvironment and its impact on the growth and ecological interactions of Rhizocarpon thalli (e.g., Pentecost, 1979; Armstrong, 1974a, 2002, 2005b; John and Dale, 1989). 
Studies of Rhizocarpon distributions with respect to microenvironment or thallus orientation on a rock have yet to discover any clear, quantitative tendencies in how Rhizocarpon thalli are distributed in a landscape (e.g., John and Dale, 1989; Armstrong, 1974a, 2005a; Pentecost, 1979). Armstrong (1974a, 2002) found that $R$. geographicum was most abundant on well-lit slate rock surfaces of southern aspect. Pentecost (1979) noted that the thalli were most abundant on south-facing aspects while John and Dale (1989) and Armstrong (2005a) found no clear relationship between Rhizocarpon abundance and orientation.

The influence of aspect on the radial growth of Rhizocarpon thalli is also unclear. Armstrong $(2002,2005 \mathrm{~b})$ provides the only published data on this topic. He described the use of calipers and painted markers to track the annual radial growth of 43 $R$. geographicum thalli on a slate outcrop in Wales (Armstrong, 2002) and at 32 thalli on granodiorite boulders in Washington state (Armstrong, 2005b). Growth was measured at four points around each thallus. In the first study Armstrong concluded that lateral growth of the thallus margin was significantly greater on north-west facets. In his second study he concluded that growth was most rapid on east-southeast facets. Thus, while Armstrong has postulated interesting links between micro-environmental conditions and the growth of Rhizocarpon thalli, it seems unreasonable to infer widespread trends from these small sample sizes and questionable measures of radial growth. Indeed, it seems reasonable to suggest that aspect is correlated with other environment variables, making it difficult to statistically establish which environmental characteristic exerts the strongest control on the growth and ecology of individual lichen thalli. 
Thus it can only be concluded from the above mentioned studies that differences in lichen growth rate, abundance and colonization patterns reflect temporal and spatial differences in disturbance regimes, local micro-environments and genetic differences between individual thalli.

\subsection{Morphology and early development of yellow-green Rhizocarpon thalli}

About two-dozen of the estimated 200 lichen species in the genus Rhizocarpon have a yellow-green coloration. The upper surface of these lichens has an array of yellow or yellowish green areolae and black apothecia surrounded by a thin fungal zone of black prothallus (called a prothallus by Clayden, 1998; Brodo et al., 2001; and some other authors). In these thalli, the prothallus can extend up to about 1-3 mm past the areolae to form a black ring around the edge of the thallus (Brodo, 2001; Benedict, 2009; Armstrong and Bradwell, 2001). Figures 2.1 and 2.2 show the internal and external features of a crustose lichen thallus. The areola have an upper cortex which protects it from abrasion and moisture loss, an algal layer where the photobionts are found and a lower medullary layer, which stores food and moisture (Benedict, 1988). The medulla makes up most of the thallus body and is composed of loosely packed hyphae that form a mesh-like network around the overlying algae (Benedict, 1988). 


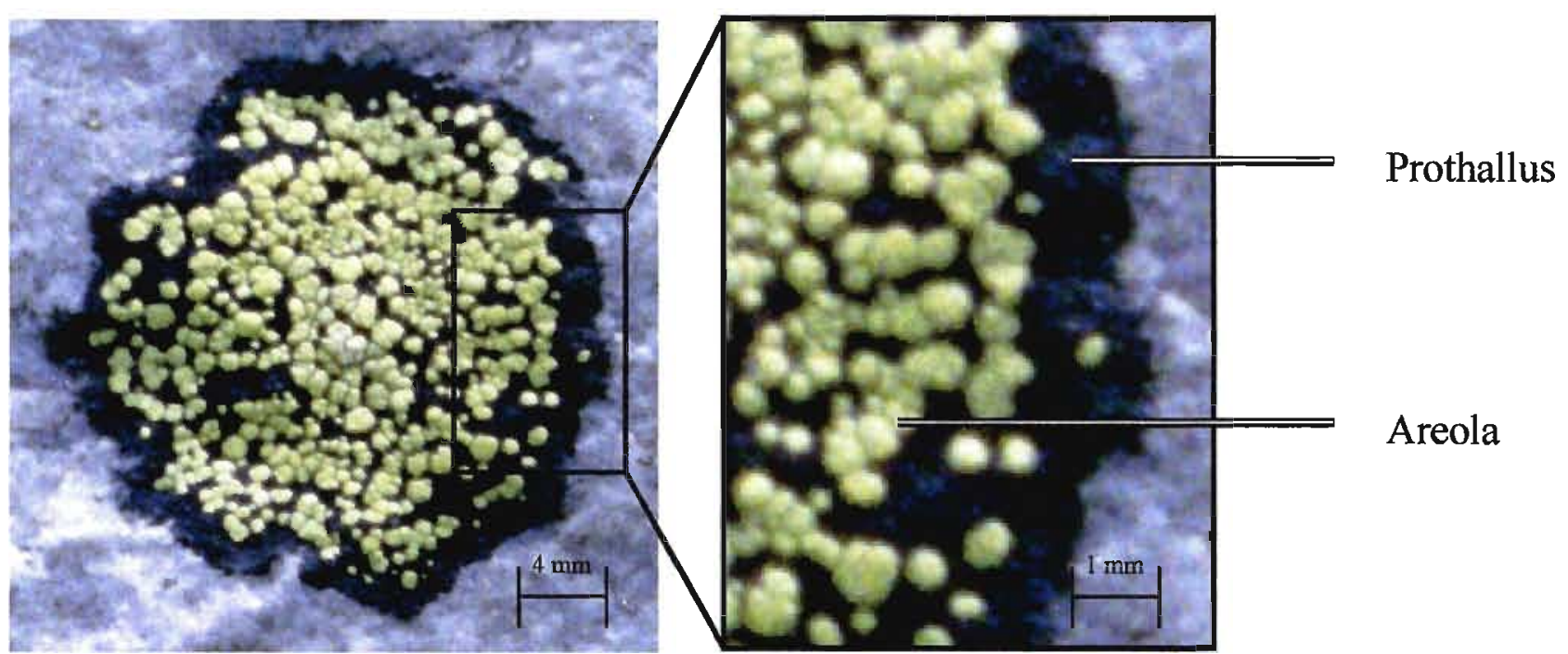

Figure 2.2: Rhizocarpon geographicum thallus showing gross morphological features. 
Disc-shaped fruiting structures called apothecia are sometimes found near the areolae on the surface of mature, fertile Rhizocarpon thalli. Each apothecium has a layer of sac-like asci with up to eight oval shaped ascospores (10 to $70 \mu \mathrm{m}$ long) (Benedict, 1988; Innes, 1985). These spores are surrounded by a gelatinous halo (perispore), which helps to anchor the ejected spores to a substrate (Honegger, 1980). When spores are present, their size, shape and number can be used to help identify a thallus to species level. However, when spores are not present, positive identification to species level may be inconclusive as the identification keys tend to rely heavily on the spore characteristics (e.g., shape, size, septation, number per ascus and colour) as well as chemical response testing of the medulla to iodine blue or potassium hydroxide (e.g., Runemark, 1956; Thomas, 1967).

Little is known about the development and reproduction of most of the yellowgreen Rhizocarpons. Clayden (1998), working with R. lecanorinum, found that ascospores were very numerous (e.g., 2300 per $\mathrm{cm}^{2}$ ) on and near the Rhizocarpon lecanorinum communities that he studied. However, as Clayden (1998) and Honegger (1993) have explained, a germinated ascospore must find a free-living algal symbiont before the lichen symbiosis can be established. While this may be difficult in some settings, new thalli often form near lichen communities where there is a ready source of free-living bionts. The smallest detectable structures of $R$. lecanorinum spore hyphae and Trebouxia algal cells have been described as greenish-black, roughly hemispherical granules measuring about $40 \mu \mathrm{m}$ in diameter and lacking a fringing prothallus. Asta and Letrouit-Galinou (1995) observed that the smallest detectable structures of $R$. geographicum consist of tiny black dots or lines usually $<0.5 \mathrm{~mm}$ in length. When 
observed under a microscope these structures appeared to be elongated fungal hyphae, which they referred to as fungal initials (Asta and Letroiut-Galinou, 1995).

Differentiation of the granules into thalli occurs when rhizocarpic acid crystals are synthesized and come into contact with unmelanized hyphae in the developing cortex. As the rhizocarpic acid spreads through the developing cortex, the melanized hyphae are sloughed off, and the granules become macroscopically visible yellowish-green areolae (0.15 to $0.2 \mathrm{~mm}$ diameter) (Clayden, 1998).

The development of areolae and prothallus differs in some of the yellow-green Rhizocarpon species. For example, while areolae undergo differentiation in R. lecanorinum, prothallus hyphae are initiated from cells which develop near the basal margin of areolae. The length and density of these prothallus hyphae vary greatly around the thallus (Clayden, 1998). In contrast, $R$. geographicum ascospores give rise to networks of melanized fungal hyphae. These hyphal networks become the prothallus and continue radial expansion after primary areolae become established (Asta and LetrouitGalinou, 1995).

Apothecia, the reproductive structures, are formed soon after the differentiation of radiating prothallus hyphae around the initial areolae in $R$. lecanorinum (Clayden, 1998). Clayden (1998) has described the development of areolae and apothecia in R. lecanorinum. He describes apothecia, the reproductive structures, as forming soon after the prothallus hyphae formed around the founding areola. He also noted that areola margins are sharply notched and that this is most prominent in the youngest areolae. 


\subsection{Primary growth in Rhizocarpon thalli}

The growth and maturation of a Rhizocarpon thallus involves a sequence of morphological changes that are macroscopically visible. Initially, a prothallus forms around a thallus-founding areola. Then a variety of obvious external changes occur, including marginal expansion, thickening of the thallus, an increase in biomass and the development of secondary structures. Asta and Letrouit-Galinou (1995) recognized four macroscopic growth stages in $R$. geographicum thalli. These can be broadly characterized as growth of primary areolae, secondary areola formation, areolae fusion, and thallus fusions. As the primary areola grows and develops it begins to crack and split. The reason for this is unknown in relation to its development. These primary areolae have a different appearance than the very angular secondary areolae, which form in mature thalli (e.g., Armstrong and Bradwell, 2001). Secondary areolae arise as discrete islands on the prothallus, triggered by a compatible Trebouxia alga in a process that closely resembles what occurs during the initiation of the thallus-founding areola. The source of the Trebouxia algal cells remains uncertain. In $R$. lecanorinum, areolae lack a floor of differentiated, melanized hyphae and the areolae arise by the growth of the prothallus over or around photobiont cells that are already attached to the substrate (Clayden, 1998). Asta and Letrout-Galinou (1995) explain that differences in the ability of the prothallus to surround compatible algal cells may be linked to biological peculiarities of the prothallus. For example, they observed that in some thalli the timing of secondary areola development is delayed following further development of the primary areola (e.g., thickening, widening). This results in a wider than normal prothallus width in these young thalli. 
As areolae grow they eventually converge with neighboring areolae. Their line of contact is at first well marked, but over time they merge (fuse) and reshape completely. This leads to the formation of the lichenized central part of the mature thallus (Asta and Letrouit-Galinou, 1995). The growth of the prothallus and areolae is highly synchronized. As the prothallus grows, areolae develop and if the marginal prothallus is removed the areolae retreat (Armstrong and Smith, 1987).

As small, young thalli come into contact with thalli of the same genetic composition, they sometimes "fuse" to become a "composite" thallus (Clayden, 1998; Letrouit-Gallinou, 1995). However, when thalli of different species or different genotypes come into contact with each other, radial growth may stop at the line of contact (e.g., different genotypes of $R$. lecanorinum do not overgrow one another; Clayden, 1998). Alternatively, thalli of different species can sometimes overgrow and out-compete each other (e.g., R. obscuratum can overgrow Lecanora gangaleoides; Hawksworth and Chater, 1979). While very few studies have examined the spatial interactions of various yellow-green and black Rhizocarpons, intraspecific interactions between thalli of R. lecanorinum, R. riparium and $R$. geographicum have been studied (Clayden, 1997). That work found that intraspecific interactions between $R$. lecanorinum thalli eventually left no distinguishable trace of the line of contact, regardless of size. Contacts between R. geographicum thalli often produce a mosaic that shows sharp demarcation of marginal contacts (e.g., Clayden, 1997). In contrast, intraspecific contacts between $R$. riparium thalli show no noticeable sign of contact between small thalli, although this line of contact is evident in larger thalli (Clayden, 1997). 


\subsection{Links between thallus morphology and growth}

The unique morphology of the yellow-green Rhizocarpons raises some interesting questions about the relationship between these morphological variables (e.g., prothallus width and areolae area) and overall thallus growth.

Based on observations of the growth and development of $R$. lecanorinum, Clayden (1998) noticed that the timing and development of areolae differed between $R$. geographicum and $R$. lecanorinum. He hypothesized that this could explain why small $R$. lecanorium thalli may have faster growth rates than small $R$. geographicum thalli. Clayden (1998) noted that in young $R$. lecanorium thalli the areolae form before the prothallus while in R. geographicum thalli, areola development occurred after the prothallus formed. He reasoned that rapid growth in $R$. lecanorinum may in part be linked to the ratio of algal mass to fungal mass and that this ratio could in part explain growth rate differences within and between thalli of all sizes (Clayden, 1998). This hypothesis has never been tested with quantitative data for similar sized $R$. lecanorinum and $R$. geographicum thalli. Armstrong and Bradwell (2001) used photogrammetry to explore the link between areola development and prothallus width in $R$. geographicum. They did a seasonal study that found a weak correlation of thallus width and areolae development. It is possible that the strength of this correlation reflects a seasonal imbalance between the rate of prothallus growth and the rate of areolae formation. Benedict (2008) also reported the link between areola formation and prothallus area. He worked with Rhizocarpon superficiale (Schaere) Vainio and found that over the long term there was a balance that existed between the area occupied by areolae and the area of the prothallus. Armstrong and Smith (1987) studied the developmental and physiological aspects of the 
areolae and marginal prothallus in $R$. geographicum to resolve their role in lichen growth through experimental manipulation of the thalli. They successfully established a link between areolae and growth. Complete areolae removal resulted in no measurable radial growth over 18 months. When the central region of the areolae was removed to within 2 $\mathrm{mm}$ of the prothallus they witnessed a $42 \%$ reduction in radial growth as compared to the control. An $86 \%$ decline in growth occurred when the areolae were removed to within $1 \mathrm{~mm}$ of the prothallus. These results suggest that it is the areolae that supply the prothallus with materials for growth.

The idea of a marginal growth ring in Rhizocarpon thalli has recurred frequently in the literature (Aplin and Hill, 1979; Proctor, 1977). In theory the rate at which this fungal ring (prothallus) expands determines the rate at which free-living algae are encountered as well as the rate at which carbohydrates are being supplied to the fungus. Several studies have suggested that variations in the width of the prothallus in Rhizocarpon are related to radial growth (e.g., Proctor, 1983; Armstrong and Bradwell, 2001). Proctor (1983) examined a small number of thalli and saw that faster-growing thalli and faster-growing regions of individual thalli were distinguishable because they had a wider prothallus. However, Armstrong (1983) was the first to study whether prothallus width varies with size. He measured the width of the prothallus at five points around each thallus (2-65 $\mathrm{mm}$ in diameter) and he found that prothallus width was not correlated with diameter. 


\subsection{Growth of Rhizocarpon thalli over the longer term}

The longevity and slow growth exhibited by yellow-green Rhizocarpon thalli has made them the subject of considerable scientific interest. This interest has arisen in part because geomorphologists and others use a technique called lichenometry to estimate the age of lichen colonized substrates.

Lichenometry employs measures of thallus diameter to determine the minimum age at which the lichen-colonized surface became exposed (Innes, 1985) (see Fig. 2.3). The minimum ages for the origin of lichen growth at a site can be estimated from historical sources (e.g., tombstone ages, historically dated quarry activity, etc.), or by the use of other independent dating techniques (e.g., dendrochronology, radiocarbon analysis of buried organics). Scatterplots called "growth curves" are then used to estimate the relationship that exists between the largest thallus in a population on each surface of known age. A line is then fitted to the data to serve as a crude calibration of the expected age-size relationships of lichens on surfaces of known age (Naveau et al., 2007). Thallus size data collected at sites of unknown age can then be compared to the lichenometric growth curve to estimate a minimum age for the lichen covered landform.

First employed by Knut Faegri in 1933, lichenometry was not well known or formalized until it was pioneered and demonstrated by Roland Beschel in the 1950's (Innes, 1985). Beschel measured the diameter of lichens on gravestones of different ages, determining the growth curve of a number of fast growing foliose species (Benedict, 2009). On a subsequent trip to the Swiss and Italian Alps he observed that the lichens on young moraines were smaller and less numerous than those on older moraines (Benedict, 2009). Historical records of glacier advance and retreat allowed him to construct size-age 


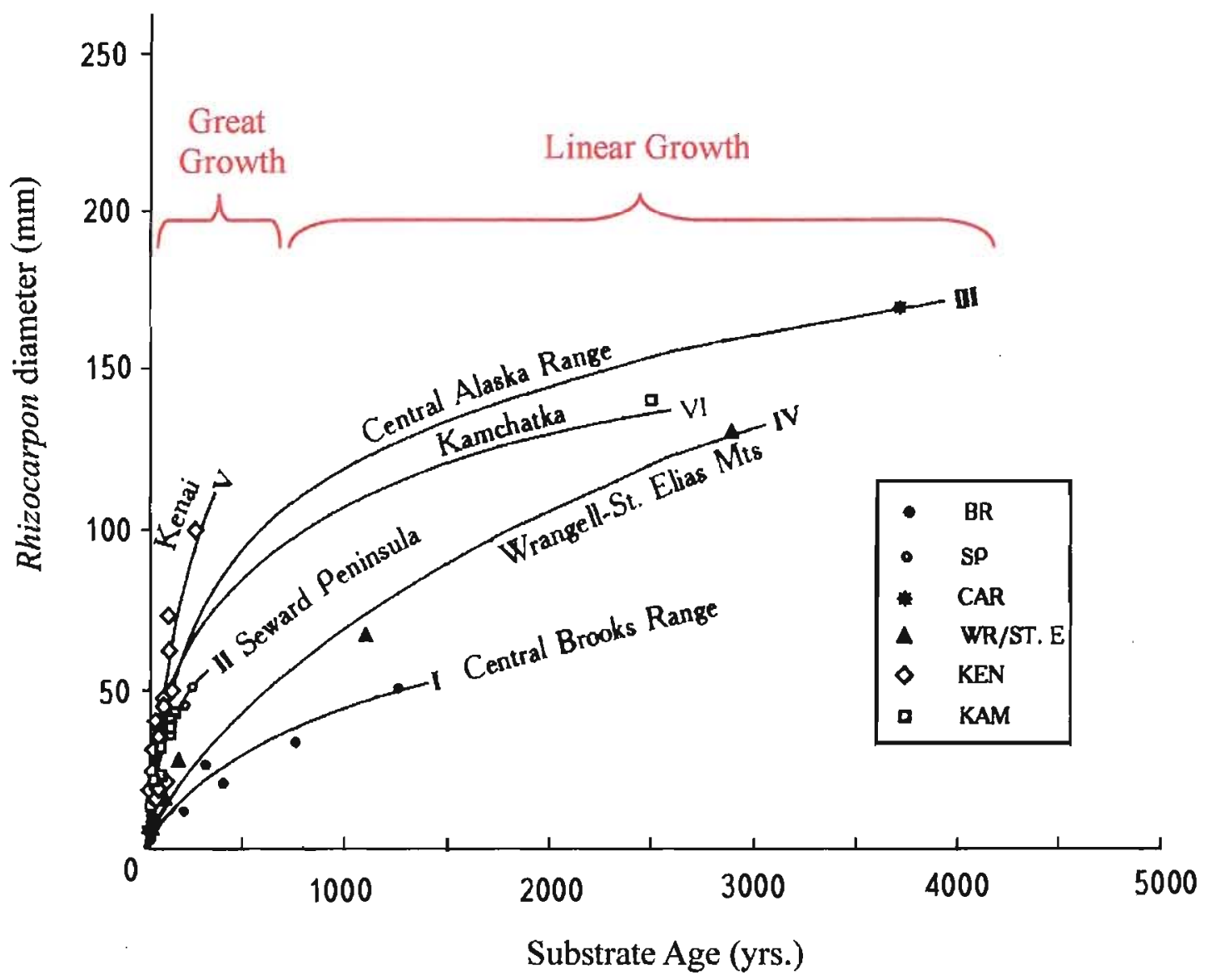

Figure 2.3: Comparison of lichenometric dating curves from Alaska and vicinity. The "Great growth" period lasts at least a few hundred years followed by a linear growth period. Lichenometric curves modeled after Solomina and Calkin (2003). 
curves that could be used to date moraines that lacked such a record (Benedict, 2009). While numerous research studies have used lichenometry, the technique remains controversial, in part because it rests on assumptions that are untenable (as discussed below) (McCarthy, 1999).

Apart from Beschel's original articles, very few publications have clearly articulated the assumptions that are used in lichenometry. The three main assumptions involved in lichenometric dating are: (1) the age of a lichen is not greater than that of its substrate, (2) over the long term, radial growth is uniform and (3) the largest thallus in a population exhibits growth under optimal conditions providing a minimum estimate of substrate age (McCarthy, 1999).

Over the years critics have questioned the assumptions and methods used in lichenometry. Some (e.g., Jochimsen, 1973; McCarthy, 1999) have noted that lichens sometimes survive glacial erosion and deposition. Thus their age may be greater than the time their substrate has been stable and exposed. They also question the assumption that the largest thalli arise solely by radial growth and are not a composite thallus that formed by coalescence of smaller thalli. They argue that such thalli may be morphologically indistinguishable from the rest of the population and would not provide a close estimate of surface age. Users of lichenometry have responded by modifying their sampling and analytical approaches to eliminate anomalous data. For example some reject thalli that do not have circular thallus outlines or reject thallus sizes that are statistically anomalous (e.g., using the mean of the five or ten largest thalli, reliance on thallus size-frequency distributions and stratified random sampling). These approaches arose in response to criticisms to ensure that the methodologies and age estimates are statistically 
reproducible. They do not, however, address or provide data that can be used to validate the underlying assumptions.

Techniques that calibrate growth curves by "indirect" measurement of thallus sizes on historically dated surfaces may or may not reflect changes in thallus size that are solely a function of the time elapsed since colonization. Any number of processes (e.g., ecological disturbance, competitive interactions, coalescence of thalli, an imbalance in mortality-natality, etc.) can change the thallus size distribution in a lichen population. Consequently, growth curves produced by matching thallus sizes against landform age may have lichenometric utility, but are of questionable biological significance. However, Beschel's publications seem to suggest that a "growth curve" developed for lichenometric use accurately represents the growth stages or phases that occur in individual lichen thalli.

Beschel (1961) interpreted the curved line as being indicative of a "great period" that was followed by a "linear growth" phase (see Fig. 2.3). Beschel did not specify how long this "great period" is expected to be or what biological processes trigger the start or end of this phase of lichen growth. Beschel (1961) believed that the centre of a growing thallus produces organic substances that are then evenly distributed to all parts of the thallus. He reasoned that if a thallus maintains a constant production rate per unit area this would lead to an exponential growth of the thallus. According to this model, if a thallus grows so large that transport of materials from the centre to the margins is slowed or ineffective, growth at the thallus margin slows. Beschel did not use experimental data to show that this occurred in any thallus.

Lichenometric growth curves have received remarkably little attention from the 
biological community. However, Loso and Doak (2006) have argued that lichenometric growth curves reflect the mortality-natality that occurs in a lichen community. They reason that in any community, thalli die and the thallus size distribution at a site is a product of the natality and mortality in that community. According to their logic, the surviving smaller, younger thalli on old surfaces may be interpreted as being the largest and seemingly oldest in the population. While Loso and Doak call attention to mortality rather than growth as a mechanism to explain why lichenometric growth curves are nonlinear, there are several alternative possibilities. For example, Asta and LetrouitGalinou (1995) and Clayden et al., (2004) have called attention to the role of thallus coalescence in the development of young thalli. Early studies by Asta and LetrouitGalinou (1995) observed that the chance of mergers was much greater in smaller thalli. If the rate of coalescence changes as thalli increase in age then it is possible that an exponential or "great period" of growth might be due to changes in the rate of coalescence. This topic has received surprisingly little attention from lichenologists and few studies (if any) have attempted to challenge or substantiate Beschel's claims.

\subsubsection{Direct measurement of Rhizocarpon growth}

While there are several ways to express the growth of higher plants and other organisms (e.g., biomass, carbon gain, shoot to root ratio, etc.), most of these biologically meaningful measures cannot readily be used for crustose thalli. Thus, with crustose thalli it has become traditional to quantify growth using indices that represent thallus size, not thallus mass. The most common growth indices for crustose thalli are (1) thallus diameter, (2) the diameter of the largest inscribed circle or (3) the longest or shortest axis 
of a thallus (e.g., Locke et al., 1979; Innes, 1985). While linear measures provide a quick and easy way to describe the approximate size of a lichen in the field, Rhizocarpon thalli rarely have perfectly circular thallus outlines (Asta and Letrouit-Galinou, 1995; Innes, 1986, Haworth et al., 1986). Most studies claim to avoid measuring a thallus that is not circular although they do not report or measure how circular any thallus is. Thallus area, perimeter and circularity can all be measured using digital photogrammetry software. However, few workers are making full and proper use of digital measurement software and measures of thallus area, perimeter and other characteristics are rarely reported.

Lichen growth rates are best determined by accurately and precisely measuring change at the same location over a period of time. A range of approaches has been used, for example, (1) a fine tipped pen and acetate sheet can be used to trace and track changes in thallus outlines (e.g., Hale, 1954, 1959), (2) a ruler, micrometer or calipers used to measure the distance between a thallus margin and a reference point (e.g., McCarthy, 2003; Armstrong, 2005a,b), or (3) take macro-photographs of the lichen thallus and use photogrammetry to measure changes (e.g., Armstrong and Bradwell, 2007; Bradwell, 2010). The photographic technique has the potential to provide a carefully controlled, reliable, permanent record.

Until very recently, direct measurements of thallus growth have usually been done using calipers or micrometers and fixed points that are painted on the rock. Manufacturers of digital calipers often claim the instruments are accurate to $\pm 0.02 \mathrm{~mm}$. However, instrument accuracy is less of a concern than is the ability of a worker to consistently measure short distances in the field. Workers have typically not used data to show that their measurements are both accurate and precise, and few have discussed the 
challenges that are involved in the measurement of growth in tiny thalli. Challenges include such practical issues as the need to use dental magnifying lenses to properly position the calipers, the danger of damaging fragile thallus margins with the steel caliper blades and the difficulty of using calipers in rain, cold weather and in tight spaces. Despite this, most workers report a nominal accuracy and precision of $\pm 0.1 \mathrm{~mm}$ or better (e.g., Armstrong, 2005b). This lack of accuracy and precision data is particularly troubling in short term studies where thallus growth may be slight. In cases where reproducibility has been reported (e.g., McCarthy, 2003) repeated measurements were done on different days with a subset of the thalli and reproducibility claims were made without providing raw data.

Growth rates have not always been determined using calipers. In a few of the older research papers (e.g., Haworth et al., 1986) thallus outlines were traced onto acetate sheets and the change in thallus size was reported. This approach can only provide crude measures and is inappropriate in situations where thalli are slow growing (Innes, 1985). Accordingly it has largely been abandoned in favor of calipers and/or photogrammetric methods.

Change in thallus shape, coloration and marginal growth can all be assessed by examination of repeated photographs of marked lichen thalli. Hooker and Brown (1977) showed how it was possible to use photogrammetry and repeated close-up photographs of crustose lichen thalli to generate accurate and precise growth rate data. Their approach used mathematics to reduce or eliminate the distortion that is caused by lenses and the bumpiness of a rock surface. They photographed lichens alongside a micrometer scale (accuracy $0.05 \mathrm{~mm}$ ) and found four natural markers surrounding each thallus so as to 
form a quadrangle of fixed points. Growth was then measured on a time series of photographic prints. Radial growth was measured with reference to straight lines that cross the center of the thallus and connected it with the fixed markers. The true distance was then mathematically determined using a formula that corrected for parallax.

Photography allows the user to see as well as measure slight changes. As Hooker and Brown (1977) explained and demonstrated in an Antarctic study, sometimes thalli do not grow or the growth is so slight that it cannot be measured with calipers that are only accurate to $0.02 \mathrm{~mm}$. In such cases, photogrammetric measures that are corrected for lens distortion may be able to accurately measure what calipers cannot. This photogrammetric approach was later used by Proctor (1983) on the Valsorey moraine in Switzerland to measure the growth of $R$. geographicum.

Until very recently, photogrammetry has not been widely used to measure the growth of $R$. geographicum. However, recent work by Armstrong and Bradwell (2007) and Bradwell (2010) has shown that repeated close-up photography, computer software (Adobe Photoshop 8.0) and simple scale bars could be used to generate growth rate data. Working near the Gigjökul Glacier in Iceland, Bradwell and Armstrong (2007) painted markers around thalli (as did McCarthy, 2003 and Armstrong, 2005a), took macrophotographs and collected a series of thallus size measurements in the field. Two series of measurements were taken. In the field, a plastic ruler $(0.1 \mathrm{~mm}$ graduations $)$ and an $8 \mathrm{X}$ magnifier were used to measure the thallus long axis and the axis that was perpendicular to this long axis. They claimed that the precision using this technique was approximately $0.5 \mathrm{~mm}$. They then photographed each thallus $(N=38)$ using a macro lens on a $35 \mathrm{~mm}$ single lens reflex film camera. The series of film-based images was digitally scanned 
(resolution unknown) and superimposed as semi-transparent layers in Adobe Photoshop software. Each photo was positioned so as to completely and exactly overlap the others. No indication was made of how the photographs were scaled. However, in one of the sample photographs a plastic ruler was laid on the rock. Minor corrections were made for geometric distortion. Each thallus was then traced under $400 \%$ magnification.

Measurements of the longest axis and $90^{\circ}$ to the longest axis were expressed as the average maximum diameter. It is unclear why they called this value an average or a diameter. They reported that this method increased their diameter measurement precision from $0.5 \mathrm{~mm}$ to $0.05 \mathrm{~mm}$ although no data or explanation were offered to validate the claim.

In a second study based in Scotland, Bradwell (2010) measured 23 R. geographicum thalli (2-28 mm). Photographs were taken with scale bars $(1 \mathrm{~mm}$ increments) and the camera positioned at a fixed height above each thallus. Images were overlaid in Adobe Photoshop 8.0 using the scale bars and natural identification markers on the rocks. He claimed that this technique replaces the need to mark the substrate in the field as suggested by McCarthy (2003) and Armstrong and Bradwell (2007). The use of these natural markers raises several problems. While they do provide a reference with which to align images this does not identify or correct errors from distortion. Thus several markers surrounding the entire thallus are needed with known distances between to provide the ability to scale an image and correct distortion around the entire thallus. Images were then enlarged to $1200 \%$ and using a $0.1 \mathrm{~mm}$ tool, the thallus was traced. Diameter measurements were taken along the maximum vertical (north-south) and the maximum horizontal (east-west) axes. They reported a measurement accuracy of 
$0.01 \mathrm{~mm}$, but did not provide supporting data or explain how this number was derived. While measurement techniques have improved in recent years there is still controversy surrounding the most fundamental concept, the measure used to describe growth (e.g., diameter or radius). Many researchers rely on measures of thallus size at one or many points around a thallus. For example, Armstrong (1983) and McCarthy (2003) marked 5-10 points around the thallus to be used as guidelines for measurement of radial growth. Armstrong (2005b) explored intrathalline growth in several Rhizocarpon thalli. He found that there was significant variation present between thalli and within thalli although the variance within thalli was greater. He concluded that there may be several sources for this variation. The first is the inclusion of individuals of different species within the section Rhizocarpon in his study. Secondly, growth rate is highly variable around the thallus and relying on one or a few measurements may cause high variation. Thus measures that encompass total thallus size are preferable but have not been fully explored. Some have measured total thallus area (e.g., Haworth et al., 1986) although they have converted these values to obtain measures of thallus diameter to allow comparison to previous diameter studies.

In conclusion, when measuring slow growing species like $R$. geographicum several variables need to be carefully controlled to ensure the reliable measurement of thalli, particularly small thalli (e.g., reliable field methods, accurate and precise measurement tools, measures that encompass total thallus size, etc.). While recent studies have initiated the use of more precise measurement techniques (e.g., photography and Adobe Photoshop software) their techniques still require some improvement. Most studies have assumed the accuracy of their measurement tool based on the manufacturers' 
estimates. Precision and accuracy are a fundamental concept in many quantitative biological studies and require further care and attention (Cassey and Blackburn, 2006).

\subsubsection{Growth of Rhizocarpon geographicum}

Armstrong and Bradwell (2007) and Trenbirth and Matthews (2010) provide comprehensive reviews and data arising from directly measured lichen growth rates. A summary of the major studies can be found in Table 2.2. Most of these studies not only have questionable methodologies, as has been discussed in detail in the previous section, but most have small sample sizes, ranging from 22-105 thalli (see Table 2.2). The following section will focus on the results of these major studies.

In 1983, Armstrong conducted a study on the growth of Rhizocarpon geographicum. The study was conducted in an Ordovician slate rock field in Gwynedd, North Wales over a period of 1.5 years (1979-1980). The study included 39 thalli ranging from 3-65 $\mathrm{mm}$ in size that were positively identified as $R$. geographicum. Over 15 years later (1995-1997) he revisited this site duplicating his first study and expanding his sample size to 53 lichens $(3-70 \mathrm{~mm}$ ) (Armstrong, 2005b). Five to ten random markers were placed around each thallus, approximately $1 \mathrm{~mm}$ away from the thallus edge. Armstrong (1983) measured the change in radius at each marker using a micrometer. On this basis he concluded that there are three growth phases in Rhizocarpon geographicum. He linked these phases to thallus diameter and described them as: 1) prelinear (radial growth accelerates in thalli $<20 \mathrm{~mm}$ in diameter), 2) linear (constant growth rate, thalli 20-45 $\mathrm{mm}$ in diameter, and 3) postlinear (radial growth decreases gradually with increasing size, thalli $>45 \mathrm{~mm}$ in diameter). This decline is poorly defined (only nine 
Table 2.2: Summary of major growth studies on Rhizocarpon geographicum thalli.

\begin{tabular}{|c|c|c|c|c|c|c|c|}
\hline Author(s) & Location & Study Period & Lichen Species & $\mathrm{N}$ & Size range & Technique & \# of measurements per lichen \\
\hline $\begin{array}{l}\text { Armstrong } \\
\text { (1983) }\end{array}$ & $\begin{array}{l}\text { Ordovician slate } \\
\text { rock field, } \\
\text { Gwynedd, } \\
\text { North wales }\end{array}$ & $\begin{array}{l}1.5 \text { years } \\
\text { (6 month } \\
\text { intervals) }\end{array}$ & $\begin{array}{l}\text { R. geographicum } \\
\text { (no indication of } \\
\text { how identified) }\end{array}$ & 39 & $2-65 \mathrm{~mm}$ & $\begin{array}{l}\text { Beck Kassal lens (fitted with a } \\
1 \mathrm{~cm} \text { micrometer with a } \times 8 \\
\text { magnification }\end{array}$ & $\begin{array}{l}\text { Marker placed } 1 \mathrm{~cm} \text { from } \\
\text { thallus lobe } \\
\text { Radius (thallus leading edge to } \\
\text { marker) } 5-10 \text { random }\end{array}$ \\
\hline $\begin{array}{l}\text { Proctor } \\
(1983)\end{array}$ & $\begin{array}{l}\text { Valsorey } \\
\text { moraine, } \\
\text { Switzerland }\end{array}$ & $\begin{array}{l}4 \text { year }(2 \text { year } \\
\text { intervals) }\end{array}$ & $\begin{array}{l}\text { R. geographicum } \\
\text { (no indication of } \\
\text { how identified) }\end{array}$ & 22 & $2-18 \mathrm{~mm}$ & $\begin{array}{l}\text { Photographs with a } 0.05 \mathrm{~mm} \\
\text { scale micrometer placed next } \\
\text { to the lichen }\end{array}$ & $\begin{array}{l}\text { Radius (thallus leading edge to } \\
\text { marker) }\end{array}$ \\
\hline $\begin{array}{l}\text { Harworth } \\
\text { et al. } \\
(1986)\end{array}$ & $\begin{array}{l}\text { Brooks Range, } \\
\text { Alaska }\end{array}$ & 4-6 year & $\begin{array}{l}R . \text { geographicum } \\
\text { s.1., majority } \\
\text { identified as } R . \\
\text { geographicum (L.) } \\
\text { DC. }\end{array}$ & 92 & $3-107 \mathrm{~mm}$ & $\begin{array}{l}\text { Tracing thallus area onto } \\
\text { acetate and converting to } \\
\text { equivalent diameter }\end{array}$ & 1 measurement/lichen \\
\hline $\begin{array}{l}\text { McCarthy } \\
(2003)\end{array}$ & $\begin{array}{l}\text { Illecillewaet } \\
\text { glacier, GNP, } \\
\text { British Columbia }\end{array}$ & $\begin{array}{l}\text { Annual } \\
\text { intervals over } \\
4 \text { years }\end{array}$ & $\begin{array}{l}\text { R. geographicum } \\
\text { (L.) DC. }\end{array}$ & 105 & $5-50 \mathrm{~mm}$ & Digital caliper $(+/-0.02 \mathrm{~mm})$ & $\begin{array}{l}\text { Radial extension at several } \\
\text { points around the thallus. } \\
(>5 / \text { lichen })\end{array}$ \\
\hline $\begin{array}{l}\text { Armstrong } \\
(2005 \mathrm{a})\end{array}$ & $\begin{array}{l}\text { Cascade } \\
\text { mountains, } \\
\text { Washington } \\
\text { State }\end{array}$ & 6 year & $\begin{array}{l}\text { Rhizocarpon section } \\
\text { Rhizocarpon (L.) } \\
\text { DC. }\end{array}$ & 39 & $3-102 \mathrm{~mm}$ & $\begin{array}{l}\text { Lens with } \times 8 \text { magnification } \\
\text { with a } 1 \mathrm{~cm} \text { micrometer scale }\end{array}$ & $\begin{array}{l}\text { Radius (thallus leading edge to } \\
\text { marker) (4/lichen) }\end{array}$ \\
\hline $\begin{array}{l}\text { Armstrong } \\
(2005 \mathrm{~b})\end{array}$ & $\begin{array}{l}\text { Ordovician slate } \\
\text { rock field, } \\
\text { Gwynedd, } \\
\text { North Wales }\end{array}$ & $\begin{array}{l}1.5 \text { year } \\
\text { ( } 3 \text { month } \\
\text { intervals) }\end{array}$ & $\begin{array}{l}\text { R. geographicum } \\
\text { (L.) DC. }\end{array}$ & 53 & $3-70 \mathrm{~mm}$ & $\begin{array}{l}\text { Micrometer scale under } \mathrm{x} 8 \\
\text { magnification }\end{array}$ & $\begin{array}{l}5 \text { random } \\
\text { thallus leading edge to marker }\end{array}$ \\
\hline $\begin{array}{l}\text { Bradwell } \\
\& \\
\text { Armstrong } \\
(2007)\end{array}$ & $\begin{array}{l}\text { Gigjokul glacier, } \\
\text { Iceland }\end{array}$ & 4.33 years & $\begin{array}{l}\text { Rhizocarpon section } \\
\text { Rhizocarpon } \\
\text { (most identified as } \\
\text { R. geographicum } \\
\text { (L.) DC.) }\end{array}$ & 38 & $<78 \mathrm{~mm}$ & $\begin{array}{l}\text { Field - ruler and } 8 \mathrm{x} \text { handlens } \\
\text { (precision is probably } 0.5 \mathrm{~mm} \text { ) } \\
\text { Photographed and Adobe } \\
\text { Photoshop (probably more } \\
\text { precise }+/-0.05 \mathrm{~mm} \text { ) }\end{array}$ & Diameter - Long \& 90 degrees \\
\hline $\begin{array}{l}\text { Bradwell } \\
(2010)\end{array}$ & $\begin{array}{l}\text { Lochiniver, } \\
\text { Scotland }\end{array}$ & $\begin{array}{l}\text { Churchyard }-5 \\
\text { year } \\
\text { Mill - } 7 \text { year }\end{array}$ & $\begin{array}{l}\text { Some identified as } \\
\text { R. geographicum } \\
\text { (L.) DC. }\end{array}$ & $\begin{array}{l}23 \\
15\end{array}$ & $\begin{array}{l}2-28 \mathrm{~mm} \\
2-43 \mathrm{~mm}\end{array}$ & $\begin{array}{l}\text { Digital Camera and Adobe } \\
\text { Photoshop } 8.0\end{array}$ & $\begin{array}{l}\text { Maximum horizontal and } \\
\text { vertical diameter. }\end{array}$ \\
\hline
\end{tabular}


thalli), and is likely an artifact of the size class designated to this decline. In his subsequent study (2005b) he again found evidence of a decline in larger thalli $(>50 \mathrm{~mm}$ in diameter) although this decline still remained poorly defined.

After Armstrong's first study he made a subsequent attempt to measure the growth of $R$. geographicum on granodiorite using a similar methodology (i.e., micrometer with 4 measures per lichen) (Armstrong, 2005a). As before, he measured 39 thalli, although the thalli were not identified beyond section level (Rhizocarpon section Rhizocarpon (L.) DC.). Thallus sizes reached $102 \mathrm{~mm}$ in diameter, although only two thalli were larger than $60 \mathrm{~mm}$ (3-102 mm). The study was conducted over 6 years (19881994) in the Cascade Mountains of Washington State, USA, on boulders of varying aspects and slopes. In contrast to his other studies he found no relationship between mean radial growth and initial diameter. Radial growth rate ranged from 0 to $1.12 \mathrm{~mm} \mathrm{yr}^{-1}$, with 7 thalli (18\%) showing no measurable growth (size range $0.2-60 \mathrm{~mm}$ in diameter). Armstrong's observation of these seven thalli found evidence of areola disintegration in 6 out of the 7 thalli while the remaining one had evidence of a retreat of the marginal prothallus.

McCarthy (2003) provided the largest data set to date, comprising 105 Rhizocarpon geographicum (L.) DC. thalli $(5-50 \mathrm{~mm})$. He measured change at the thallus margin. He used this change to infer radial growth. He did not attempt to use thallus diameter to subdivide these thalli into groups and infer growth stages and phases for the species. Unlike Armstrong (1983) the data from this larger study did not find a significant relationship between radial growth and thallus size $\left(R^{2}<0.29\right.$ in all years $)$. McCarthy's data did not support the three growth stage model proposed by Armstrong (1983). 
Haworth et al. (1986) studied 92 thalli of Rhizocarpon geographicum sensu lato (size range 3-107 $\mathrm{mm}$ in diameter) in the Atigun Pass, Alaska. Using a fine tip pen they traced the thallus outline onto an acetate sheet determining the area of each thallus and converting this value into its corresponding diameter. Several moraines were selected at varying altitudes and substrate types. They found that growth rate varied from 0 to 0.35 $\mathrm{mm} \mathrm{yr}^{-1}$. After 6 years, $30 \%$ of thalli showed no measurable change (which was not restricted to a particular thallus size range). Linear regression indicated a negative relationship between thallus size and absolute growth rate $\left(R^{2}=-0.30\right)$. Like McCarthy (2003) but unlike Armstrong (1983) and Armstrong's subsequent work (2005b) they found that the growth rate was highly variable, even between thalli of similar size. They attributed this intraspecific variation to differences in age, nature of the substrate, biological interactions and macro and microclimate.

Proctor (1983) photographed 22 thalli ranging from 2-18 $\mathrm{mm}$ in diameter. Lichens were photographed in 1975, 1977 and 1979 on the Valsorey moraine, Switzerland. However, growth rate was reported as the 4 year average growth from 1975-1979. No data were reported or described for growth between 1975 and 1977 or from 1977 and 1979. Each thallus was photographed alongside a micrometer and the distance from the thallus edge to a control marker was determined using the method of Hooker and Brown (1977). Proctor found that growth rate increased with thallus size, following an asymptotic course of growth. As in Armstrong $(1983,2005 b)$, growth was rapid in small thalli $(<10 \mathrm{~mm}$ in diameter) and was slower in larger thalli ( $>10 \mathrm{~mm}$ in diameter).

A recent study by Bradwell and Armstrong (2007) was carried out on the Gigjökul Glacier, Iceland. They measured 41 thalli (3-80 $\mathrm{mm}$ in diameter) of 
Rhizocarpon section Rhizocarpon, but most were identified as Rhizocarpon geographicum. Each thallus was photographed and the longest thallus diameter and $90^{\circ}$ to the longest axis diameter was measured using Adobe Photoshop. Over the 4 year study period 38 of the 4.1 thalli showed measurable growth. Like Armstrong (1983; 2005b) evidence of three growth phases was seen. Growth was described as being rapid in small thalli (3-20 $\mathrm{mm}$ in diameter), with diametric growth rates ranging from $0.2-0.8 \mathrm{~mm} \mathrm{yr}^{-1}$. After the thallus exceeded $20 \mathrm{~mm}$ in diameter its growth rate reached a plateau at a diametric growth rate of approximately $0.7 \mathrm{~mm} \mathrm{yr}^{-1}$ before gradually declining after the thallus exceeded $60 \mathrm{~mm}$ in diameter. Several regression lines were fitted to the data to determine the best, linear $\left(r^{2}=0.004\right), 2^{\text {nd }}$ order polynomial $\left(r^{2}=0.34\right)$ and $3^{\text {rd }}$ order polynomial $\left(r^{2}=0.44\right)$ fits.. All three curves revealed a weak relationship between thallus size and diametric growth rate.

In a second study based in Scotland, Bradwell (2010) measured 23 $R$. geographicum thalli (size range, $2-28 \mathrm{~mm}$ in diameter). Two study sites were set up, one in Alltanabradhan Mill, a late $18^{\text {th }}$ century mill with a yellow-green Rhizocarpon population growing on the granite-gneiss block walls $(N=15$, size range $3-43 \mathrm{~mm}$ in diameter). A second study site was selected on an orthoclase-granite gravestone, located in the same region although it represented a wetter climate. Fifty thalli were measured at the start of this study. After 5 years, 27 thalli were lost or rejected due to coalescence and death. Some, but not all, were identified as $R$. geographicum, therefore thalli were referred to as Rhizocarpon section Rhizocarpon. Each thallus was photographed and the average change in maximum vertical and horizontal thallus diameter was measured annually using Adobe Photoshop 8.0. Data were expressed as the mean annual change in 
thallus diameter over a 5 year period. The mean diametric growth rate was plotted against mean initial diameter as well as the error between these two measurements to show the variation between the maximal and minimal growth rates. At the mill site there was a general trend of an asymptotic growth curve (using a logarithmic function $r^{2}=0.74$ ). However, the authors concluded that sample sizes were too small to provide close calibration for an age-size curve. At the second site (gravestone) 12 of the 15 thalli were rejected because they had coalesced with adjacent thalli.

Overall, there is still no definitive study to show that there are only three growth phases in the lichen $R$. geographicum. The first two phases of growth have been supported by the majority of studies (e.g., Armstrong, 1983; Armstrong 2005b; Armstrong and Bradwell, 2007; Proctor, 1983; Bradwell, 2010). Several studies have suggested that a third growth phase occurs in thalli greater than $50 \mathrm{~mm}$ in diameter (e.g., Armstrong, 1983; Armstrong 2005b; Armstrong and Bradwell, 2007). The size class designated to this third phase is insufficient in all cases to definitively define this phase ( $N<10$ thalli in all cases). While the majority of studies focus on obtaining large thalli, small thalli are of equal if not more importance as they show real time changes in environment. Further study is required with greater sample sizes and focus on smaller thalli.

While progress is being made to provide closer control over measuring Rhizocarpon growth all of the above-mentioned studies have weaknesses. For instance, greater trust could be placed in the growth rate data if workers used painted markers. Ideally, markers should surround the entire thallus at known distances. This would allow the entire image to be scaled and distortion corrected. Secondly, all should employ 
photographic techniques and computer software. This technique has the ability to provide a non-destructive, reliable, accurate and permanent record of thallus growth and development. While this is a tedious process, care must be taken to determine the accuracy, precision and reproducibility of the measure you wish to use. Thirdly, studies should measure and report total thallus size. As I will demonstrate, with slow growing species like $R$. geographicum, measures of diameter or radius provide only some insight into Rhizocarpon growth.

\subsection{Approach and research objectives}

This thesis will demonstrate and critically use Adobe Photoshop CS3 Extended software to measure growth and morphological changes in Rhizocarpon geographicum thalli. It will also develop and analyze quantitative data that can be used to test hypotheses concerning the growth and development of Rhizocarpon thalli.

The objectives of this thesis are:

1) Develop and test a new methodology for tracking visible or morphological changes occurring in $R$. geographicum thalli.

2) Critically apply these methods to develop quantitative measures of thallus size, growth and morphological characteristics.

The general hypotheses being tested are:

1) Adobe Photoshop CS3 Extended can be used to provide accurate and highly reproducible measures of thallus size. 
2) The areal growth rate of a $R$. geographicum thallus is positively correlated with thallus size.

3) The diametric growth rate of a $R$. geographicum thallus is

a. negatively correlated with thallus size.

b. uniform along the entire thallus margin.

4) Areola area and prothallus width in $R$. geographicum thalli are positively correlated with thallus size.

5) The prothallus of a $R$. geographicum thallus has a uniform width. 


\section{Methods}

\subsection{Study setting and environment}

The lichens examined in this study are growing on the quartzite boulders of a moraine complex in the Selkirk Mountains of Canada's Glacier National Park, British Columbia $\left(51^{\circ} 15.116^{\prime} \mathrm{N}, 117^{\circ} 28.226^{\prime} \mathrm{W}\right)$. The lichens are located in a subalpine clearing at an elevation of approximately $1531 \mathrm{~m}$ on the western lateral-terminal moraine complex of the Illecillewaet Glacier. Lichen colonization at this site post-dates the formation of the moraine, which is estimated to have become ice free and stable in $1838 \mathrm{AD}$ (McCarthy, 2003). Nearby, crustose lichens and a sparse, young forest of Engelmann spruce (Picea engelmannii Parry ex. Engelm.) and alpine fir (Abies lasiocarpa [Hook.] Nutt.) saplings have become established on the Illecillewaet Glacier forefield and a mature forest of Engelmann spruce and subalpine fir lies about $50 \mathrm{~m}$ to the west. This forest burned in the late 1880s (Johnson et al., 1990). However, flames stopped at the treeless boulders in this moraine complex and did not damage the lichen community. The lichen community has no obvious disturbance regime. This particular site is not on a snow avalanche path and it is not visible from the nearby Great Glacier trail. Thus it is seldom visited or disturbed by human activity.

\subsection{The lichen community}

The lichens measured in this study are part of a broader community of lichens that colonized the morainic debris. The $5 \mathrm{~m}$ wide by $25 \mathrm{~m}$ long portion of the moraine where the measured lichens are located has very few lichen species. Individuals identified on this narrow strip of moraine include Buellia (unidentified species), Rhizocarpon 
geographicum (L.) DC., Rhizocarpon inarense (Vainio) Vainio, Lecidea atrobrunnea (Lam. and DC.) Schaer., Sporastatia testudinea (Ach.) A. Massal., and Xanthoria elegans Th. Fr. The yellow-green Rhizocarpons are by far the most common lichen on these rocks (Dr. Daniel McCarthy, personal communication, April 22, 2010). Here and elsewhere, many of the crustose thalli are irregularly shaped due in part to marginal contact and competitive interactions with neighboring thalli (Dale, 1995). While some thalli are clustered around cracks and irregularities in the rock surfaces, all thalli measured in this thesis have oval to circular shaped thallus outlines, are on flat rock faces and have distinct margins that are free of contact with other lichens. Each thallus was examined to ensure that it did not comprise two or more inter-grown individuals (see Appendix II for details).

Every primary lichen thallus used in this thesis was identified to subgenus Rhizocarpon section Rhizocarpon by lichenologist Dr. K. Glew in the summer of 1997 (Dr. Daniel McCarthy, personal communication, April 22, 2010). It should be noted that most thalli at this site were positively identified as Rhizocarpon geographicum (L.)DC. Unfortunately, in McCarthy (2003) these thalli were incorrectly reported as $R$. lecanorinum. Species identification included the microscopic examination of spores and the use of reagents on a small section of each thallus. In each case the reagent was applied sparingly to a small section of thallus and was quickly blotted up with a tissue. In some thalli, a small cutting was taken from the central part of the thallus. The resulting damage was minimal and photography in subsequent years shows that the excised areas (e.g., $2 \mathrm{~mm}$ diameter) rapidly healed and that growth around the thallus margin was continuous in all cases. 


\subsection{Digital image set}

In 1996, Dr. D. McCarthy selected 143 thalli for growth analysis. He attempted to photograph each thallus in 1996, 1999, 2002, 2003, 2006 and 2007. However, not all thalli were photographed each year and thallus image availability varied from year to year. Examination of the image sets from 1996, 1999, 2002, 2003, 2006 and 2007 showed that not all of the images are suitable for detailed analysis. Most of the photographs from 1999 were blurred and only 19 images from 2002 were properly exposed. In addition, lichen mortality, erosion of the painted control points and competition has led to the loss of lichens from the dataset over the years. Photographs from 1996 and 1999 were scanned from film based images (see Appendix I). Appendix II illustrates examples of thalli used in this study (e.g., smallest and largest thalli used for measurement). In most cases, small irregularly shaped secondary thalli have formed in close proximity to the primary thalli. Some of these had merged with adjacent thalli or stopped growing where they have come into marginal contact with larger thalli. Appendix II also illustrates mergers between analogous and dissimilar species. While thallus mergers are common, merged or compound thalli often produced irregularly shaped thallus outlines and do not well represent radial growth of a single thallus. Consequently, merged thalli and primary thalli that do not have at least 4 control points near the top, bottom and sides are not included in this study. Thus, only 115 thalli were accepted for final analysis based on shape, clarity, photographic availability and the presence of adequate control points. In total, 115 thalli and three growth intervals were considered: one year (2006-2007), 3 year (2003-2006) and 7 year (1996-2003) (Table $3.1)$. 
Table 3.1: Number and sizes of lichens measured in the repeated photographs.

\begin{tabular}{|c|c|c|c|}
\hline Growth Period & 1 Year $(2006-2007)$ & 3 Year (2003-2006) & 7 Year $(1996-2003)$ \\
\hline Number of thalli (N) & 36 & 43 & 36 \\
\hline Mean Area $\left(\mathrm{mm}^{2}\right)$ & 98.21 & 105.89 & 128.30 \\
\hline Standard Deviation & 241.35 & 233.41 & 208.76 \\
\hline Size Range $\left(\mathrm{mm}^{2}\right)$ & $0.53-1317.19$ & $0.23-1247.84$ & $0.38-1049.88$ \\
\hline
\end{tabular}




\subsection{Image quality and image analysis}

The images used in this study were produced with a variety of camera and lens systems. Each image was prepared and analyzed using Adobe Photoshop CS3 Extended software. The choice was made to generate high quality originals derived from Canon Raw Image files. Using this approach it was possible to do most of the necessary adjustments before the Canon Raw file was saved and analyzed. Since the quality of each image is in part a function of photographic technique as well as post-exposure processing these technical issues are important and received considerable attention. Appendix I lists the camera systems used and describes the resulting image resolution. Appendix III provides a step-by-step description of the operations involved and the commands used with the software. The post-exposure treatment of each image is described as follows.

Each image received individual attention to ensure that I could clearly distinguish between thallus-rock boundaries and prothallus-areola boundaries. Sharpening, contrast adjustment and standardization of the white balance was done before the Canon Raw file was saved and analyzed as a 24 bit tagged image file (TIFF). All of the Canon Camera Raw files were manually white balanced to $5800^{\circ} \mathrm{K}$. This adjustment standardized the image colour so that images that were exposed under bright skies at a colour temperature of $5500^{\circ} \mathrm{K}$ had the same colour balance as images that were captured at $6500^{\circ} \mathrm{K}$ under cloudy skies. This adjustment then made it easier for the operator to distinguish between morphological features.

All images in a time series were oriented and scaled roughly to the same size using the oldest image in a time series as a reference (Fig. 3.1A). Perspective was adjusted and distortion was removed by manually stretching or compressing portions of 
each image to ensure that the known distances between control markers were correctly maintained. Rock crystals as well as the painted cross-hairs were used to ensure that the image pairs were correctly aligned.

Since the elevation of the grid of fixed points that surround each thallus was not known, slight micro-topographic irregularities in the central portion of a thallus introduced an unknown amount of error in the measurement of thallus area. However, a shallow depth-of-field in the macro photographs made it possible to visually identify and exclude out-of-focus specimens that were on bumpy rocks. While errors due to topographic irregularities should be minor and infrequent, the measurements of surface area are presented as minimum estimates.

\subsubsection{Measurement of areal change}

Thallus area and perimeter were measured by tracing the thallus outline (set to a width of 1 pixel, $\leq 0.01 \mathrm{~mm}$ ) (Fig. 3.2). The pen tool is roughly 18 times smaller than the tip of a ball-point pen. Since it was used to mark thallus boundaries under $300 \%$ magnification, this sharp pen made it possible to closely mark even the slightest of changes at the thallus margin. Use of the "magic wand" tool also allowed groups and/or individual pixels to be selected or deselected. Its use was tested and critically used to collect highly reproducible measures of areola area that could not readily be obtained in any other way. Areola area $\left(\mathrm{mm}^{2}\right)$ was determined by cropping out the lichen of interest and pasting it onto a new layer. The areolae were then broadly selected using the "magic wand" tool and the selection was adjusted manually to ensure that the selected pixels were appropriate. 


\section{A}

Repeat photographs and calipers are used to measure distances between control points.
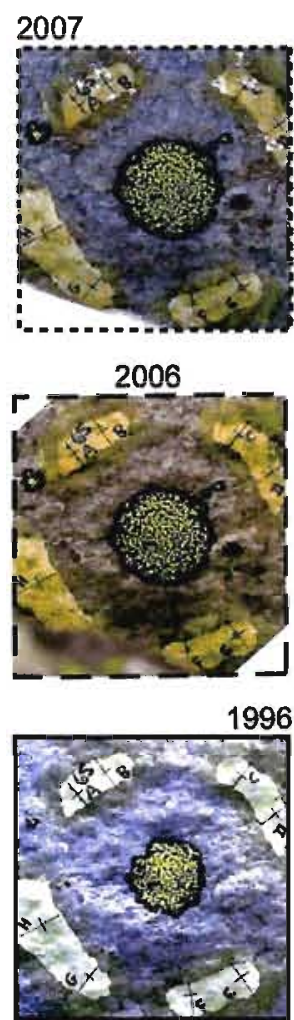

Figure 3.1: Illustration of how an image was scaled (A) and superimposed (B), aligned and traced (C) using Adobe Photoshop CS3 Extended.

\section{C}

Thallus outlines are traced using Adobe $\circledast$ Photoshop $₫$

pen tool.

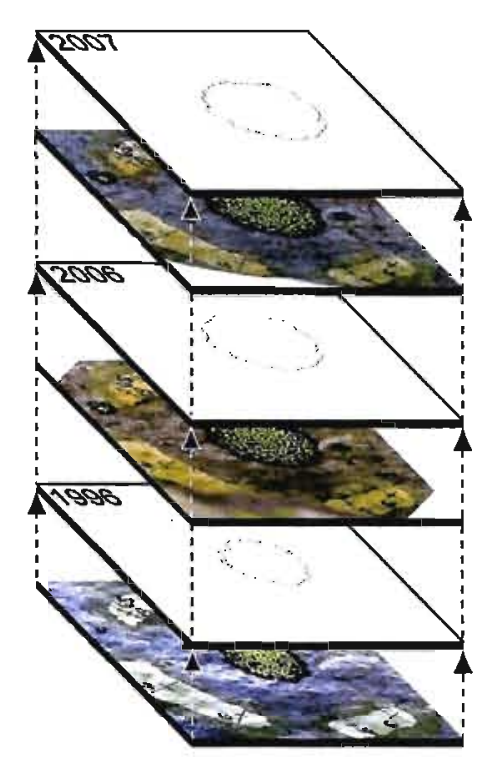

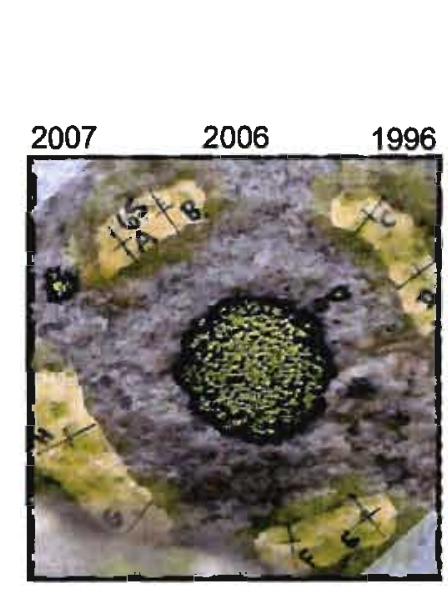
distortion is corrected and
images are superimposed. distortion is corrected and
images are superimposed.
B 
Measurement precision for thallus area, areola area and perimeter was evaluated by taking 15 repeated measures of thallus area and areola area on 27 thalli of various sizes $\left(0.18-764.89 \mathrm{~mm}^{2}\right)$. Precision was expressed as the percentage by which each of the 15 measurements differed from the mean measurement value. For example if a measurement was identical to the mean it would be represented as $0 \%$ precision. A measurement was classified as being highly precise if all 15 measures were within $\pm 5 \%$ of the mean. Each vertical bar represents a single thallus with each of the 15 individual measurements displayed as a tick on the bar. Testing was also done to assess measurement precision as a function of image quality. This testing used 15 repeated measures of 16 thalli. All measures were done on different days without reference to previous results. The repeated measures data were then expressed as the percentage by which each of the 15 measures deviated from the mean. Appendix IV highlights the calculations used to obtain precision measures. Precision measures are expressed as the percentage by which each measure differs from the mean of 15 measures.

A separate test was done to assess the role of image quality on measurement precision. In this test, 16 thalli (paired for size, 8 size classes) were chosen for repeated measurement (Table 3.2). Each image pair consisted of a low and a high quality thallus. Thalli were designated as high or low quality based on visual clarity of the thallus-rock and prothallus-areola boundary. While some of the thalli were measured at $2400 \mathrm{dpi}$ (dots per inch), image resolution does not ensure clarity or ease of measurement. One of the clearest thalli in the collection was measured at a resolution of $240 \mathrm{dpi}$. Image quality was classed as low if the image lacked a crisp tonal distinction between the thallus and the rock or where the areolae are visible, but not distinct. 


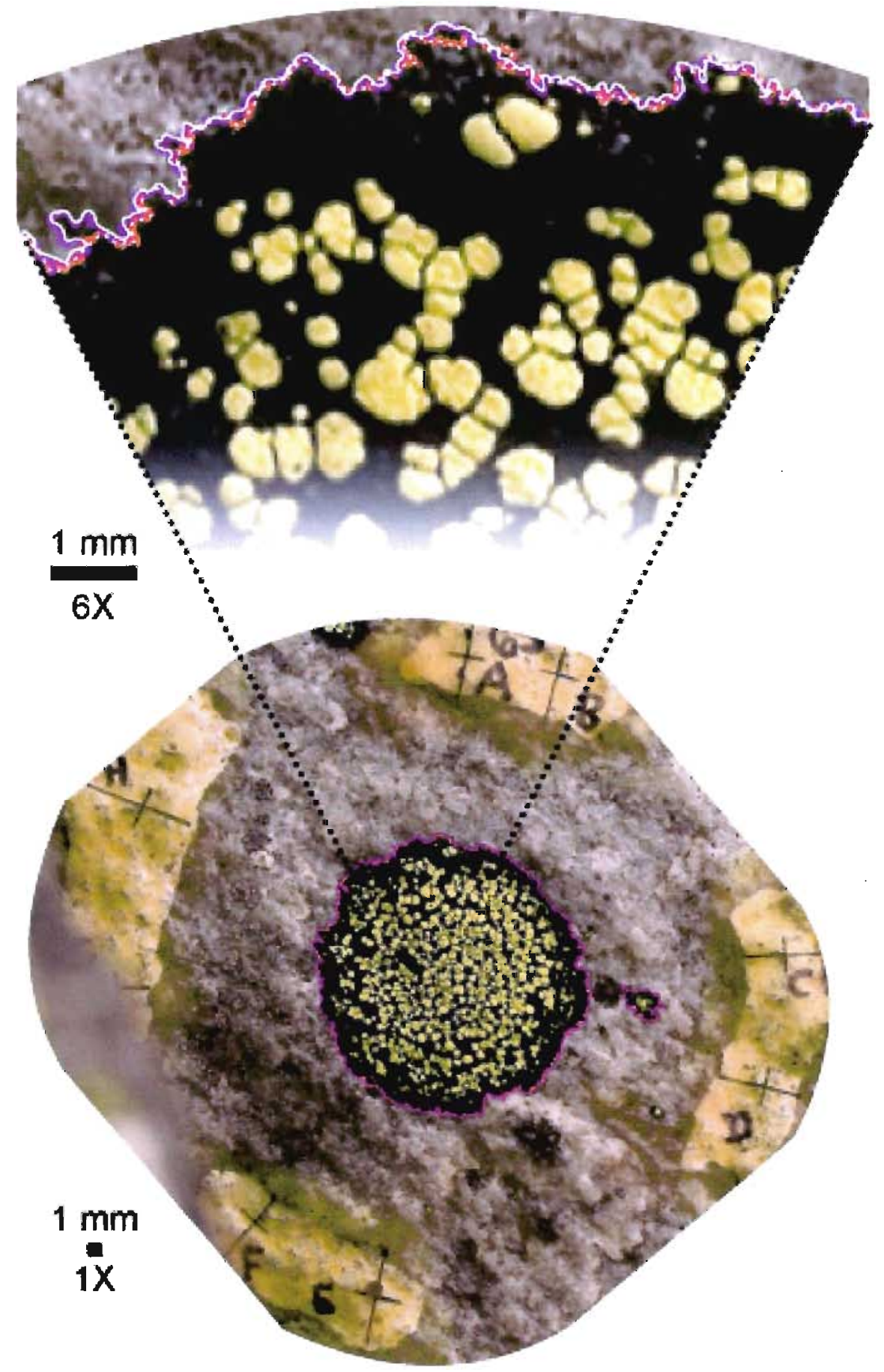

Figure 3.2: Illustration of how thallus outlines were traced. 
Table 3.2: Thallus size and image resolution data for test thalli. These thalli were used to assess the precision of areal measurements with image quality.

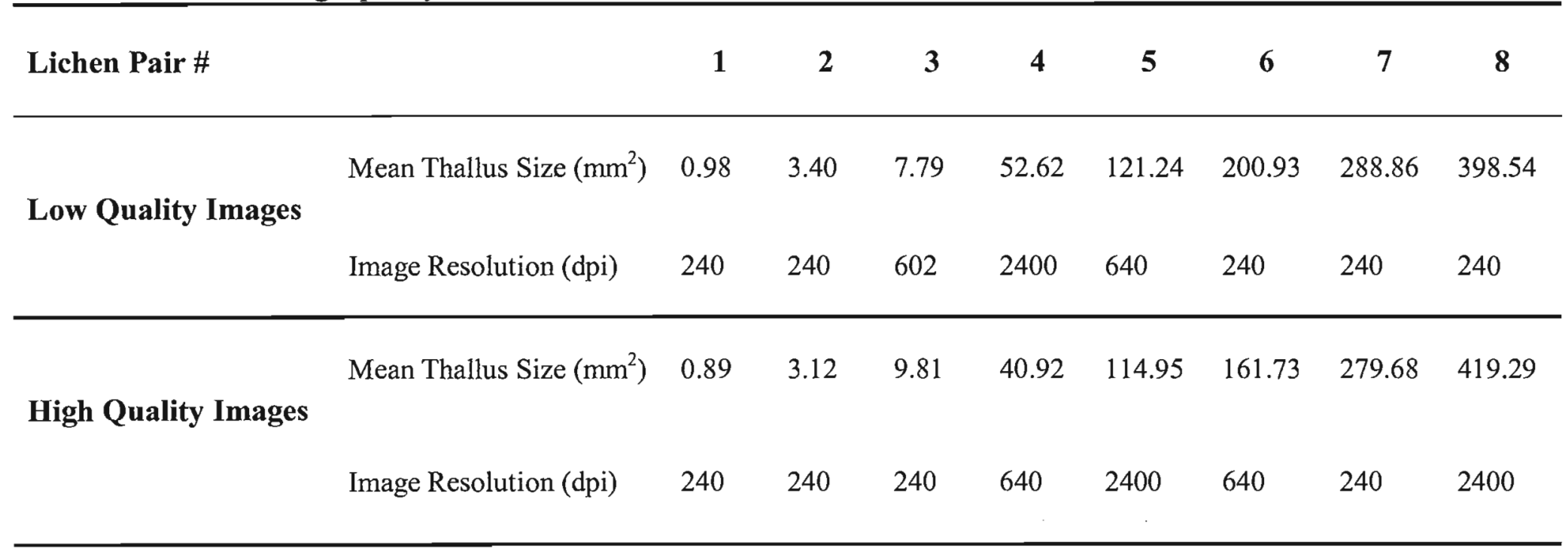


All measurements used in this thesis were generated by myself. A small test was done to broadly evaluate bias between several operators. Accordingly, four thalli of midhigh quality were independently measured by three people. Each person traced each of the four thallus outlines ten times on ten different occasions with no reference to previous results (see Appendix V). These results broadly showed that in this case, measurements were reproducible to within a few millimeters in large thalli and $0.02 \mathrm{~mm}$ in small thalli.

\subsubsection{Measurement of linear change}

A fixed grid overlay was created to provide eight reference lines in an evenly radiating circular pattern (Fig. 3.3A). The grid was positioned in the approximate centre of the thallus so that three grid lines bisected each quadrat into four equal areas. Use of this grid reduced operator bias and ensured that a regular sample was collected that well represented growth and character differences around the thallus. Eight diametrical measures were made per thallus. Data were expressed as the total and percent change in diameter. In some cases both positive and negative changes in diameter occur within a single thallus due to growth and shrinkages in the thallus margin. Prothallus was measured as a straight-line distance on the grid line from the outer edge of the thallus to the first areola (Fig. 3.3B). Sixteen prothallus measurements were then made per thallus. Measurements were expressed as a proportion of the radius that is made up of prothallus. This takes into account the size of the lichen (prothallus width divided by radius). 


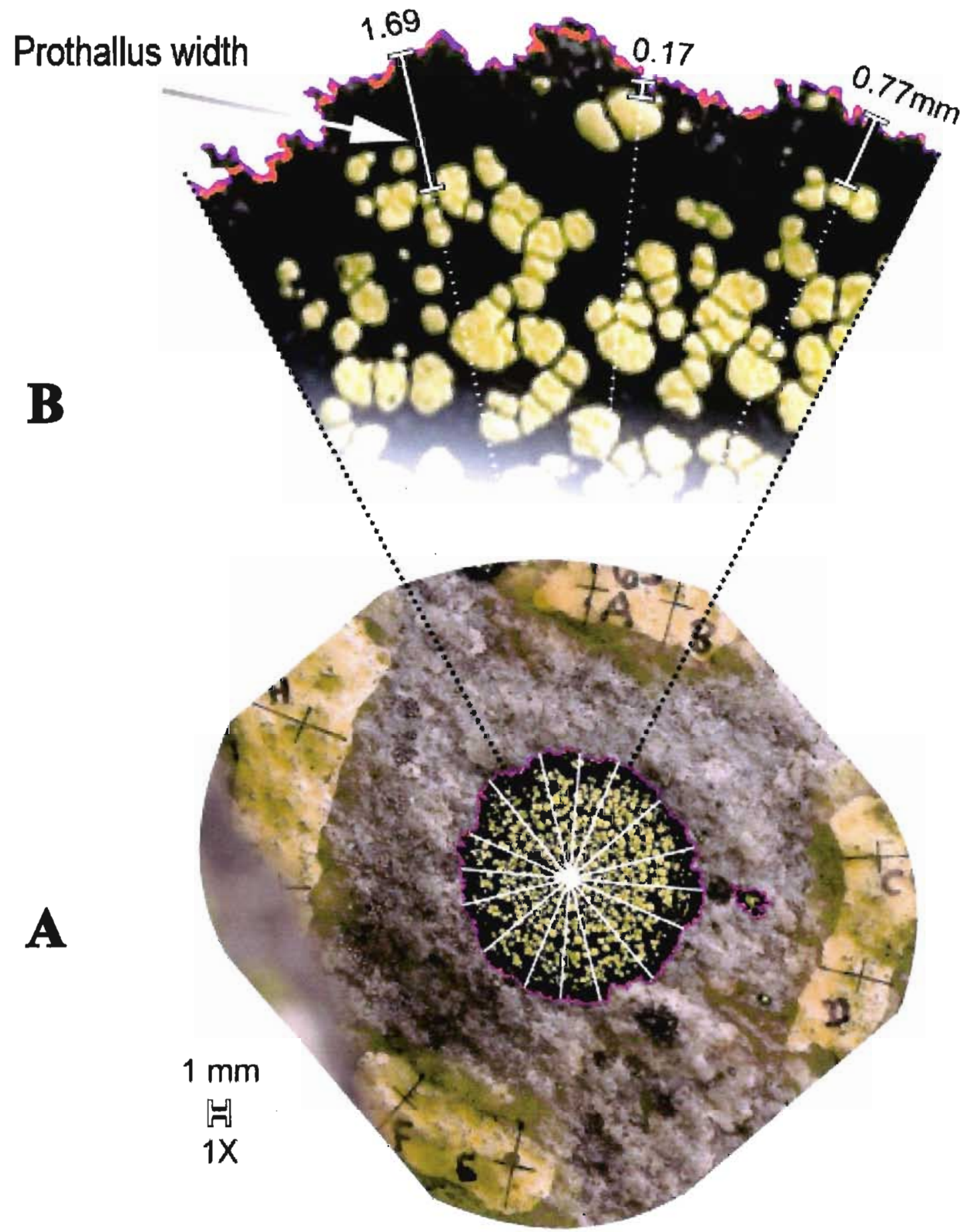

Figure 3.3: Illustration of the grid pattern used to measure the diameter (A) and prothallus width (B) of a lichen. 


\subsection{Data management and statistical analysis}

These data were entered into Microsoft Excel 2004 for Mac version 11.3.7 where scatterplots and basic statistical descriptors were generated. Trend lines and tests of significance were also done using Microsoft Excel 2004 for Mac version 11.3.7. Scatterplots were used to identify trends and search for errors in measurement or data entry. Widely differing values were revisited and remeasured so as to confirm the values. 


\section{Results}

\subsection{Measurement precision: thallus area, thallus perimeter and areola area}

The mean measurement precision for thallus area (Fig. 4.1) was less than $10 \%$ and was almost perfect ( $<2 \%$ precision) in larger thalli. In the few cases where the lower limit of precision approached/exceeded $10 \%$, thalli were small $\left(\leq 3 \mathrm{~mm}^{2}\right)$ and the contrast between the thallus and rock was slightly lower than was seen in most thalli. Overall mean measurement precision for total thallus area increased with thallus size.

Thallus perimeter is also a precise measurement (Fig. 4.2). Mean precision is less than $10 \%$ in all 27 thalli. Thallus precision does not vary with thallus size.

Mean areola area is also a highly precise measure (Fig. 4.3). The lowest measurement precision was $10 \%$ and mean precision was less than $6 \%$ in most cases. Larger thalli (e.g., thalli greater than $10 \mathrm{~mm}^{2}$ ) had a greater spread in the data points. Overall, these results suggest that measurement precision may be linked with factors other than thallus size (e.g., image quality). 


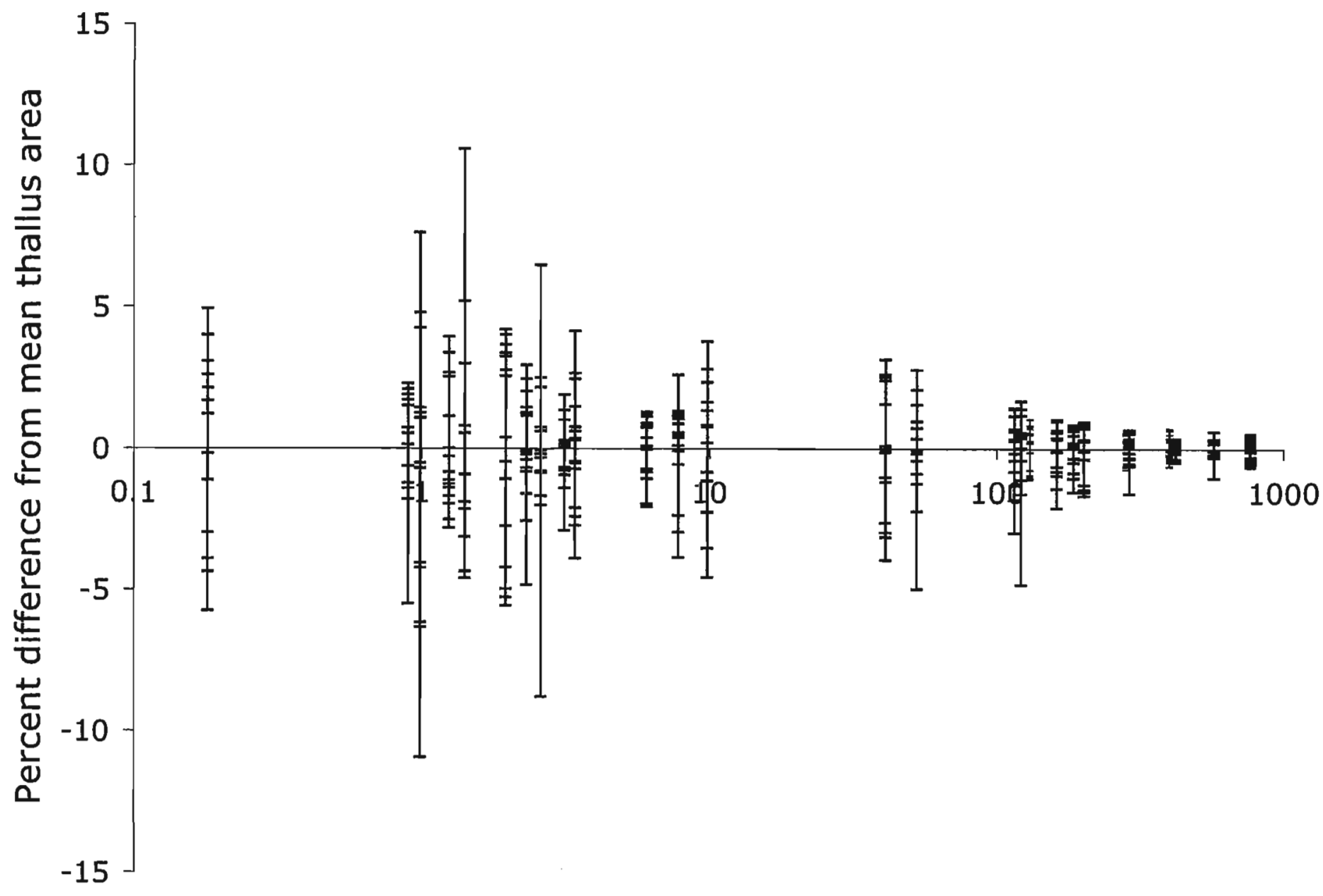

\section{Mean Thallus Area $\left(\mathrm{mm}^{2}\right)$}

Figure 4.1: Plot used to assess the precision of total thallus area measurements. Each vertical bar represents a single thallus, with each tick mark representing one of the 15 measurements per thallus. Thallus precision increases with thallus size. 


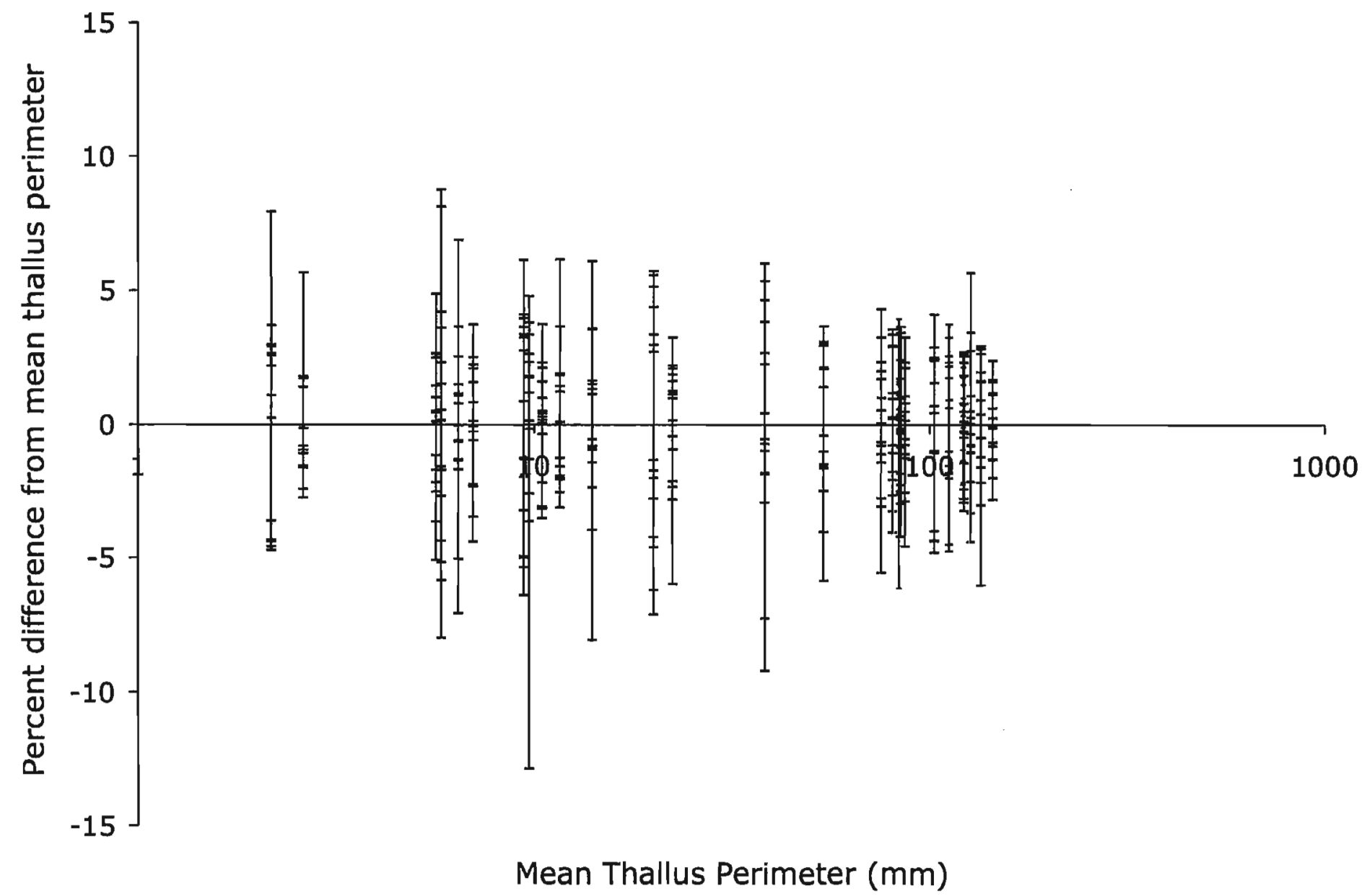

Figure 4.2: Plot used to assess the precision of thallus perimeter measurements. Each vertical bar represents a single thallus, with each tick mark representing one of the 15 measurements per thallus. Thallus precision does not vary with thallus size. 


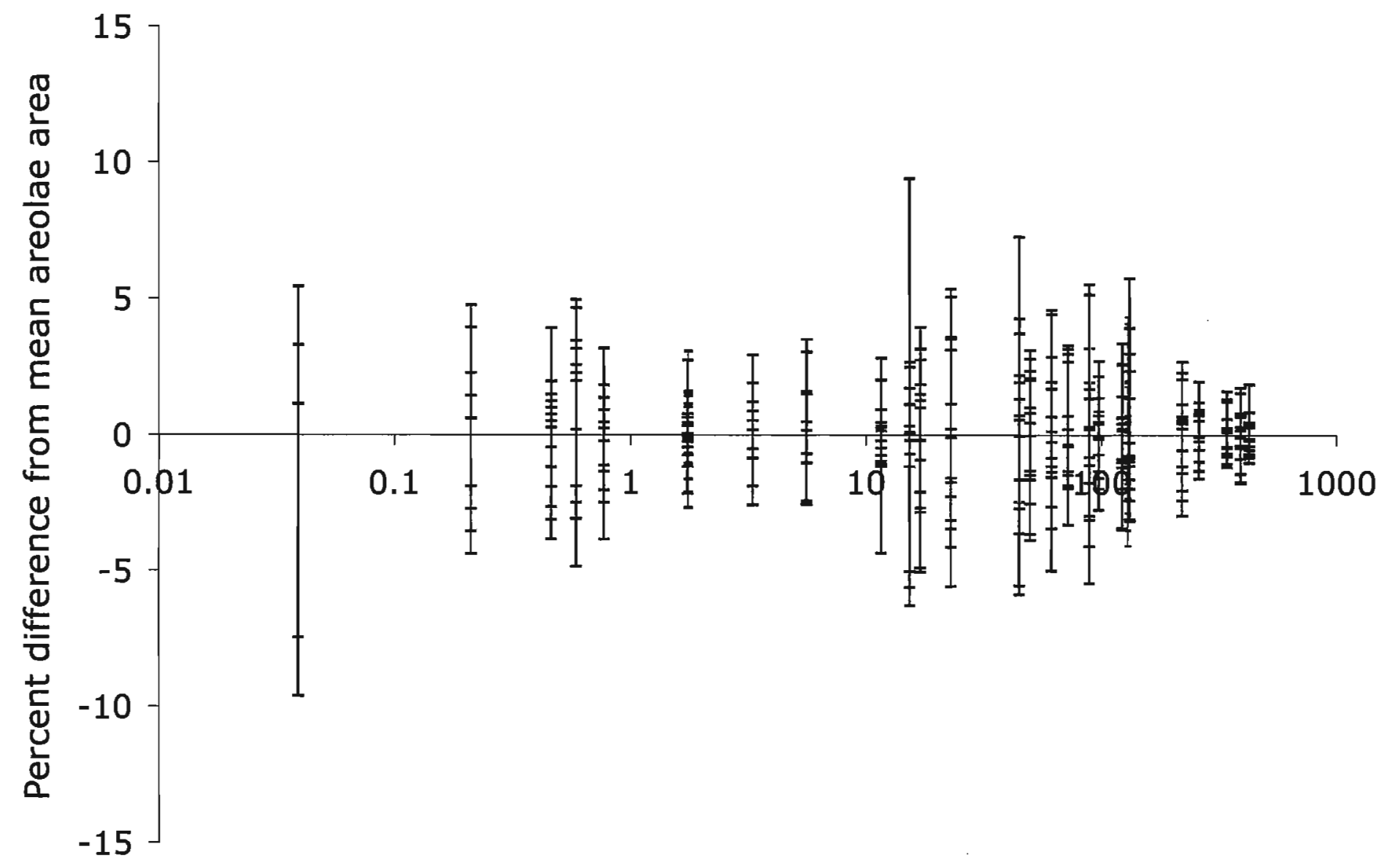

\section{Mean Areolae Area $\left(\mathrm{mm}^{2}\right)$}

Figure 4.3: Plot used to assess the precision of areolae area measurements. Each vertical bar represents a single thallus, with each tick mark representing one of the 15 measurements per thallus. Thallus precision decreases slightly with increasing thallus size. 


\subsection{Measurement precision and image quality}

Figure 4.4 shows that image quality is strongly linked with areal measurement precision. Measurements done using high quality images (see Table 3.2) were in all cases more precise than those done with low quality images.

Figure 4.5 shows that image quality is linked with perimeter measurement precision. Measurements done using high quality images were in all cases more precise than those done with low quality images.

Figure 4.6 shows that image quality is not linked with total areolae area measurement precision. Measurements done using high quality images were in some cases more precise than those done with low quality images.

Overall, higher quality images are ideal to obtain precise area, perimeter and areola measurements.

\subsection{Quantitative findings on the growth of Rhizocarpon geographicum}

\subsubsection{Thallus growth: area and diameter}

The relationship between thallus area $\left(\mathrm{mm}^{2}\right)$ and change in area $\left(\mathrm{mm}^{2}\right)$ is shown in Fig. 4.7. Fig. 4.7A illustrates the raw data, while Fig. 4.7B represents the data standardized to an annual growth rate (see formulae in Appendix 4.3). Lines of best fit were applied to the data and it was determined that the power regression equation provided the best fit in all three growth intervals. Table 4.1 shows the supplementary data for Fig. 4.7 (e.g., sample size, mean change in area, standard deviation, power regression equation and corresponding correlation coefficient). 


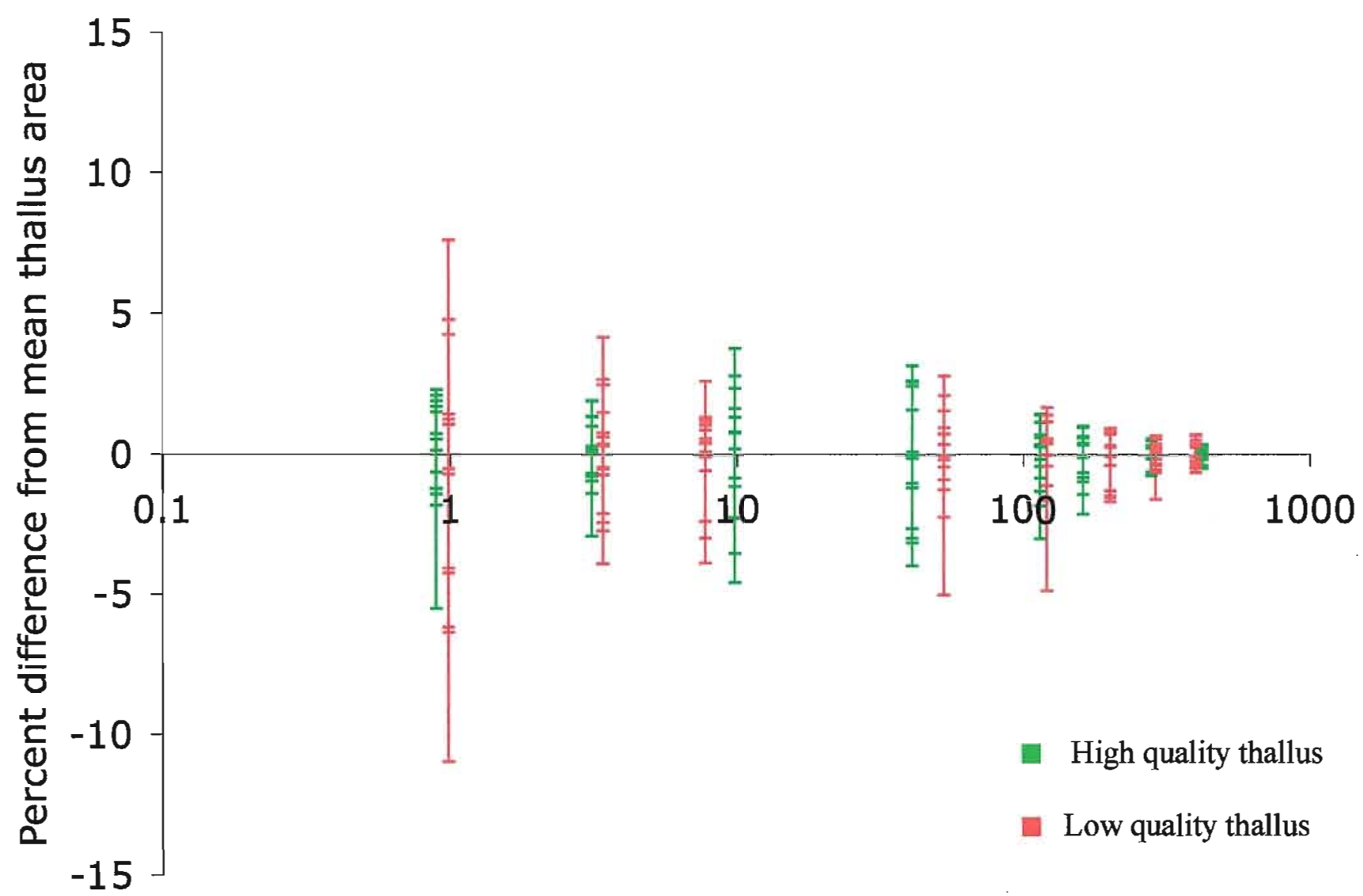

\section{Mean Thallus Area $\left(\mathrm{mm}^{2}\right)$}

Figure 4.4: Plot used to assess the precision of thallus area measurements with image quality. Each vertical bar represents a single thallus, with each tick mark representing one of the 15 measurements per thallus. Measurement precision increases with image high quality images. 


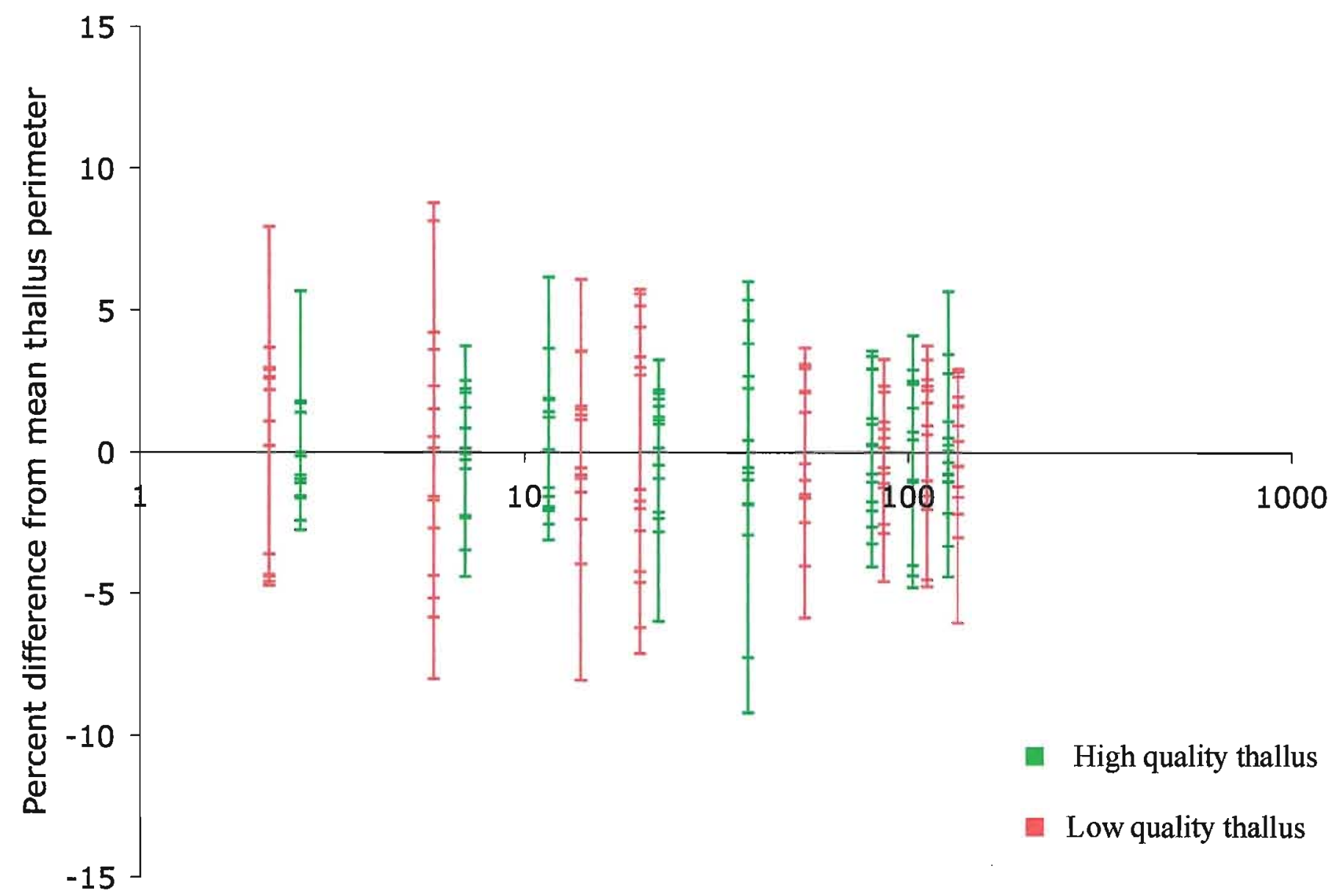

\section{Mean Thallus Perimeter $(\mathrm{mm})$}

Figure 4.5: Plot used to assess the precision of thallus perimeter measurements with image quality. Each bar represents the mean, max and min measurement precision for a single thallus. Image quality does not affect measurement precision. 


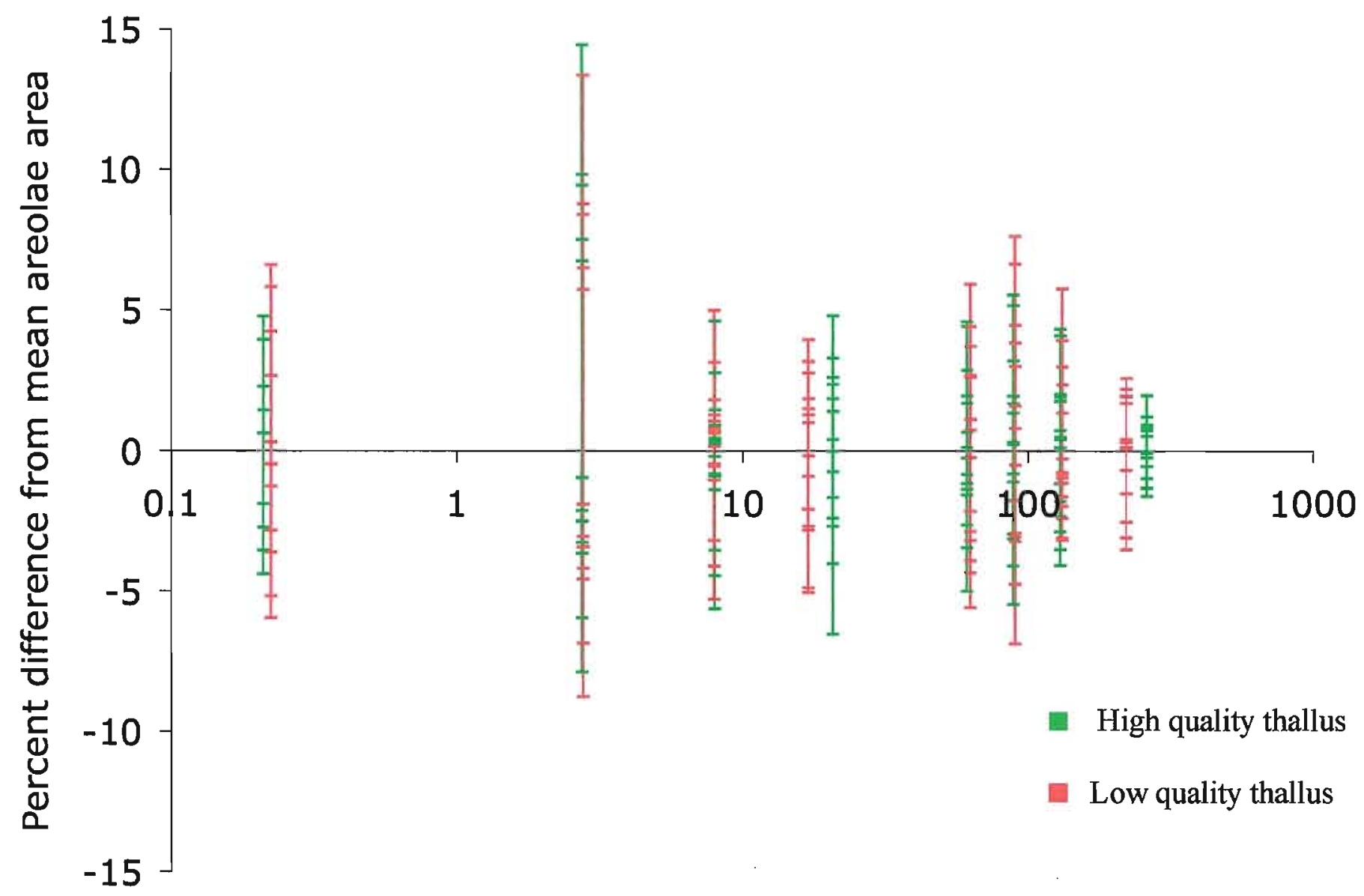

\section{Mean Areolae Area $\left(\mathrm{mm}^{2}\right)$}

Figure 4.6: Plot used to assess the precision of thallus areolae area measurements with image quality. Each vertical bar represents a single thallus, with each tick mark representing one of the 15 measurements per thallus. Image quality does not affect measurement precision. 
A

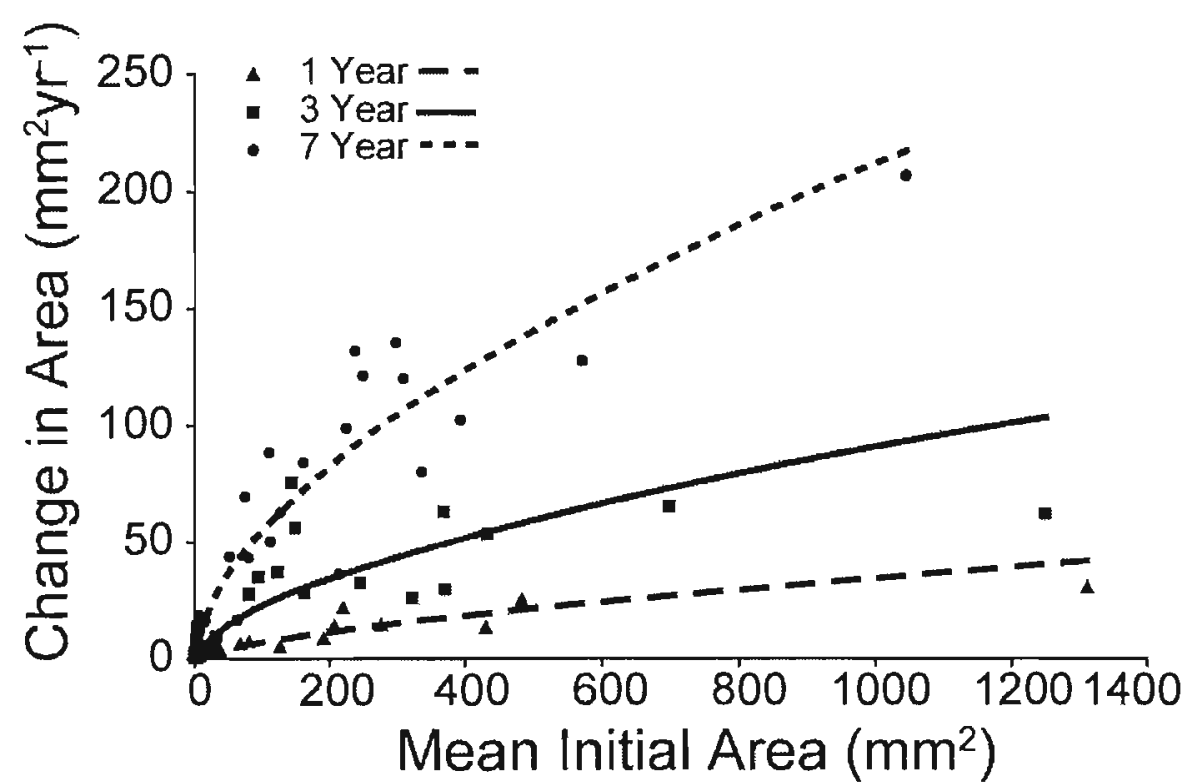

$B$

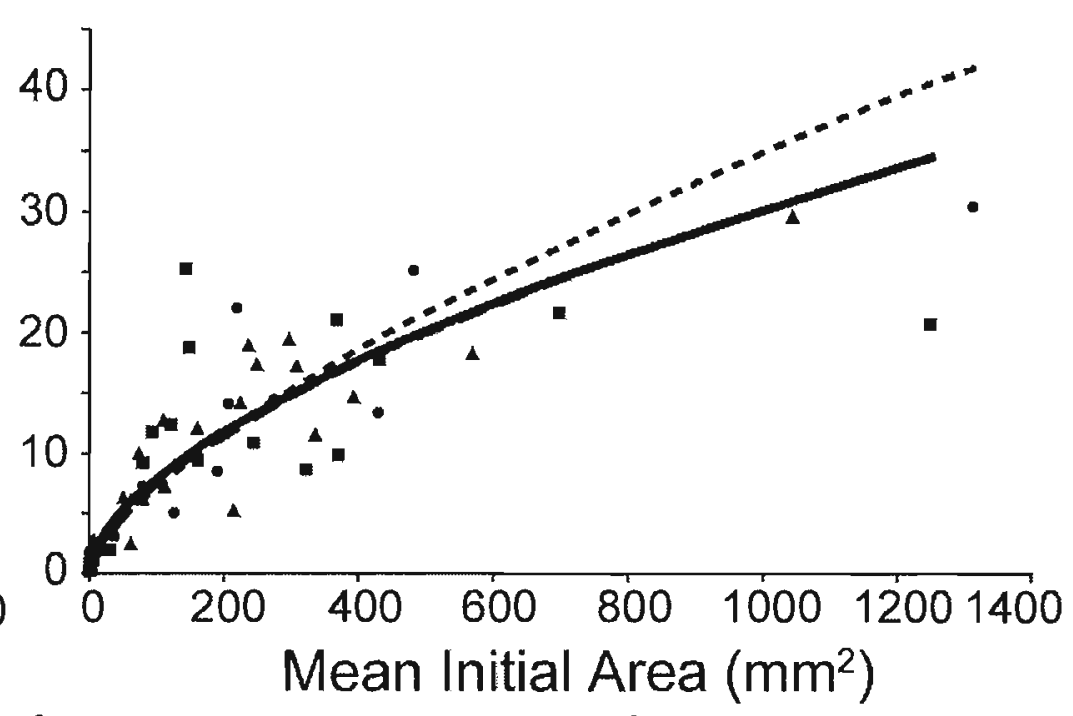

Figure 4.7: Scatterplots showing linear regression of thallus size $\left(\mathrm{mm}^{2}\right)$ against mean change in area $\left(\mathrm{mm}^{2}\right)$ for all three growth intervals. Strong correlation coefficients and linear regression lines with a positive slope indicates that areal growth slows as lichens increase in size (A). When growth is normalized to one year (B) all regression lines overlap indicating that the growth trend is similar regardless of the growth interval. Table 4.1 provides the correlation coefficients and additional data. 
Table 4.1: Summary list of the change in thallus area data (companion table to Fig. 4.7). (A) represents details from the raw data, (B) represents data standardized to one year. Data were standardized by dividing the raw measurements by the number of years in the photographic interval.

\begin{tabular}{|c|c|c|c|c|}
\hline & & $\begin{array}{c}1 \text { Year } \\
(2006-2007)\end{array}$ & $\begin{array}{c}3 \text { Year } \\
(2003-2006)\end{array}$ & $\begin{array}{c}7 \text { Year } \\
(1996-2003)\end{array}$ \\
\hline & Number of thalli (N) & 36 & 43 & 36 \\
\hline \multirow{4}{*}{ Raw Data } & Mean Change in Area $\left(\mathrm{mm}^{2}\right)$ & 4.44 & 15.33 & 48.39 \\
\hline & Standard Deviation & 7.05 & 22.21 & 51.81 \\
\hline & Power correlation $\left(R^{2}\right)$ & 0.94 & 0.93 & 0.89 \\
\hline & Power Regression Equation & $y=0.3497 x^{0.6504}$ & $y=1.3934 x^{0.603}$ & $y=3.7035 x^{0.5822}$ \\
\hline \multirow{4}{*}{ Standardized to yearly growth } & Mean Change in Area $\left(\mathrm{mm}^{2}\right)$ & 4.44 & 5.11 & 6.91 \\
\hline & Standard Deviation & 7.05 & 7.40 & 7.40 \\
\hline & Power correlation $\left(R^{2}\right)$ & 0.94 & 0.93 & 0.89 \\
\hline & Power Regression Equation & $y=0.3497 x^{0.6504}$ & $y=0.4645 x^{0.603}$ & $y=0.5291 x^{0.5822}$ \\
\hline
\end{tabular}


All three growth intervals reveal a strong positive correlation between thallus size $\left(\mathrm{mm}^{2}\right)$ and change in area (Fig. 4.7). Strong correlation coefficients and linear regression lines with positive slopes indicate that areal growth increases with thallus size (Fig. 4.7A). When growth is standardized to an annual rate all regression lines overlap indicating that the annual growth is similar in all growth intervals (Fig. 4.7B).

Areal growth rates were then expressed on a percentage change basis and standardized to an annual rate (Fig. 4.8). Table 4.2 shows the supplementary data for Fig. 4.8 (e.g., sample size, mean change in area, standard deviation, power regression equation and corresponding correlation coefficient).

Overall, the annual growth of thalli is similar regardless of the growth period. The annual areal growth of small thalli $\left(<30 \mathrm{~mm}^{2}\right)$ is highly variable (12 to $105 \%$ change in area per year), but this variability drops to $<10 \%$ once thallus area exceeds $30 \mathrm{~mm}^{2}$ (Fig. 4.8B). An outlier exists $\left(177 \mathrm{~mm}^{2}\right)$ which experiences a higher than average percentage change in area. This thallus has a wider prothallus than other thalli of comparable size. The relationship between the annual diametric change and thallus diameter is shown in Fig. 4.9. The growth trend is best shown using a $3^{\text {rd }}$ order polynomial equation for each of the three growth intervals. 
A

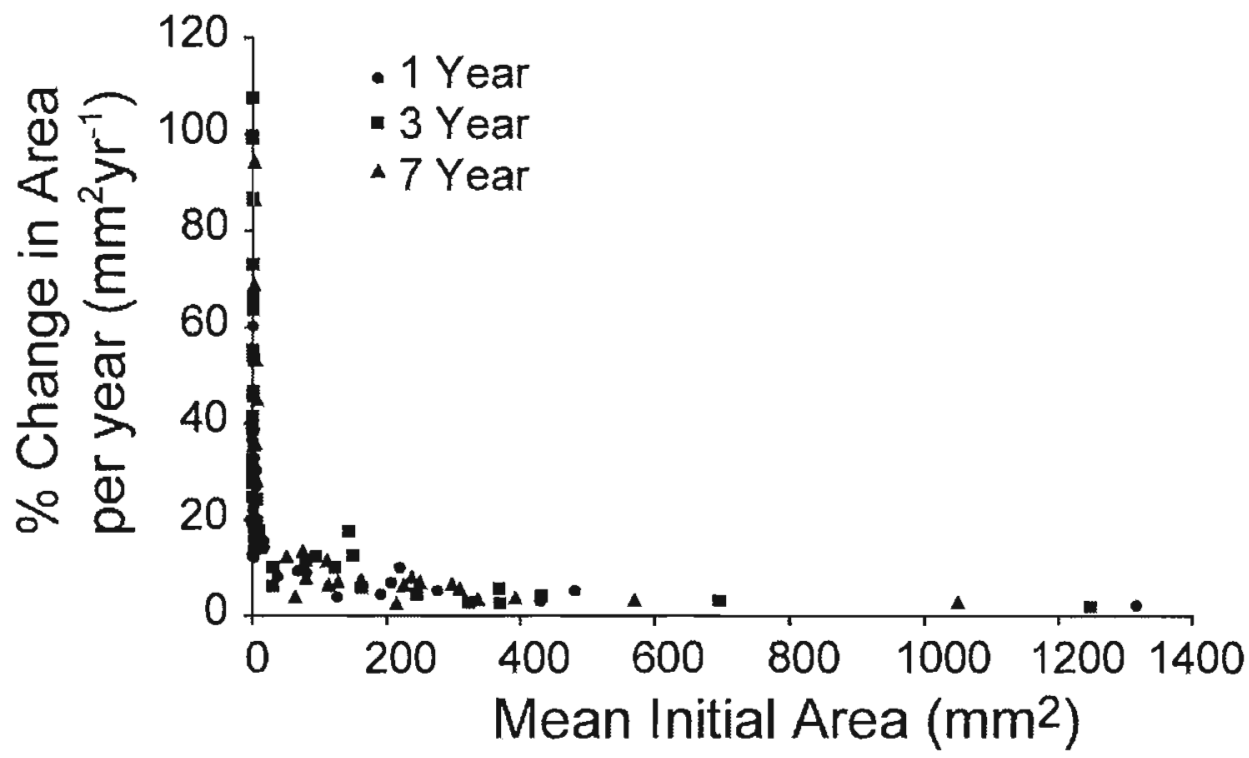

B

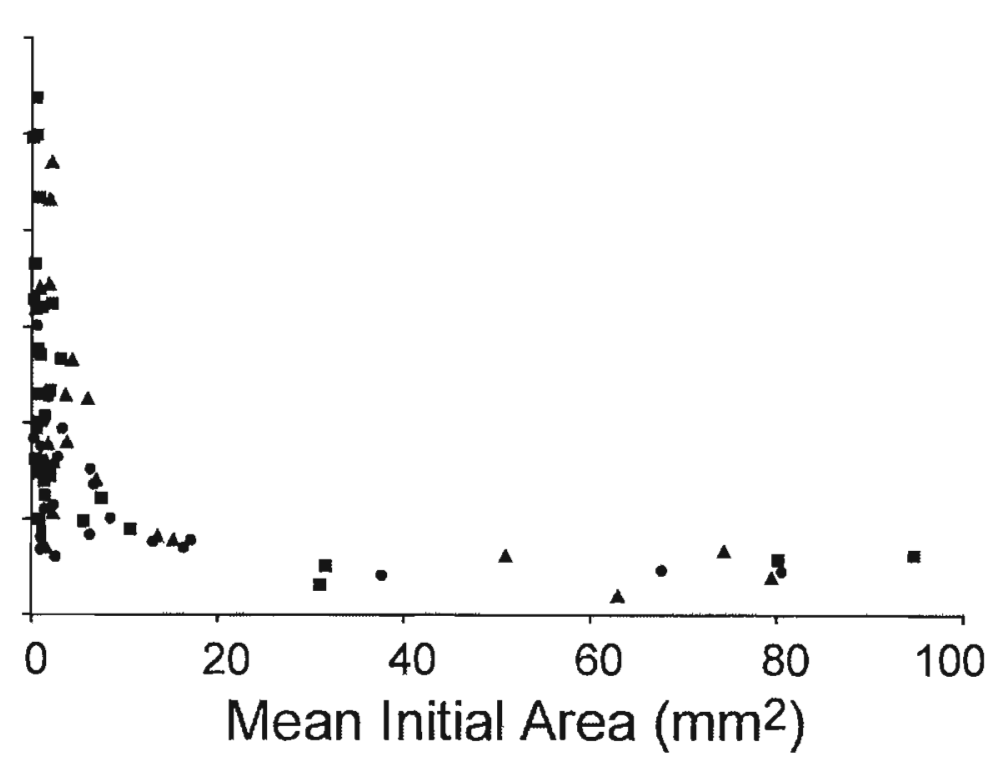

Figure 4.8: Scatterplot showing mean initial area $\left(\mathrm{mm}^{2}\right)$ against mean percent change in area for all three growth intervals. Mean initial area represents the mean measurement of thallus area at the start of the growth interval. Areal change was standardized to an annual rate to facilitate comparison. (A) represents all thalli, (B) represents only small thalli $\left(<100 \mathrm{~mm}^{2}\right)$. (See companion Table 4.2) 

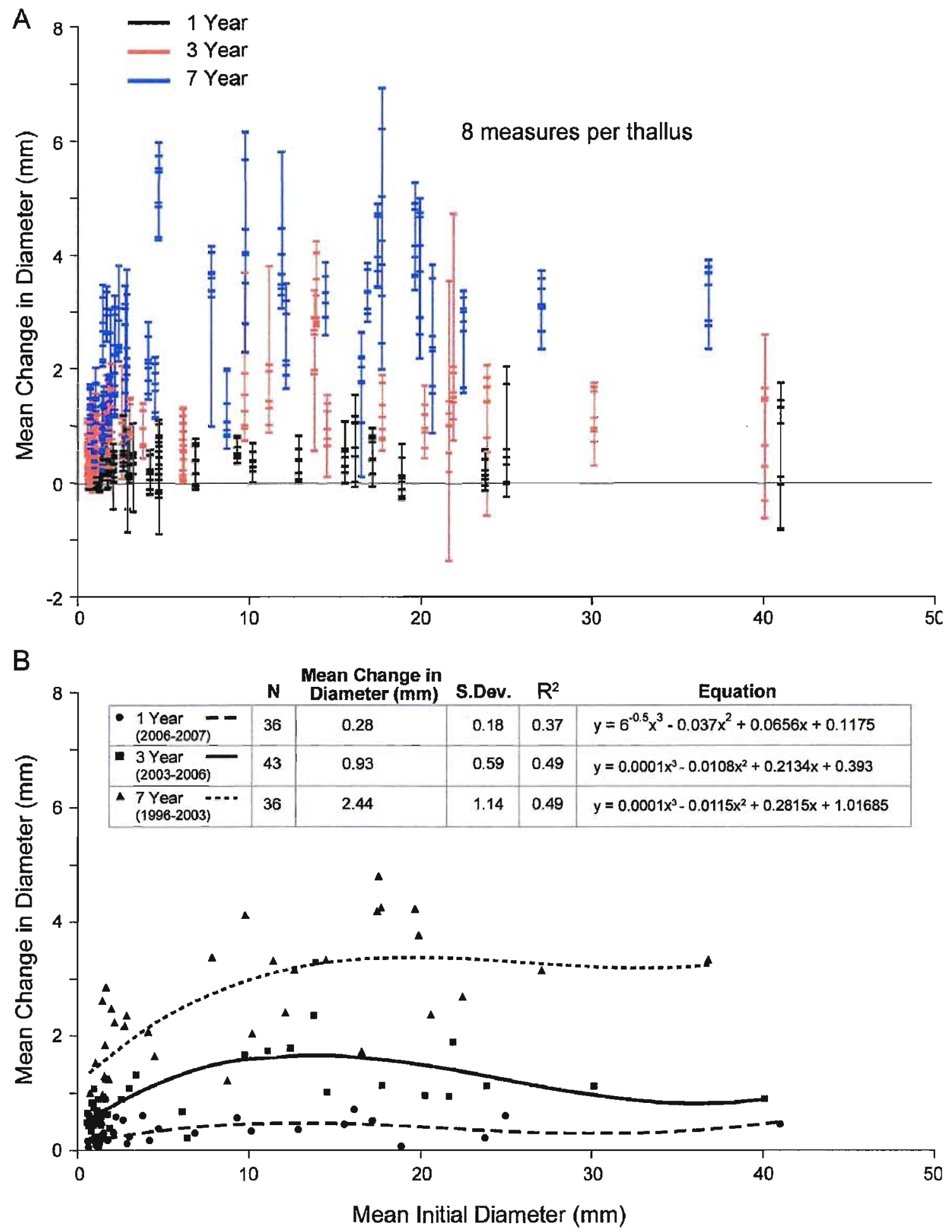

Figure 4.9: Scatterplots showing the annual change in diameter in relation to mean initial thallus diameter for all three intervals, 1 year, 3 year and 7 year. (A) Each bar represents the mean diameter for a single thallus, points within that bar represent the change in diameter $(\mathrm{mm})$ at 8 separate points around that thallus. (B) The mean change in diameter. 
Table 4.2: Details of percent change in area for Rhizocarpon geographicum thalli (companion table to Fig. 4.9). Represents data standardized to an annual rate.

\begin{tabular}{lccc}
\hline Growth Interval & $\begin{array}{c}\text { 1 Year } \\
(2006-2007)\end{array}$ & $\begin{array}{c}\text { 3 Year } \\
(2003-2006)\end{array}$ & $\begin{array}{c}\text { 7 Year } \\
(1996-2003)\end{array}$ \\
\hline Number of thalli (N) & 36 & 43 & 36 \\
\hline Mean Change in Area (\%) & 23.42 & 36.14 & 25.38 \\
Standard Deviation & 16.42 & 31.56 & 26.09 \\
\hline
\end{tabular}


Overall there is a high variability in diametric growth around the thallus (Fig. 4.9A). These results indicate that growth is not equal around the thallus margin, thus in these data, no single diameter well represents thallus growth. Indeed, over a one-year period (2006-2007) the majority of thalli (78\%) show both positive and negative changes in thallus diameter (Fig. 4.10). The data are expressed as the mean of eight measures. There is an overall net increase in mean thallus diameter over the one year period, 20062007 (Fig. 4.9B). In this case, diameter is a poor predictor of annual growth.

When the change in diameter data are expressed as the percent change in diameter all show a decrease in growth rate variability when thalli exceed $5 \mathrm{~mm}$ in diameter (Fig. 4.11). Reduced variance in diametric growth may simply mean that the diameters are growing at an even rate. This would help to keep thallus shape at what it was to start with (irregular thallus margins or not). The shape would be held constant if growth was steady and not highly variable on any diameter.

\subsubsection{Morphological changes}

The relationship between prothallus area and areola area is shown in Fig. 4.12. The data suggest that areola area and prothallus area maintain a fairly constant relationship throughout the life cycle of a lichen. This relationship is not apparent when prothallus width is expressed as a proportion of thallus diameter (Fig. 4.13). The width of the prothallus is highly variable around the entire thallus. There is a general decrease in overall prothallus width with increasing thallus size (Fig. 4.13). 


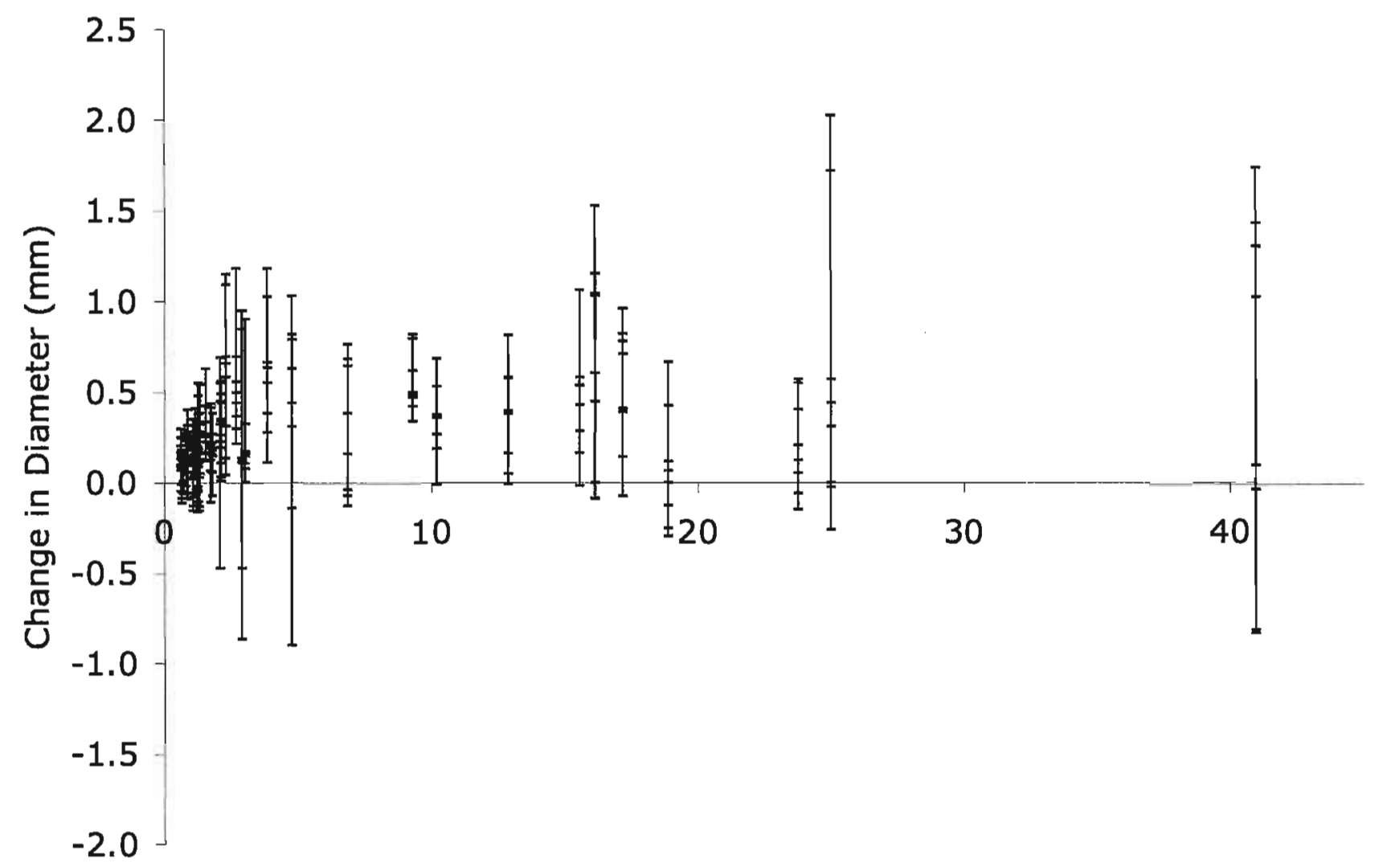

\section{Mean Initial Diameter in $2006(\mathrm{~mm})$}

Figure 4.10: Annual change in thallus diameter. $X$-axis shows the mean initial thallus diameter at the start of the year. Each bar represents the mean diameter for a single thallus. The points within each vertical bar represent the change in diameter at 8 locations around the thallus. The majority of thalli $(78 \%)$ show both positive and negative changes in diameter. 

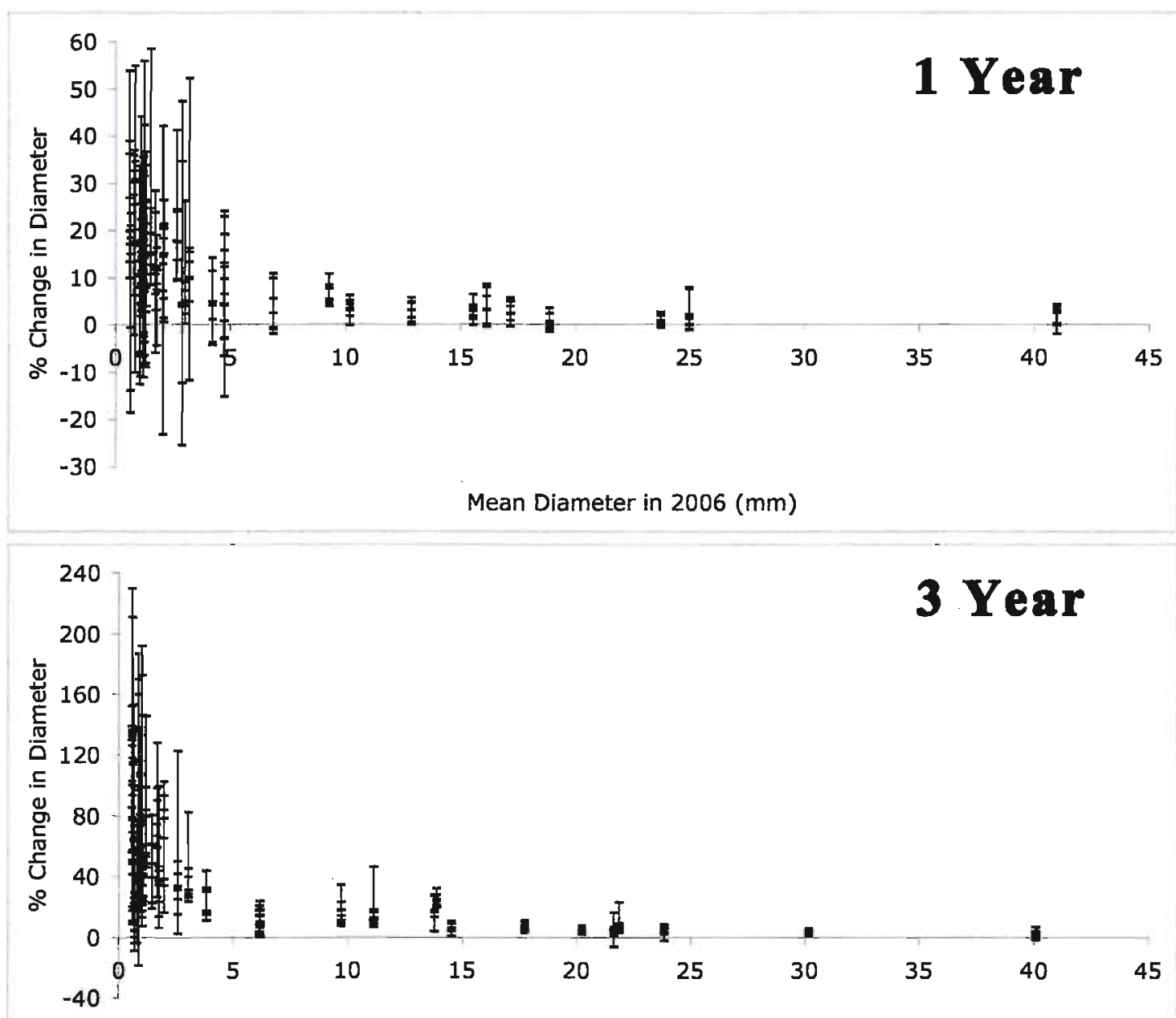

Mean Diameter in $2003(\mathrm{~mm})$

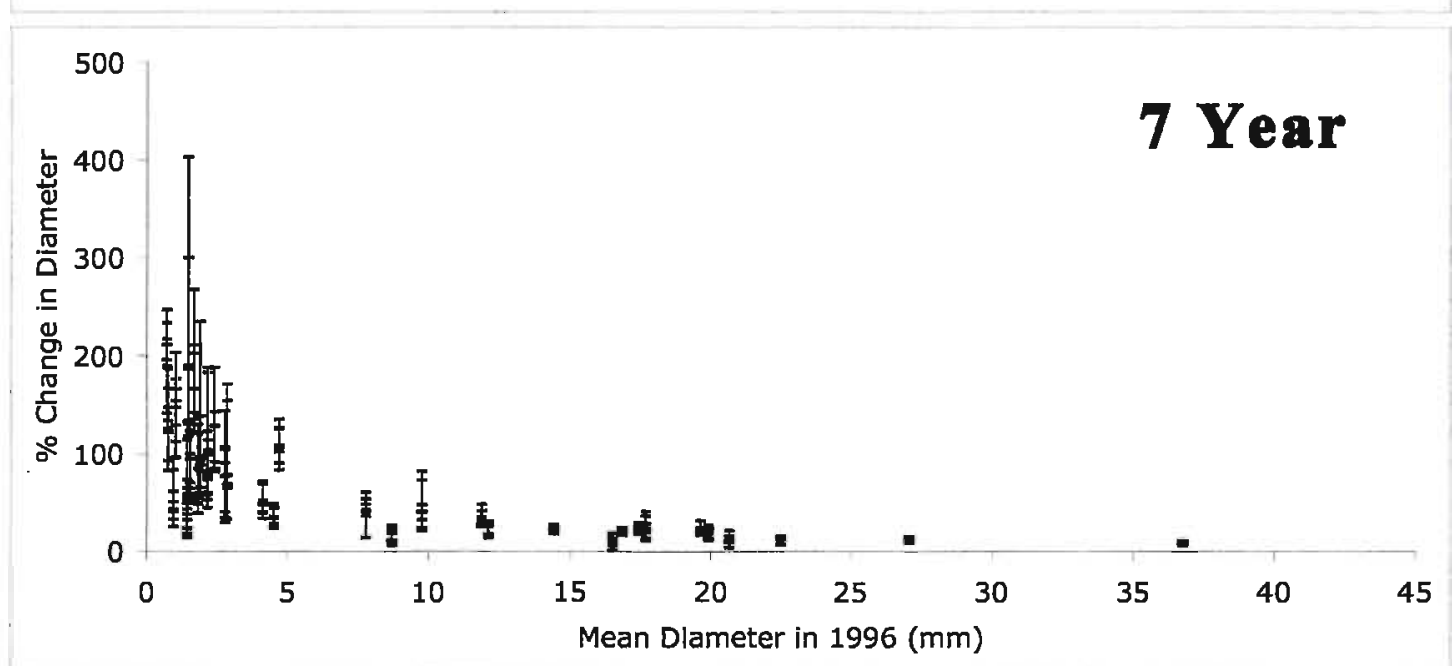

Figure 4.11: Percent change in thallus diameter for all three growth intervals, 1 year, 3 year and 7 year. Each bar represents the mean diameter for a single thallus. The points within each vertical bar represent the percent change in diameter at 8 locations around the thallus. In all growth intervals the percent change in diameter is highly variable in small thalli $(<5 \mathrm{~mm})$. As thallus size increases beyond $5 \mathrm{~mm}$ the percent change in diameter becomes more constant around the entire thallus. 


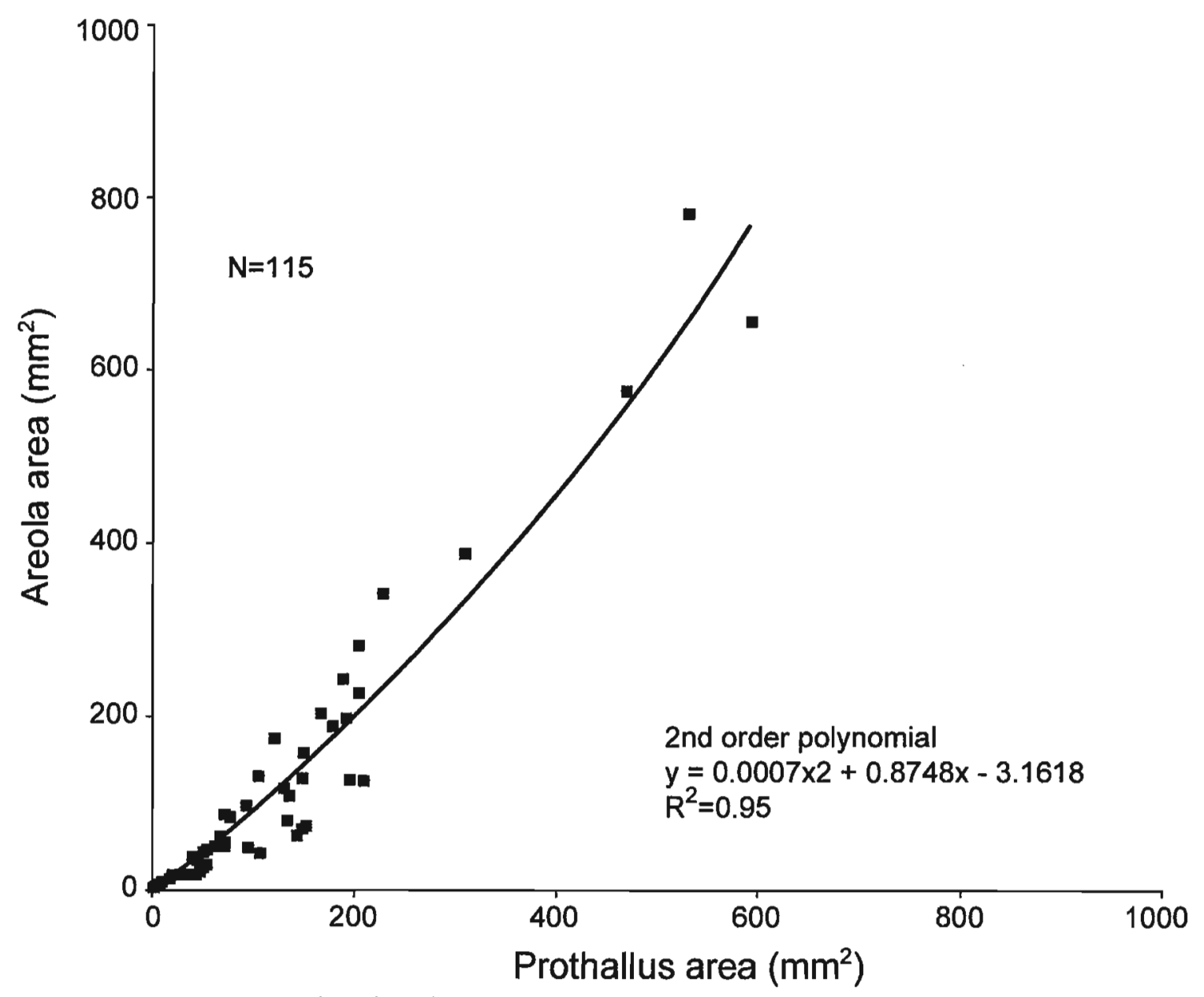

Figure 4.12: Scatterplot showing the association between mean areolae area and prothallus area $\left(\mathrm{mm}^{2}\right)$. 


\section{A - 1 Year}
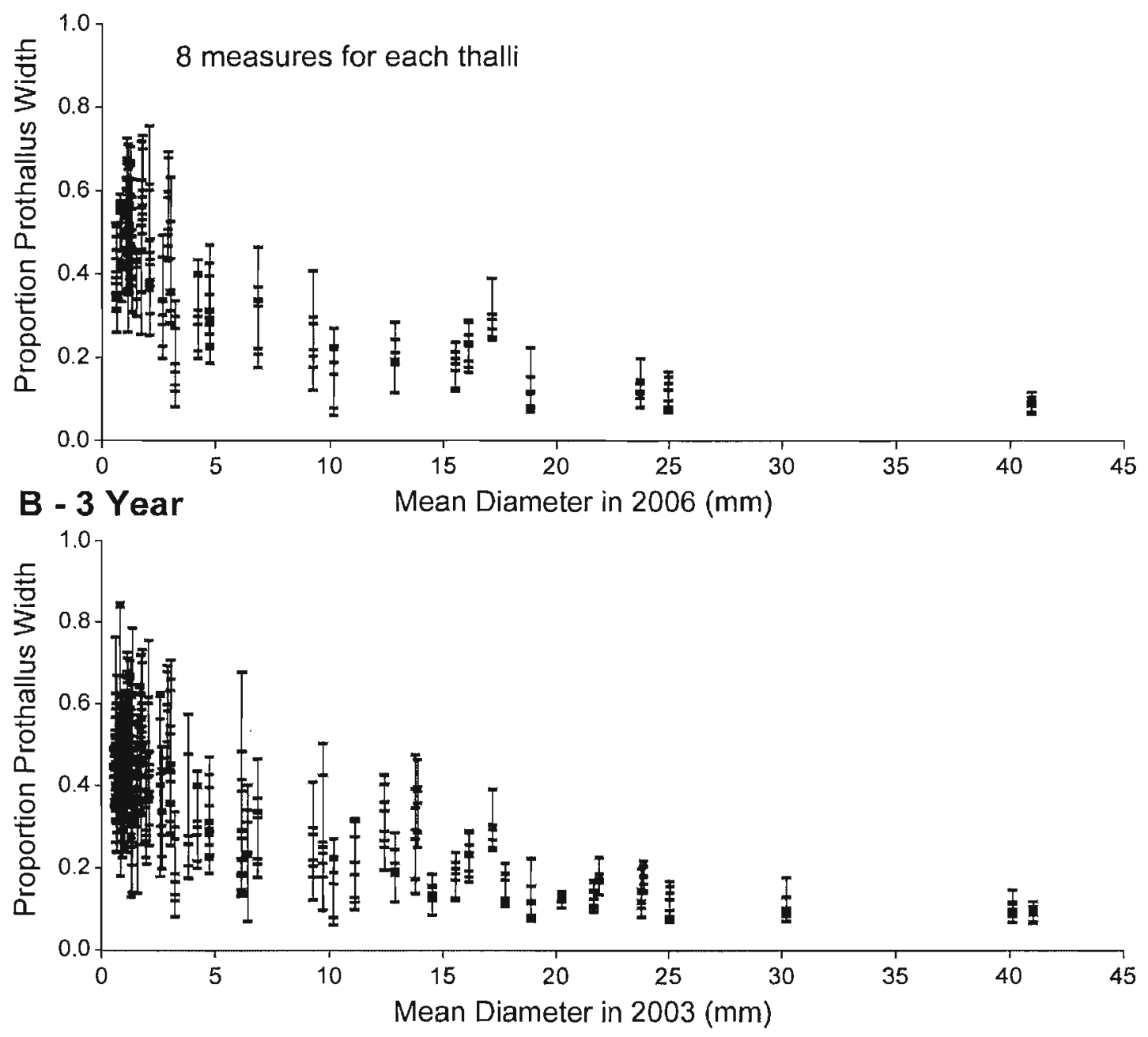

Figure 4.13: Change in the proportion of prothallus width. Prothallus width is shown here as the ratio of prothallus width to thallus diameter. Prothallus width was measured at 8 locations around each thallus. The ratio between prothallus width and thallus diameter is highly variable in small thalli and decreases as thallus size increases. 


\section{Discussion}

\subsection{Photoshop as an investigative tool}

One of the main aims of this study was to explore the use of Adobe Photoshop CS3 Extended software as a tool that could be used to systematically sample and generate accurate data about the growth and development of $R$. geographicum thalli. This thesis developed, tested and critically used photogrammetry to quantitatively describe growth and morphological changes in Rhizocarpon thalli. It is the first known attempt to use repeated digital photography to systematically sample and generate accurate and precise measurements of change in areola area, thallus perimeter, thallus diameter and prothallus width in yellow Rhizocarpons. This work shows how measurement precision and reproducibility can be assessed between operators and with images of different quality (see Appendix V). In this way, the thesis has contributed a methodology that others can use or emulate and has produced an accurate and precise data set that provides unique insight into the nature of growth and morphological changes in $R$. geographicum thalli.

The operations described in this thesis required an enormous amount of time. Each image had to be enhanced (e.g., white balanced, contrast, colour adjustment) so that the operator could clearly distinguish areolae and the thallus-rock transition. Image enhancement, proper alignment and precise scaling against calibrated reference markers are tedious processes that require considerable skill and patience. Valuable information can be lost if the operator cannot properly perform any of these steps.

Image editing programs like Adobe Photoshop use raster based images, which makes them resolution-dependent. When enlarged, the images "pixelate" and in most cases they cannot be used if enlargement exceeds $300 \%$. Accordingly, only medium to 
high quality images were used in this work and the study attempted to assess the relative impact of "pixelation" on measurement precision. This too was a novel investigation as it used 16 thalli of various sizes and image qualities to quantify the link between image quality and areola area, total area and perimeter. The findings showed that there is a clear link between image quality and measurement precision (see Fig. $4.4-4.6$ ). The quantitative differences between measurements done using high and low quality images were most apparent in measures of small thalli $\left(<5 \mathrm{~mm}^{2}\right)$. The need for high image resolution and good image quality is essential if high reproducibility is to be maintained in the measurement of tiny thalli. When image quality was low, areola area was consistently underestimated. To account for anomalous data, repeated measurements were taken for each thallus (e.g., 2 total thallus area measurements and 8 total areolae area measurements were taken per thallus).

Since image quality is so important, care was taken to select and prepare each image prior to analysis. In each case, images had to be clear, sharp and of sufficient contrast to clearly show the key lichen characteristics and boundaries. Since light, focus and the character of the object are different in each case, each image received individual attention and many subjective adjustments were made so as to ensure that I could clearly distinguish between thallus-rock boundaries and prothallus-areola boundaries.

In film based photography the sequence of procedures described in this thesis would be roughly analogous to a customized development of negatives that would occur prior to making a photographic print. In digital photography, the manipulation of raw files conserves image quality and is the preferred way to make post exposure adjustments. 
This thesis also involved quite a bit of undocumented trial and error experimentation. White balance adjustment and standardization of image colour temperature was one of the areas that received extra attention. The unrealized hope was that the software could be "trained" to recognize and measure colours that were associated with key morphological features. Accordingly, all of the Canon Camera Raw files were manually white balanced to $5800^{\circ} \mathrm{K}$ (Daylight, $5500^{\circ} \mathrm{K}$ and Cloudy, $6500^{\circ} \mathrm{K}$ ). This ensured that the digital files were of similar colour character as the older film-based images, which were exposed on overcast days. It also helped the operator distinguish between morphological features such as the areolae that are most readily distinguished by their bright yellow colouration.

Contrast and sharpness were also recognized as key factors that could influence measurement resolution. Sharpness was of particular importance in the areola measurements while proper contrast was needed to allow the operator to correctly delimit the thallus-rock margin. In most cases, the images chosen and used in this work were properly exposed and were of such high quality that image sharpness and contrast were rarely adjusted. Where adjustments were made, areola boundaries often became a very distinct yellow that sharply defined each areola. Overall, it is concluded that the image resolution and quality provided by consumer grade camera systems is more than adequate to allow an operator to detect and measure miniscule changes in lichen thalli. When high quality images are used, the potential sources of error are greatly reduced and primarily relate to the skill and attention to detail shown by the operator.

Proper scaling and removal or reduction of distortion are also key elements that received a great deal of attention in this work. Several key steps were followed to 
systematically address and minimize distortion and scaling errors. Image scale was calibrated based on reference points that surrounded each thallus. These reference points were visible in all image sets. Thus, each image in the sequence was exactly registered with all others and linear distances between reference points were measured in the field with an accuracy of $\pm 0.025 \mathrm{~mm}$ (see McCarthy, 2003). Unlike other studies, each lichen thallus in this data set had at least four fixed control points around it. When this net of fixed distances was correctly adjusted, distortion was corrected around the entire thallus. Lichens outside of this "control area" were not used as distortion at those locations could not be adequately controlled. Careful use of the "warp" command allowed the "rubber sheeting" and perspective control of images. Since image quality deteriorates with repeated use of the "warp" tool, the high accuracy and reproducibility of the data attest to the amount of care that was taken in making the tedious adjustments that were an essential step in the measurement process. Proper use of the "warp" command requires skill and enormous patience. Even when images are properly exposed, it sometimes takes several days of manipulation to properly adjust perspective and scale before an image can be precisely aligned and measured.

Once the net of fixed points was properly scaled, the mathematical difference between the perimeter of the "field" and "image" polygons was determined. In each case the mathematical difference was $\leq 2 \%$. This establishes that each image base in a photo series was closely scaled and had the potential to provide accurate planar and linear measurement data. The use of mathematics to define the accuracy of the fixed point polygons in the field and in the image may be a "first" in any lichenological application. Other users superimpose image pairs (e.g., Armstrong and Bradwell, 2007; Bradwell, 
2010), but have not used a net of fixed points that completely surround the thallus. The work documented in this thesis gives a quantitative measure of accuracy. This is an important methodological improvement that is much preferred to approaches that can at best make nominal and unsubstantiated claims of measurement precision and accuracy (e.g., Armstrong and Bradwell, 2007; Bradwell, 2010).

While some of the tools and approaches used in this thesis have been used in other lichenological studies, the way that the tools were used clearly sets this study apart from others. For example, the pen tool was used to manually trace thallus outlines. In this work, the "pen" was set to a width of 1 pixel $(\leq 0.01 \mathrm{~mm})$. Since it was used to mark thallus boundaries under $300 \%$ magnification, this sharp pen made it possible to closely mark even the slightest of changes at the thallus margin. Use of the "magic wand" tool also allowed groups or individual pixels to be selected or deselected. Its use was tested and critically used to collect highly reproducible measures of areola area that could not readily be obtained in any other way.

The precision of total areola area, total thallus area and total perimeter measurements with size was determined with a subset of 27 lichens of various sizes and qualities. Total thallus area precision exceeded $95 \%(p>0.05)$ in each of the 27 thalli and was almost perfect ( $99 \%$ precision) in larger thalli. Perimeter was also a highly precise measurement with mean precision $>88 \%$ in all cases. Areola area was also highly precise with mean precision exceeding $95 \%$ in each case $(p=0.05)$. Thus, with careful use of the methods demonstrated here, thalli as small as $1.0 \mathrm{~mm}$ in diameter $\left(0.30 \mathrm{~mm}^{2}\right)$ can be reliably measured.

Measurement and analysis of the prothallus poses an interesting methodological 
challenge. Invariably, the measurements are a product of the approach that is used and some approaches provide more meaningful data than others. For example, when a measurement is taken from the edge of a thallus margin to the first areola it is not uncommon to find tiny, "new" areolae formed as isolated islands atop the peripheral prothallus ring. Measurement to these new areolae would provide a different measure than would the measurement of the distance from the thallus edge to the first "mature" areola as was done in this study. Measures of circularity were also attempted using the "magic wand" tool and a preset measurement function for circularity with Adobe Photoshop CS3 Extended. This software package can be used to generate a measure of the circularity of an object. When this is done, a value of 1.0 would be reported for a perfect circle. Unfortunately, repeated attempts to use this function with a few thalli showed that the co-ordinates reported for the centre of mass of an object were not close to the visual centre of mass. Also testing with some basic shapes (e.g., triangle, square, circle etc.) as well as some slight variations of a circle (e.g., oval) found that the circularity did not match the expected results. This experience suggests that the software cannot be used to accurately locate the centre mass of an object or generate reliable measures of thallus circularity.

\subsection{Quantitative findings on the growth of Rhizocarpon geographicum}

This thesis sought to develop and carefully use a method that would generate quantitative measures of $R$. geographicum size, growth and morphological characteristics. A variety of indices were used to describe growth (e.g., areal change, diametric growth, change in perimeter, ratio of prothallus width to diameter, areola change, etc.) over 1, 3 and 7 year intervals. Unlike most studies, this work examined and 
produced accurate quantitative measures of very small thalli $(1.0-25 \mathrm{~mm} / 0.30-600$ $\mathrm{mm}^{2}$ ). As such it provides a unique glimpse of the early growth and development of R. geographicum thalli. While most researchers are focused on large thalli $(>50 \mathrm{~mm})$ in hopes of providing insight into lichen longevity or lichenometric utility, young, small thalli should be of equal if not more importance as they show real time changes that may be closely linked to local environmental conditions. The potential of using small thalli as environmental indicators has not yet been explored. The methods detailed in this thesis may enable researchers to better investigate this possibility.

Data compiled in this study suggest that the radial growth of $R$. geographicum thalli is not uniform along the entire thallus margin. Qualitative observations of small and large thalli revealed that the shape of small thalli is irregular with many finger-like, branching lobes, while in larger thalli the shape is more uniformly circular. This is most clearly demonstrated by the diametric growth rate data where in a single year, $78 \%$ of thalli showed both advances (positive growth) and retreat (negative growth) at various locations along their margins. However, when growth is expressed as mean diametric growth, as many previous researchers have done, a weak positive trend was found. Unfortunately, the use of averages can be misleading as it gives an unstable estimate of over-all growth at the perimeter over a given period. Thus, this is one reason why diameter should be viewed as an inappropriate index of growth in irregularly shaped lichen species.

While many studies have used measures of radial and diametric expansion as measures of thallus growth, mean diametric growth rate data provide only some answers as to how Rhizocarpon communities grow and slowly develop. The data presented for the 
total change in thallus area was found to follow the general growth trend found in most previous studies that use measures of radial or diametric growth (e.g., Proctor, 1983, Armstrong, 1983; Armstrong, 2005b). For example, rapid growth in small thalli was followed by a decline in growth to a more constant level in larger thalli. While diametric studies can provide insight into the general growth pattern of a species, it cannot resolve minor changes occurring over the entire thallus.

This study provides the best predictor of thallus growth to date. Previous studies have been unable to achieve correlation coefficients greater than 0.60 using measures of radial and diametric growth. For example, Bradwell and Armstrong (2007) used a $3^{\text {rd }}$ order polynomial and recieved a very weak correlation. These low correlations are primarily due to the fact that diametric growth indices do not well represent changes in total thallus size.

While the change in total thallus area is a good measure of thallus growth it does not describe how growth changes in proportion to the size of a thallus. This is best done using a variable such as percentage change in total thallus area. This study also serves to illustrate how the distribution of thallus sizes in a sample set can make it difficult for a worker to estimate long term growth trends. Most of the thalli in this study were small and should not be used to estimate growth and developmental trends in larger thalli. The percent change in area revealed two distinct trends in small thalli (size range $0.30-1137$ $\mathrm{mm}^{2}$ ). In thalli less than $30 \mathrm{~mm}^{2}$ (approximately $5 \mathrm{~mm}$ in diameter) growth is highly erratic (change in area 12-115 percent per year), although as thalli exceed $30 \mathrm{~mm}^{2}$ growth approaches a more constant rate $(<10 \%$ change in area per year). Few studies include thalli less than $5 \mathrm{~mm}$ in diameter. For example, both Armstrong and Bradwell (2007) and 
Proctor (1983) studied only two thalli less than $5 \mathrm{~mm}$ diameter, whereas Armstrong (2005) only studied three small thalli. Previous studies (e.g., Bradwell, 2010; Armstrong, 1983; Armstrong, 2005b; Proctor, 1983) have claimed the occurrence of three growth phases based on the change in diameter. All claim there is at first a phase of accelerating growth in small thalli (referred to as the "great growth" period), although as thalli reach $10-15 \mathrm{~mm}$ in diameter this growth levels off followed by a declining growth phase in larger thalli $(\sim 50 \mathrm{~mm})$. The data presented in this thesis provide insight into the early development of $R$. geographicum thalli that is broadly consistent with both Beschel's "great growth" hypothesis and the anecdotal reports and the stages/phases model proposed by Asta and Letrouit-Galinou (1995). The "great growth" period isn't shorter; it just isn't as simple and smooth as is suggested by the constant and rapid rise seen in lichenometric growth "curves" (see Fig. 2.2). The data presented in this thesis suggest that development and growth in small thalli is a function of thallus size, age or developmental status. Once thallus area approaches $30 \mathrm{~mm}^{2}$, growth becomes steady and slow and the thallus begins to lose the jagged, angular outline that it had when it was small. It is unclear if this signals a physiological change such as the maturation of the areola or a reduced investment in the growth of jagged hyphal extensions that give the tiniest thalli their spiny shape. The observation that early growth in young Rhizocarpon thalli has two stages does, however, show that Beschel's "great growth" period may be more complex than he believed. Further evidence is needed using this technique to define this growth phase in different geographic and climatic regions.

Several factors may account for the reduced growth in larger thalli. Firstly, the crustose species studied have distinct areolae and a marginal prothallus. Many have 
hypothesized that the timing and development of these morphological features may affect growth rate (e.g., Clayden, 1998; Proctor, 1983). The algae, contained within the areolae, supply the fungi with carbohydrates. A greater abundance of areolae may increase the carbohydrates available for marginal expansion. However, in this study the relationship between areola area and prothallus area was found to be proportional throughout the life of a lichen, with areola area being always slightly greater than that of prothallus area. The proportion of areolae in small thalli is slightly greater than that of large thalli. While several studies have sought to determine the relationship between diametric growth and prothalus width (e.g., Armstrong and Bradwell, 2007) none has determined the actual relationship between areolae area and prothallus area. Some researchers have also proposed that a reduction in diametrical growth is due to changes in the peripheral growth zone. Benedict (1988) hypothesized that a wider prothallus width results in increased growth due to the increased supply of carbon to the fungi contained in this peripheral zone. However, findings from the current study suggest that this relationship is not apparent when prothallus width is expressed as a proportion of thallus diameter. The width of the prothallus is highly variable around the entire thallus, although there is a general decrease in overall prothallus width with increasing thallus size. Armstrong (1983) was the first to study whether prothallus width varies with size. He found that prothallus width was not correlated with diameter. A later study by Armstrong and Bradwell (2001) found that radial growth rate was positively correlated with prothallus width.

The timing and development of reproductive structures can affect growth rate. In the case of Rhizocarpon superficiale, this decelerating growth phase was hypothesized to 
be due to a diversion of the photosynthates from radial growth to spore-bearing apothecia (Benedict, 2009). Upon further investigation he found that apothecia first appeared when radial growth rates began to decline, at approximately $5.0-7.5 \mathrm{~mm}$ diameter. In this study, growth rates decreased once thalli were $\geq 5 \mathrm{~mm}$ diameter. Perhaps closer inspection of thalli used in this study would show a link between the onset of apothecia development and growth rate decline.

Growth rate data from the one, three and seven year intervals in this study were standardized to an annual rate so as to facilitate comparison. This approach showed that the growth rates recorded in each interval were virtually identical. This observation is important for many reasons. It suggests that growth rates are constant and predictable. It suggests that the growth trend can be determined through the use of short-term observations and that growth need not be measured every year. It also suggests that some short term climatic changes (e.g., the abnormally warm and dry summers such as occurred during this interval) are not reflected in the annual growth rates of these R. geographicum thalli. This observation does not lend support to those who suggest that climatic deterioration during the Little Ice Age may have had a measurable effect on the growth of Rhizocarpon thalli (e.g., Trenbirth \& Matthews, 2010). 


\section{Conclusions}

\subsection{Photoshop as an investigative tool}

Objective 1: Develop and test a new methodology for tracking visible or morphological changes occurring in R. geographicum thalli.

This thesis has provided lichenology with a new investigative technique that will facilitate the study of tiny lichen thalli. It has demonstrated that when carefully applied, this digital approach can generate accurate and precise measures of change in the tiniest of lichen thalli. As such it represents a marked improvement over the use of thallus tracings and calipers or even the use of film based photogrammetry. Unlike some other approaches, digital photogrammetry can reduce errors associated with distortion, accommodates the use of standardized sampling grids and provides highly reproducible measures of thallus area. The technique is novel as it produces a photographic record that shows exactly where each measure was taken. These records can be easily shared with other workers and serve as an archival record against which future changes can be revealed. Workers should now use this technique to generate accurate and reproducible data sets.

\subsection{Quantitative findings on the growth of Rhizocarpon geographicum}

Objective 2: Critically apply these methods to develop quantitative measures of thallus size, growth and morphological characteristics.

This study provided quantitative insight into the early growth and development of 
R. geographicum thalli. Unlike other studies, the sample sizes were large, several growth intervals were directly compared and methodological details and measurement precisions data were fully reported (see Table 2.2).

This study provided novel insight into the areal growth of Rhizocarpon thalli. Thallus area proved to be the best predictor of thallus growth. Two growth phases were defined. Small thalli (area $<30 \mathrm{~mm}^{2}$ ) showed rapid and highly variable growth (12 to $105 \%$ areal change per year). Larger thalli $\left(>30 \mathrm{~mm}^{2}\right)$ had slow and less variable growth $(<10 \%$ areal change per year). Measurement of diameter ( 8 per thallus) showed that change in diameter was highly variable within and between thalli, indicating that change in thallus diameter is a weak index of overall thallus growth. The ratio of areola area to prothallus area was roughly 1:1 in all thalli and the proportion of prothallus width to thallus area was highly variable and decreased with increasing thallus size. 


\section{Literature cited}

Aplin, P.S. and Hill, D.J. (1979) Growth analysis of circular lichen thalli. Journal of Theoretical Biology, 78: 347-363.

Armstrong, R.A. (1974a) The descriptive ecology of saxicolous lichens in an area of south Merionethshire, Wales. Journal of Ecology, 62(1): 33-45.

Armstrong, R.A. (1974b) Growth phases in the life of a lichen thallus. New Phytologist, 73(5): 913-918.

Armstrong, R.A. (1983) Growth curve of the lichen Rhizocarpon geographicum. New Phytologist, 94 (4): 619-622.

Armstrong, R. A. (1996) Experimental studies of prothallus growth in the lichen Rhizocapron geographicum. New Phytologist, 132 (1): 123-126.

Armstrong, R.A. (2002) The effect or rock surface aspect on growth, size structure and competition in the lichen Rhizocarpon geographicum. Environmental and Experimental Botany, 48: 187-194.

Armstrong, R.A. (2005a) Growth rate measurements of Rhizocarpon geographicum in the Snoqualmie Pass, Washington. USA. Arctic, Antarctic and Alpine Research, 37: 411-415.

Armstrong, R.A. (2005b) Growth curves of four crustose lichens. Symbiosis, 38: 47-57.

Armstrong, R.A. and Bradwell, T. (2001) Variation in prothallus width and the growth of the lichen Rhizocarpon geographicum (L.) DC. Symbiosis, 30(4): 317-328.

Armstrong, R.A. and Smith, S.N. (1987) Development and growth of the lichen Rhizocarpon geographicum. Symbiosis, 3: 287-300.

Asta, J. and Letrouit-Galinou, M-A. (1995) Observations on the early growth of Rhizocarpon geographicum. Herzogia, 11: 239-252.

Benedict, J. B. (1988) Techniques in lichenometry: Identifying the yellow Rhizocarpons. Arctic and Alpine Research, 20 (3): 285-291.

Benedict, J.B. (1990) Experiments on lichen growth. I. Seasonal patterns and environmental controls. Arctic and Alpine Research, 22(3): 244-254.

Benedict, J.B. (1991) Experiments on lichen growth II: Effects of a seasonal snow cover. Arctic and Alpine Research, 23(2): 189-199. 
Benedict, J. B. (2009) A review of lichenometric dating and its applications to archaeology. American Antiquity, 74: 143-172.

Beschel, R.E. (1961) Dating rock surfaces by lichen growth and its application to glaciology and physiography (lichenometry). Geology of the Arctic, 2: 1044-1062.

Bradwell, T. \& Armstrong, R.A. (2007) Growth rates of Rhizocarpon geographicum lichens: a review with new data from Iceland. Journal of Quaternary Science, 22: 311-320.

Bradwell, T. (2010) Studies on the growth of Rhizocarpon geographicum in NW Scotland, and some implications for lichenometry. Geogr. Ann., 92A(1): 41-52.

Brodo, I.M., Sharnoff, S.D. and Sharnoff, S. (2001) Lichens of North America. - Yale University Press, New Haven, CT. 795 pgs.

Chapin, F.S., Walker, L.R., Fastie, C.L. and Sharman, L.C. (1994) Mechanisms of primary succession following deglaciation at Glacier Bay, Alaska. Ecol. Monogr., 64: $149-175$.

Clayden, S.R. (1997) Intraspecific incteractions and parasitism in an association of Rhizocaron lecanorinum and $R$. geographicum. Lichenologist, 29(6): 533-545.

Clayden, S.R. (1998) Thallus initiation and development in the lichen Rhizocarpon lecanorinum. New Phytologist, 139(4): 685-695.

Clayden, S.R., Pentacost, A. and Dawson, R.J. (2004) Growth of the lichen Rhizocarpon lecanorinum, with comments on Aplin-Hill and lichenometric curves. Symbiosis, 37: 379-393.

Dale, M.R.T. (1995) Spatial pattern in communities of crustose saxicolous lichens. Lichenologist, 27(6): 495-503.

Haworth, L.A., Calkin, P. E., and Ellis, J.M. (1986) Direct measurement of lichen growth in the Central Brooks Range. Alaska, USA, and its implications to lichenometric dating. Arctic and Alpine Research, 18: 289-296.

Hawksworth, D.L. and Chater, A.O. (1979) Dynamisn and equilibrium in a saxicolous lichen mosaic. Lichenologist, 11(1): 75-80.

Honegger, R. (1980) The ascus apex in lichenized fungi II. The Rhizocarpon-type. Lichenologist, 12(2): 157-172.

Honegger, R. (1993) Developmental biology of lichens. New Phytologist, 125(4): 659677. 
Hooker, T.N. and Brown, D.H. (1977) A photographic method for accurately measuring the growth of crustose and foliose saxicolous lichens. Lichenologist, 9: 65-75.

Ihlen, D. and Ekman, S. (2002) Outline of phylogeny and character evolution in Rhizocarpon (Rhizocarpaceae, lichenized Ascomycota) based on nuclear ITS and mitochondrial SSU ribosomal DNA sequences. Biological journal of the linnean society, 77(4): 535-546.

Innes, J.L. (1983) Use of aggregated Rhizocarpon "species" in lichenometry: an evaluation. Boreas, 12: 183-190.

Innes, J.L. (1985) A standard Rhizocarpon nomenclature for lichenometry. Boreas, 14, 83-85.

Innes, J.L. (1986) Dating exposed rock surfaces in the Arctic by lichenometry: The problem of thallus circularity and its effect on measurement errors. Arctic, 39(3): 253259.

John, E. and Dale, M.R.T. (1989) Niche relationships amongst Rhizocarpon species at Jonas rockslide, Alberta, Canada. Lichenologist, 21(4): 313-330.

Johnson, E.A., Fryer, G.I. and Heathcott, M.J. (1990) The influence of man and climate on frequency of fire in the interior wet belt forest, British Columbia. Journal of Ecology, 78: 403-412.

Jochimsen, M. (1973) Does the size of lichen thalli really constitute a valid measure for dating glacial deposits? Arctic and Alpine Research, 5(4): 417-424.

Locke, W.W., Andrews, J.T. and Webber, P.J. (1979) British Geomorphological Res. Group Bull, 26: 47pp.

Loso, M.G. and Doak, D.F. (2006) The biology behind lichenometric dating curves. Oecologia, 147: 223-229.

Luckman, B.H. and Osborn, G.D. (1979) Holocene glacier fluctuations in the middle Canadian Rocky Mountains. Quaternary Research, 11(1): 52-77.

McCarthy, D.P. (1999) A biological basis for lichenometry? Journal of Biogeography, 26: $379-386$.

McCarthy, D.P. (2003) Estimating lichenometric ages by direct and indirect measurement of radial growth: a case study of Rhizocarpon agg. at the Illecillewaet Glacier, British Columbia. Arctic, Antarctic, and Alpine Research, 35(2): 203-213. 
Naveau, P., Jomelli, V., Cooley, D., Delphine, G. and Rabatel, A. (2007) Modeling uncertainties in lichenometry studies. Arctic, Antarctic and Alpine Research, 39(2): 277-285.

Pentecost, A. (1979) Aspect and slope preferences in a saxicolous lichen community. Lichenologist, 11:81-83.

Poelt, J. (1988) Rhizocarpon Ram. em. Th. Fr. Sugen. Rhizocarpon in Europe. Arctic and Alpine Research, 20: 292-298.

Proctor, M.C.F. (1977) The growth curve of the crustose lichen Buellia canescens (Dicks.) De Not. New Phytologist, 79(3): 659-663.

Proctor, M.C.F. (1983) Sizes and growth-rates of thalli of the lichen Rhizocarpon geographicum on the marines of the glacier de Valsorey, Valais, Switzerland. Lichenologist, 15(3): 249-261.

Runemark, H. (1956a) Studies in Rhizocarpon, I. Taxonomy of the yellow species in Europe. Opera Botanica, 2(1): 1-152.

Runemark, H. (1956b) Studies in Rhizocarpon. II. Distribution and ecology of the yellow species in Europe. Opera Botanica, 2(2): 1-150.

Sancho, L.G. and Pintado, A. (2004) Evidence of high annual growth rate for lichens in the maritime Antarctic. Polar Biology, 27: 213-319.

Sancho, L. G., Green, T.G. and Pintado, A. (2007) "Slowest to fastest: Extreme range in lichen growth rates supports their use as an indicator of climate change in Antarctica." Flora - Morphology, Distribution, Functional Ecology of Plants, 202(8): 667-673.

Solomina, O., Calkin, P. (2003) Lichenometry as applied to moraines in Alaska, USA, and Kamchatka, Russia. Arctic, Antarctic, and Alpine Research, 35(2): 129-143.

Thomson, J. W. (1967) Notes on Rhizocarpon in the Arctic. Nova Hedwigia, 14: $421-$ 481.

Trenbirth, H.E. and Matthews, J.A. (2010) Lichen growth rates on glacier forelands in southern Norway: preliminary results from a 25 -year monitoring programme. Geogr. Ann., 92A(1): 19-39. 


\section{APPENDIX I: Equipment \& software}

Repeat photographs were obtained annually using film (1996 \&1999) and digital photography $(2002,2003,2006 \& 2007)$.

\section{Film based image}

Images were recorded on Kodacolor 100 ASA colour negative film. The film was scanned using a Minolta Dimage scan Dual II film scanner set to scan at $2700 \mathrm{dpi}(2688 \mathrm{x}$ 4032 pixels) to create a 16-bit Tagged Image File Format (TIFF) file (Dr. Daniel McCarthy, personal communication, Oct 15, 2007).

\section{Digital image}

Photographs were taken on overcast days to ensure even illumination. A flash was not used.

\section{Computer hardware}

The operations described here were done using a personal computer with Intel Core 2 Duo processor running at $2.2 \mathrm{GHz}$ with $2 \mathrm{~GB}$ of RAM, a Macintosh OS X (Version 10.5.2) operating system and an LCD display set at 1400 by 900 resolution. This combination is adequate to manipulate up to $300 \mathrm{MB}$ image files (e.g., a time series of 5 photographs and 25-30 layers).

Software

Adobe Photoshop CS3 Extended software was used to enhance, edit and measure digital images. 
Table 1: Details of camera and lens systems used and the resulting image resolution.

\begin{tabular}{|c|c|c|c|c|c|c|}
\hline \multirow{3}{*}{ Camera } & & 1996 & 1999 & 2002 & 2003 & $2006 \& 2007$ \\
\hline & Model & $\begin{array}{c}\text { Canon F1 } \\
\text { Single lens reflex }\end{array}$ & $\begin{array}{c}\text { Leica R8 } \\
\text { Single lens reflex }\end{array}$ & $\begin{array}{c}\text { Canon Powershot } \\
\text { GS }\end{array}$ & $\begin{array}{l}\text { Canon EOS-20D } \\
\text { Single lens reflex }\end{array}$ & $\begin{array}{l}\text { Canon EOS 450D } \\
\text { Rebel Xsi } \\
\text { Single lens reflex }\end{array}$ \\
\hline & Resolution & $2688 \times 4032$ pixels & $2688 \times 4032$ pixels & $2272 \times 1704$ pixels & & $4274 \times 2848$ pixels \\
\hline Lens & Model & Canon FL bellows & Leica Apo Macro & & Canon EF-S macro & Canon EF-S macro \\
\hline \multirow{4}{*}{ Image } & Focal length & $100 \mathrm{~mm}$ & $100 \mathrm{~mm}$ & & $60 \mathrm{~mm}$ & $60 \mathrm{~mm}$ \\
\hline & Aperture range & $\mathrm{F} / 4.0$ constant & $\mathrm{F} / 2.8$ constant & & $\mathrm{F} / 2.8$ constant & $\mathrm{F} / 2.8$ constant \\
\hline & Output & $\begin{array}{l}\text { Color negative } \\
\text { film }\end{array}$ & $\begin{array}{l}\text { Color negative } \\
\text { film }\end{array}$ & $\begin{array}{c}\text { Canon raw format } \\
\text { and were } \\
\text { automatic white } \\
\text { balance corrected }\end{array}$ & $\begin{array}{l}8 \text { MP images } \\
\text { recorded in Canon } \\
\text { RAW file format }\end{array}$ & $\begin{array}{l}12.2 \text { MP images } \\
\text { recorded in Canon } \\
\text { RAW file format }\end{array}$ \\
\hline & $\begin{array}{l}\text { Max Resolution } \\
\text { Min Resolution }\end{array}$ & $\begin{array}{l}3864 \times 2616 \text { pixels } \\
3712 \times 2520 \text { pixels }\end{array}$ & $1152 \times 864$ pixels & $\begin{array}{l}1036 \times 742 \text { pixels } \\
852 \times 725 \text { pixels }\end{array}$ & $\begin{array}{l}3504 \times 2336 \text { pixels } \\
1720 \times 1560 \text { pixels }\end{array}$ & $\begin{array}{l}3504 \times 2336 \text { pixels } \\
3504 \times 2332 \text { pixels }\end{array}$ \\
\hline
\end{tabular}




\section{APPENDIX II: Image quality comparison}

The following images illustrate the characteristics of the lichens encountered and chosen for this study.

\subsection{Visual comparison of the largest and smallest measurable lichens} study.

The following images will illustrate the smallest and largest thalli chosen for this
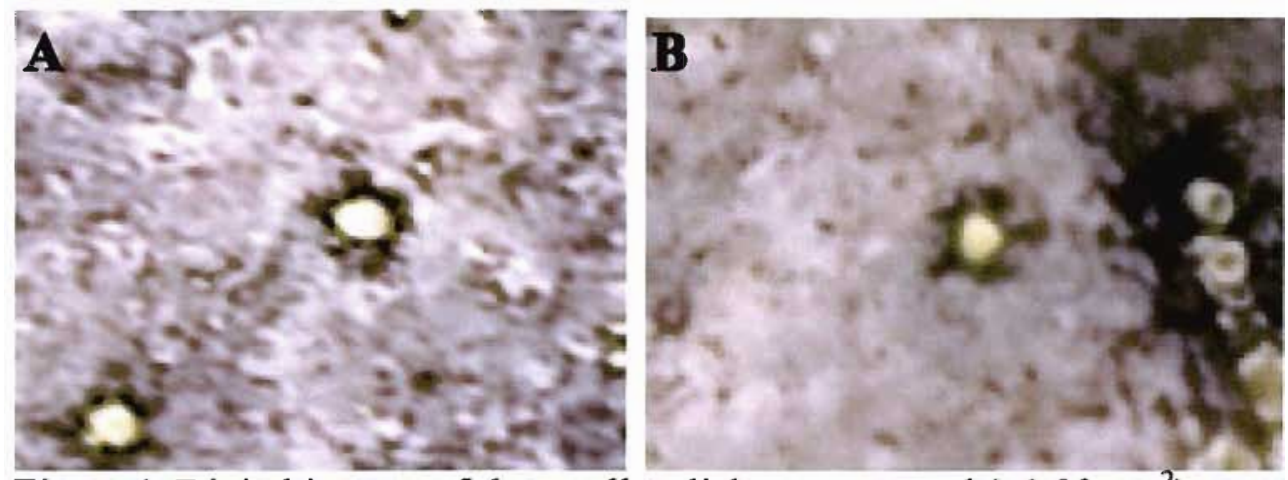

Figure 1: Digital images of the smallest lichens measured $\left(\sim 0.30 \mathrm{~mm}^{2}\right)$ at $300 \%$ magnification. Highest quality (A) image vs. lowest quality image (B) selected for analysis.
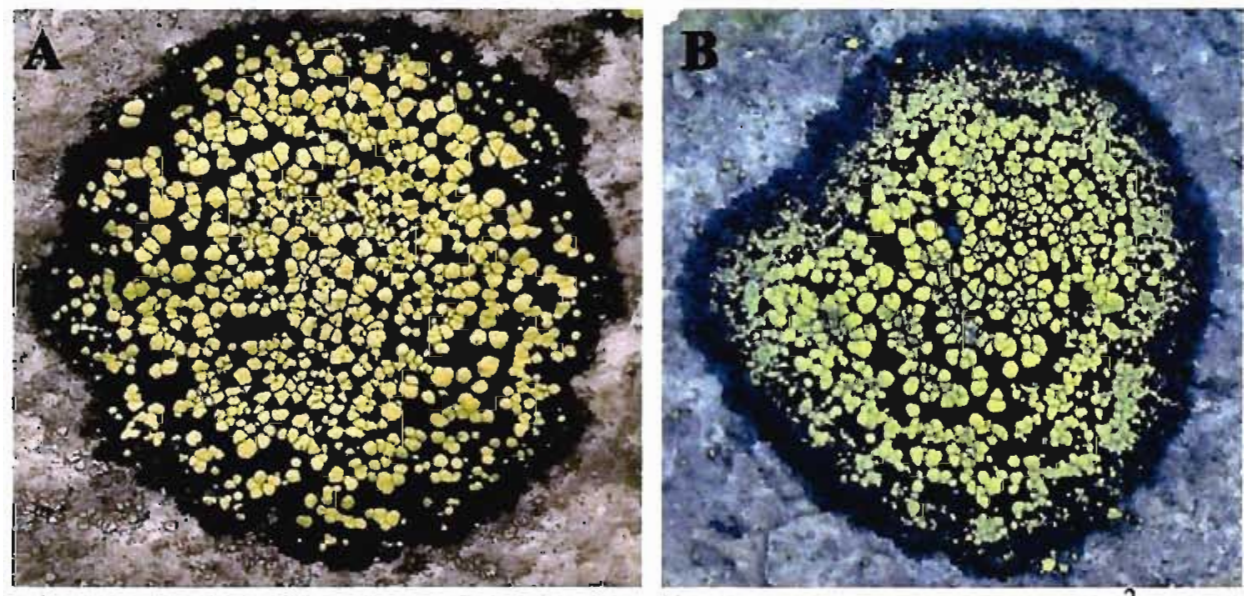

Figure 2: Digital images of the largest lichens measured $\left(\sim 400 \mathrm{~mm}^{2}\right)$ at $60 \%$ magnification. Highest quality image (A) vs. lowest quality image (B) selected for analysis. 

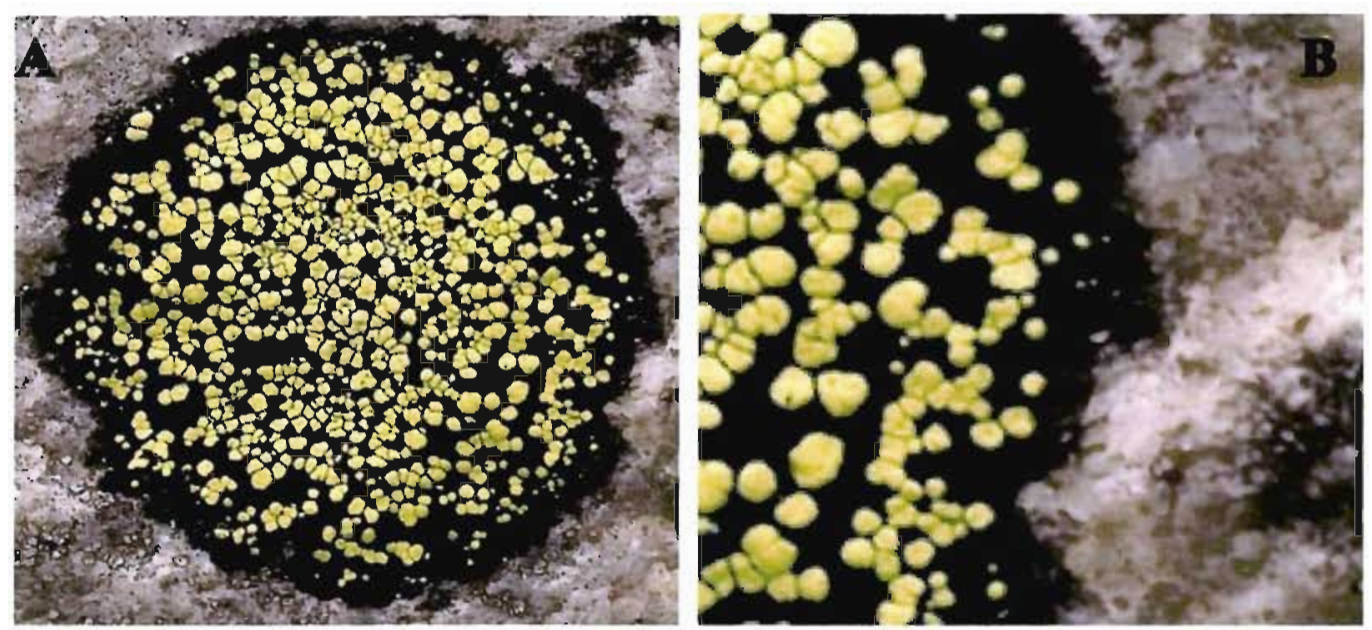

Figure 3: Digital image at $67 \%(\mathrm{~A})$ and $400 \%$ magnification (B).

\section{2: Visual comparison of composite thalli}

The following images illustrate the type of lichen interactions that are found at this site. These lichens illustrate cases in which lichens were rejected from analysis.
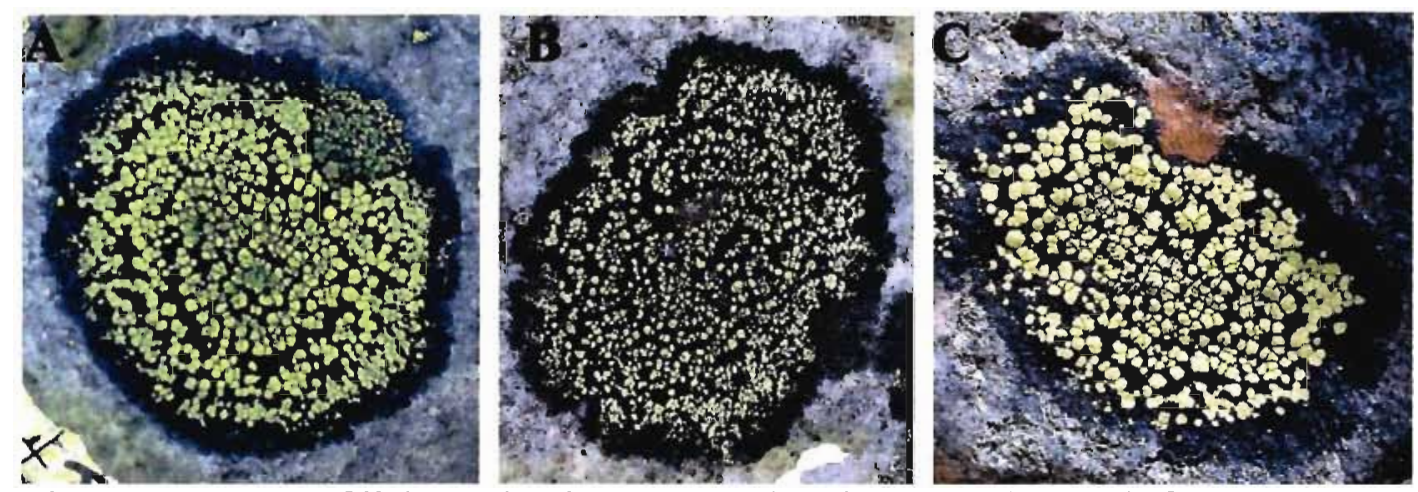

Figure 4: Images of lichens that have merged with similar (A) or different species $(\mathrm{B}, \mathrm{C})$.
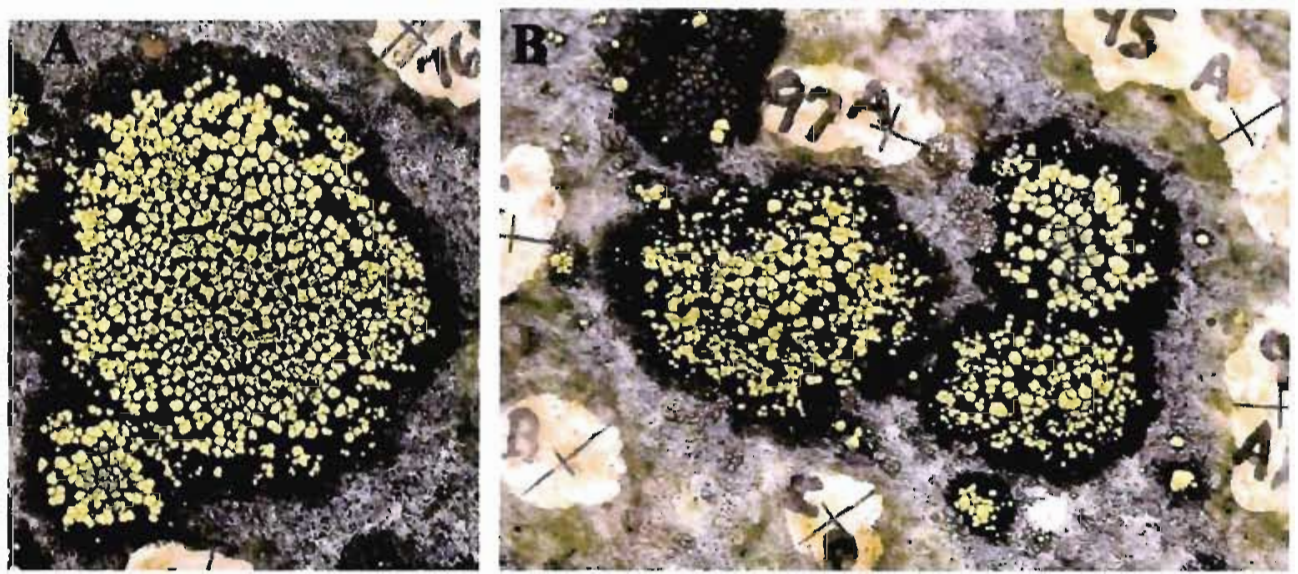

Figure 5: Images of lichens that have merged with surrounding Rhizocarpon thalli. 

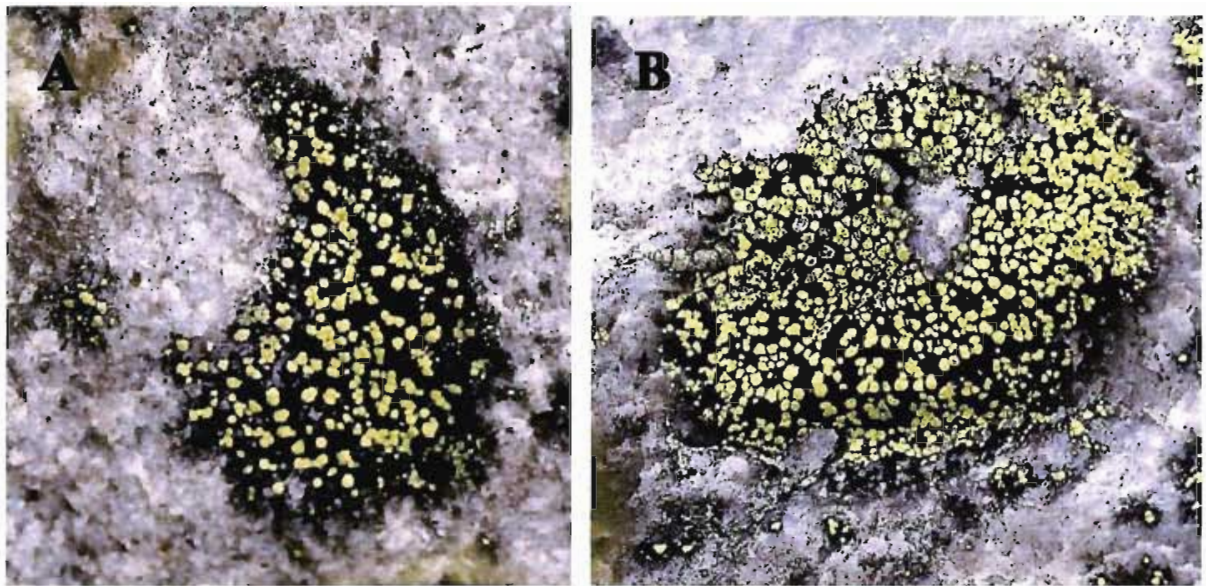

Figure 6: Images of lichens that have started to disintegrate and eventually die. 


\section{APPENDIX III: Worked example}

The following example is intended to serve as a guide to the steps taken from the preparation of the raw image to final analysis of a single lichen over three years.

\section{Image preparation:}

1. Select and open the oldest raw image (Canon camera raw file format) in the time series using Camera Raw 4.3.1.

2. Adjust: White balance (custom) $\rightarrow$ removing unrealistic colour casts (white)

i. Colour Temperature: relative warmth or coolness of the white. When the light source is daylight with sun overhead the temperature is usually between $5000-6500 \mathrm{k}$ (as a rule).

ii. Exposure as needed

iii. Brightness as needed

iv. Sharpness

v. Contrast

3. Open image in Adobe Photoshop CS3 Extended and save as TIFF (Workbook 1/Original workbook) (ie. 1996).

4. Repeat steps 1-3 for the second image. It is opened in a second workbook (Workbook 2) (ie. 2003).

\section{Repeat steps 1-3 for all remaining images.}

\section{Image scale \& orientation:}

6. Window, Layers, Tools: This opens the layers view box and the basic tool set.

7. Open Workbook 1/Original:

a. Label: Lichen \# (year) layer $1 \rightarrow 65(1996)$

\section{Open Workbook 2:}

a. Select, All, Edit, Copy: Image 2 (2003) has been copied to memory.

\section{Open Workbook 1/Original:}

a. Layer, New Layer, OK: This creates a new layer, where the next image will be placed. Click on the small box on the left hand side of each layer 
to view the layer. This allows you to view multiple layers at the same time by adjusting the opacity of each to approximately $68 \%$. After clicking anywhere else on the layer it will turn blue indicating that the layer is now active.

i. Selecting $\rightarrow$ allows viewing and adjustment to the layer.

ii. Highlighting $\rightarrow$ allows only viewing.

b. Edit, Paste: Image 2 is now pasted into the Layer 2 .

c. Edit, transform, rotate: reorient image 2 (2003) to match that of image 1 (1996).

d. Visually compare the size of image 2 (2003) to the size of image 1 (1996).

i. If not similar discard image 2 and proceed to step 10 .

ii. If similar proceed to step 12 .

\section{Open Workbook 2:}

a. Image, Image Size. Adjust the size as needed.

11. Repeat steps 8-9 until the images are of similar scale.

12. Label second image: Lichen \# (year) layer $2 \rightarrow 65$ (2003)

13. Repeat steps 8-12 for the remaining images in the time series.

\section{Image distortion correction:}

14. Ruler tool: Measure the distance between each of the control points (A-H). Compare these measurements to the actual measurements taken in the field. This gives an approximation of how the image should be adjusted. Choose the image that has the least amount of distortion and proceed to step 15 (ie. layer 2 , $65(2003))$

15. Edit, Free transform: Scale the image to match the actual measurements taken from the field. This may take several attempts to determine the minimal adjustments needed.

\section{Image alignment:}

16. Highlight layer chosen in step 14: allows viewing only (ie layer 2, 65(2003))

17. Select next layer to be transformed (ie. layer 1, 65(1996)) 
18. Opacity: Change the opacity of layer 1 to $68 \%$ allowing both layers to be viewed simultaneously.

19. Edit, Free Transform: Align the image in layer 1 (1996) with the markers and rock crystals common in both images.

20. Edit, Free transform: Manually adjust the image using the superimposed grid.

21. If the image becomes to distorted undo the transformation and repeat steps 17-20.

22. Continue steps $17-20$ for all remaining images.

\section{Image Analysis:}

PART I: Total Area \& Perimeter

23. Highlight the first image you want to analyze, ie. 65(1996)

24. Create new layer: Select this layer.

25. Label new layer: Lichen \# (year) - type of measurement (ie. 65 (1996) - Area)

26. Brush tool: select the brush tool (1 pixel diameter - smallest possible)

27. Trace the thallus outline.

28. Magic wand: select the outline (ie. 65(1996) - Area).

29. Analysis, Record measurements: Record the area and perimeter of the image.

30. Repeat steps $17-23$ a second time to reduce within thallus variability.

31. Repeat steps 17-24 for remaining images/years.

PART II: Areola area

32. Crop out the desired lichen.

a. Select the outline for the first image you want to analyze (ie. 65 (1996) Area):

b. Magic wand tool: select the thallus outline

c. Select the layer containing your original image (65-1996).

d. Edit, Copy: Creates a copy of only the desired thallus.

e. Layer, New Layer, OK: select layer

f. Edit, Paste: only desired lichen is visible (background removed)

g. Label: lichen \# (year) - measurement type) (ie. 65(1996) - areola area)

Selection of areola: 


\section{Magic wand:}

a. Add to selection (allows you to sample numerous colours at once). Select a variety of areola, which are a good representation of the sample.

i. The selected area is automatically highlighted on the screen, the selection process can be controlled at every step and necessary corrective measures can be taken.

ii. Tolerance was adjusted to ensure the entire areola was selected (start at 15) with lower numbers indicating a small range of colours to be selected. Tolerance was continually adjusted to enhance or reduce the range of colours selected.

b. Select, Similar all pixels on the image that fall within the selected colour range and are not included in the initial selection are then added.

c. Select, Grow: expand the selection to neighboring pixels.

34. Verify that only the desired areola is selected:

a. Manually adjust selection using add and subtract from selection commands to ensure that all areola is selected.

35. Analysis, Record measurements: Record the area and perimeter of the areola.

36. Repeat steps $26-28$ seven times to reduce within thallus variability.

PART III: Diameter \& Prothallus width

37. Select, New Layer, OK: creates a new layer on which a grid was created using the line tool and the ruler tool to create 8 lines in an evenly radiating circular pattern. Highlight this layer.

38. Select original image: $65(1996)$

\section{Ruler tool:}

a. Choose one of the eight lines. Start at the edge of the thallus, measure along the line to the opposing edge.

b. Using that same line measure the prothallus width. Measure from the edge of the thallus along the line until it intercepts an areola. Repeat this measurement on the opposing thallus edge.

40. Repeat for the remaining seven lines. 


\section{APPENDIX IV: Sample calculations}

The following section highlights the calculations used in this thesis. Some calculations (e.g., change in diameter) are simple so they were not included in this section.

\subsection{Precision calculations}

The following section highlights the calculations used to obtain precision

measures. For each of the 27 thalli chosen for precision analysis each were traced 15

times. The following example follows all calculations for one of the 27 thalli.

Table 2: Raw data from a single lichen, 15 areal measurements/thallus.

\begin{tabular}{|l|c|c|l|}
\hline Measurement \# & Areal Measurement & $\begin{array}{c}\text { \% error from the Mean } \\
\text { (converted to + numbers) }\end{array}$ & $\begin{array}{l}\text { \% error out of } \\
100\end{array}$ \\
\hline 1 & 277.925653 & 0.626192214 & \\
\hline 2 & 277.62248 & $0.734593346(\mathrm{max})$ & \\
\hline 3 & 277.988378 & 0.603764554 & \\
\hline 4 & 277.868155 & 0.646750932 & \\
\hline 5 & 279.396214 & $0.100385241(\mathrm{~min})$ & \\
\hline 6 & 279.28296 & 0.140879817 & \\
\hline 7 & 279.291672 & 0.137764794 & \\
\hline 8 & 281.049725 & 0.490836485 & \\
\hline 9 & 280.567088 & 0.318267037 & \\
\hline 10 & 280.398078 & 0.257836605 & \\
\hline 11 & 281.17866 & 0.536937885 & \\
\hline 12 & 280.349292 & 0.240392909 & \\
\hline 13 & 280.507847 & 0.2970851 & \\
\hline 14 & 281.286687 & 0.575563519 & \\
\hline 15 & 280.441637 & 0.273411359 & \\
\hline \multicolumn{5}{|}{} & & \\
\hline Mean Area & 279.676968 & & 99.60128921 \\
\hline \multicolumn{5}{|r|}{} & 0.398710786 & \\
\hline Mean Error & & 0.100385241 & 996961476 \\
\hline Max Error & & & \\
\hline Min Error & & & \\
\hline
\end{tabular}


$\%$ Difference or error from the mean:

$\%$ Difference $=[($ Measurement \# $1-$ Mean Area $) /$ Mean Area $] 100$ $=[(277.925653-279.676968) / 279.676968] 100$ $=-0.6261922 \rightarrow$ converted to a positive number $=0.6261922$

This calculation was continued for the remaining 14 measurements. 


\subsection{Diameter \& Prothallus Width (Raw data - Table 3)}

\section{Proportion Prothallus width:}

The diameter was measured at 8 locations around each thallus. For each these 8 lines two prothallus width measurements were made.

$$
\begin{aligned}
& \text { Proportion Prothallus width }=[\text { Total Prothallus width } / \text { diameter }] \\
& =[(0.91+0.67) /(14.32)] \\
& =0.11 \text { or } 11 \% \text { of that diameter is } \\
& \text { prothallus. }
\end{aligned}
$$

This calculation was then repeated for each of the remaining 14 prothallus width measurements. 
Table 3: Raw data for diameter and prothallus width measurements for a single lichen.

\begin{tabular}{|c|c|c|c|c|c|c|c|c|}
\hline \multirow[b]{2}{*}{ Measurement \# } & \multicolumn{4}{|c|}{ Diameter (mm) } & \multicolumn{4}{|c|}{ Prothallus width (mm) } \\
\hline & 1996 & 2003 & 2006 & 2007 & 1996 & 2003 & 2006 & 2007 \\
\hline \multirow[t]{2}{*}{1} & 14.32 & 17.41 & 18.41 & 18.56 & 0.91 & 0.75 & 0.32 & 0.70 \\
\hline & & & & & 0.67 & 0.84 & 0.70 & 0.96 \\
\hline \multirow[t]{2}{*}{2} & 13.98 & 17.8 & 19.91 & 20.25 & 1.1 & 1.89 & 1.04 & 1.01 \\
\hline & & & & & 0.84 & 1.62 & 0.84 & 0.75 \\
\hline \multirow[t]{2}{*}{3} & 14.65 & 17.87 & 18.99 & 19.01 & 1.06 & 1.16 & 0.40 & 1.11 \\
\hline & & & & & 1.00 & 0.71 & 0.54 & 0.67 \\
\hline \multirow[t]{2}{*}{4} & 13.23 & 17.78 & 19.34 & 19.19 & 0.98 & 0.98 & 0.35 & 0.57 \\
\hline & & & & & 0.53 & 0.60 & 0.50 & 0.65 \\
\hline \multirow[t]{2}{*}{5} & 14.05 & 18.28 & 18.49 & 18.64 & 0.63 & 1.20 & 0.30 & 0.88 \\
\hline & & & & & 0.59 & 1.60 & 0.42 & 0.69 \\
\hline \multirow[t]{2}{*}{6} & 14.95 & 17.87 & 18.89 & 19.69 & 0.63 & 0.69 & 0.52 & 0.67 \\
\hline & & & & & 0.46 & 0.96 & 0.92 & 0.65 \\
\hline \multirow[t]{2}{*}{7} & 14.21 & 17.67 & 18.59 & 17.69 & 0.8 & 0.66 & 0.99 & 0.93 \\
\hline & & & & & 0.25 & 1.39 & 0.43 & 1.11 \\
\hline \multirow[t]{2}{*}{8} & 14.53 & 17.66 & 19.95 & 20.07 & 0.32 & 0.78 & 1.13 & 0.72 \\
\hline & & & & & 0.57 & 0.46 & 0.52 & 0.34 \\
\hline Average & 14.24 & 17.7925 & 19.07125 & 19.1375 & 0.70875 & 1.018125 & 0.62 & 0.775625 \\
\hline
\end{tabular}




\subsection{Area and Areola Area (Raw data - Table 4)}

\section{Total Area:}

Total Change in Area $=($ Avg. Final Area - Avg. Initial Area $)$

$$
\begin{aligned}
& =\mathrm{mm}^{2} \\
& =(128.00-108.84) \\
& =19.16 \mathrm{~mm}^{2} / 3 \text { years }
\end{aligned}
$$

Total Change in Area - standardized to an annual growth rate

$$
\begin{aligned}
& =[(\text { Avg. Final Area }- \text { Avg. Initial Area }) / \Delta \text { time }] \\
& =(128.00-108.84) / 3 \\
& =6.38 \mathrm{~mm}^{2} \mathrm{yr}^{-1}
\end{aligned}
$$

\section{Prothallus Area:}

$$
\begin{aligned}
\text { Prothallus Area } & =\text { Total Area }- \text { Areola area } \\
& =160.70 \mathrm{~mm}^{2}-87.96 \mathrm{~mm}^{2} \\
& =72.74 \mathrm{~mm}^{2}
\end{aligned}
$$


Table 4: Raw data for total area and areola area measurements for a single lichen.

\begin{tabular}{|c|c|c|c|c|c|c|c|c|}
\hline \multirow[b]{2}{*}{ Measurement \# } & \multicolumn{4}{|c|}{ Total Area $\left(\mathrm{mm}^{2}\right)$} & \multicolumn{4}{|c|}{ Areola Area $\left(\mathrm{mm}^{2}\right)$} \\
\hline & 1996 & 2003 & 2006 & 2007 & 1996 & 2003 & 2006 & 2007 \\
\hline 1 & 160.698909 & 245.141194 & 277.925653 & 290.075208 & 87.965370 & 108.697837 & 127.910965 & 138.030658 \\
\hline 2 & 161.570095 & 245.528000 & 277.622480 & 290.284293 & 88.880105 & 108.406860 & 132.003795 & 142.320376 \\
\hline 3 & & & & & 83.823985 & 107.561810 & 135.016355 & 139.922873 \\
\hline 4 & & & & & 85.905877 & 105.998903 & 125.682472 & 142.843087 \\
\hline 5 & & & & & 86.047009 & 106.683655 & 127.093793 & 142.843087 \\
\hline 6 & & & & & 85.047009 & 111.583203 & 126.391617 & 143.776999 \\
\hline 7 & & & & & 88.955927 & 110.532553 & 129.547583 & 135.338694 \\
\hline 8 & & & & & 93.251714 & 111.281773 & 120.354589 & 137.215228 \\
\hline Average & 161.134502 & 245.334597 & 277.7740665 & 290.1797505 & 87.965370 & 108.697837 & 127.910965 & 138.030658 \\
\hline
\end{tabular}




\title{
APPENDIX V: Measurement reproducibility by different operators
}

\begin{abstract}
Although all of the measurement data used in this thesis were generated by a single operator, a small test was done to broadly evaluate operator bias. Accordingly, four thalli of mid-high quality resolution were independently measured by three different investigators. These workers traced each of the four thallus outlines and determined areola area ten times on ten different occasions with no reference to previous results.
\end{abstract}

The results (Fig. 7) provide insight into the ability of an operator to consistently delimit and measure the thallus-rock boundary. As thallus size increases the percentage change from the mean decreases.

The results (Fig. 8) provide insight into the ability of an operator to consistently delimit and measure the prothallus and areola boundary. As thallus size increases the percentage change from the mean decreases. 


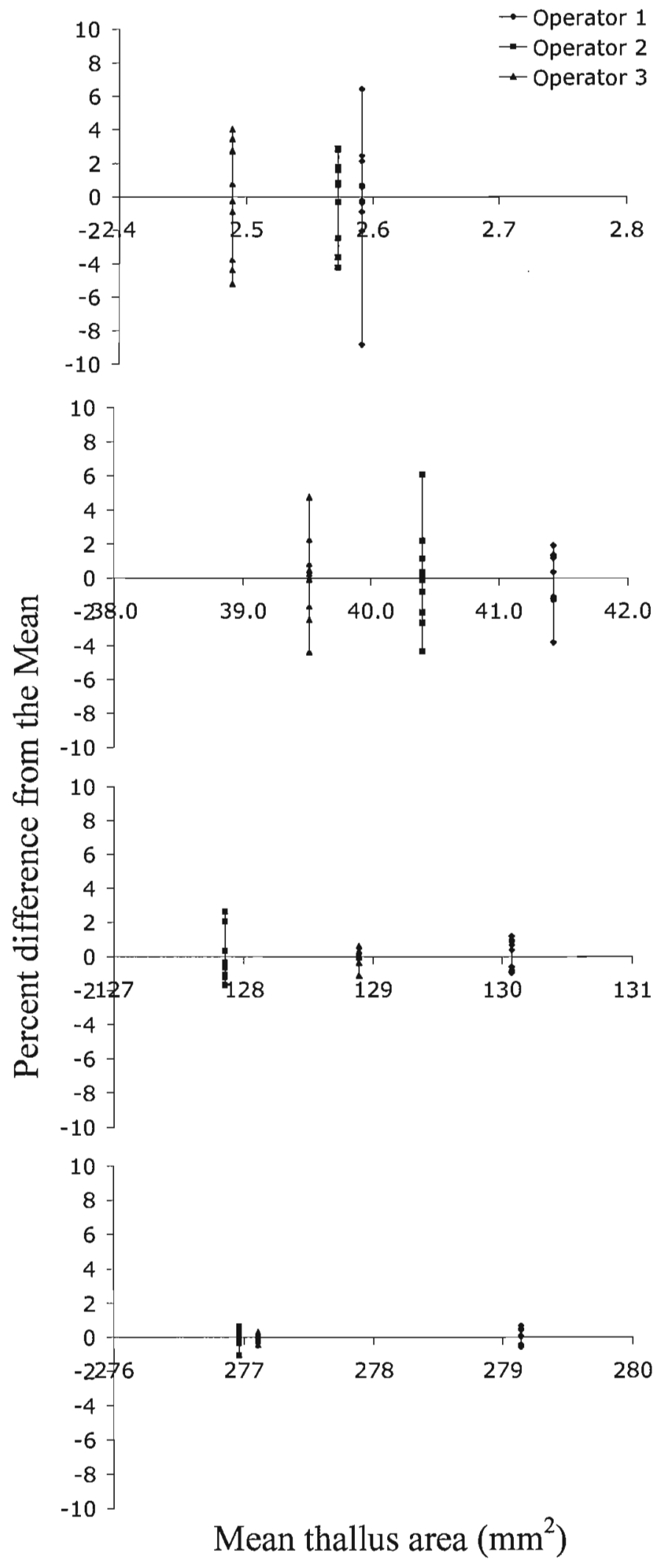

Figure 7: The percent by which each value differs from the mean of 10 areal measures. Each line represents a different operator. 


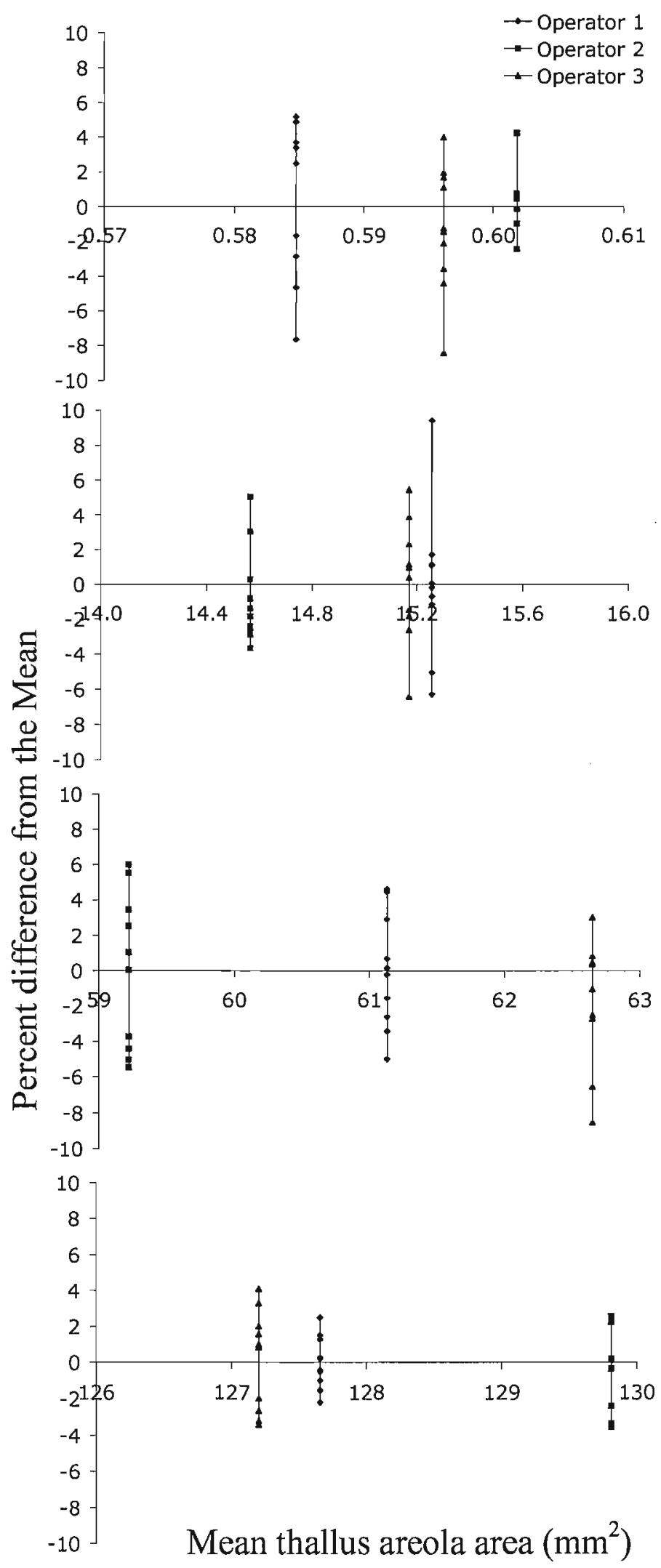

Figure 8: The percent by which each value differs from the mean of 10 areal measures. Each line represents a different operator. 
